Including: Social Work, Humanitary Health Intervention, Nursing, Missionary Work

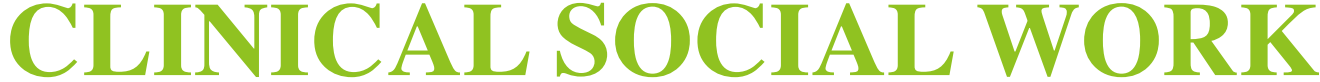

\title{
AND HEALTH INTERVENTION
}

international

scientific

group

of applied

preventive

medicine I - GAP

vienna,

austria

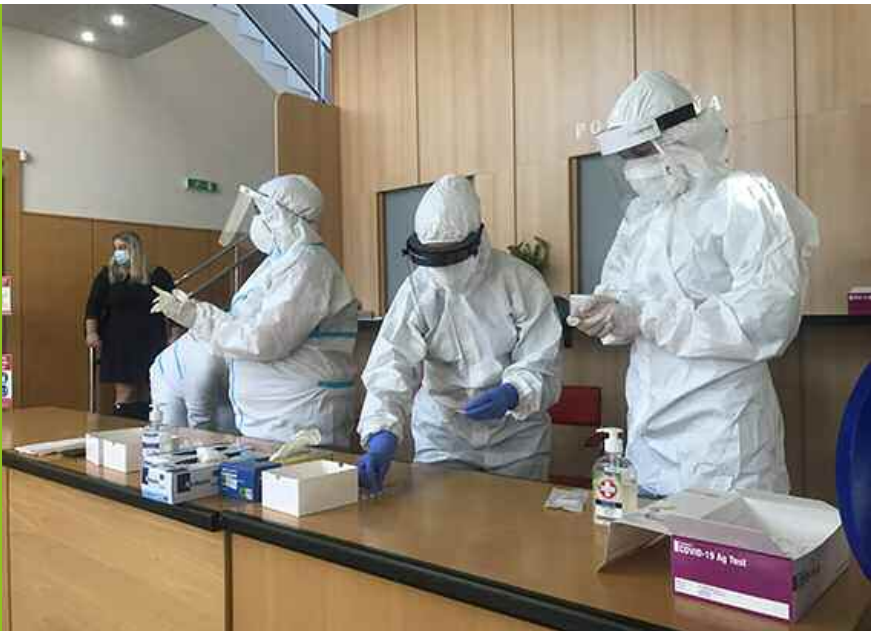

Author: Michal Olah

Late Psychosocial Consequences of Pandemics, from HIV to Covid

Original Articles

$\checkmark$ EDITORIAL: LATE PSYCHOSOCIAL CONSEQUENCES OF PANDEMICS, FROM HIV TO COVID

$\checkmark$ THE NEED FOR RAPID VACCINATION COVERAGE AGAINST COVID IN PEOPLE WITH NEUROMUSCULAR DISEASES

$\checkmark$ PHARMACY VACCINATIONS

- SOCIO-CULTURAL FACTORS AND THE TRANSMISSION OF HIV/AIDS IN MALAKAND DIVISION: A QUALITATIVE ANALYSIS

$\checkmark$ SOCIAL ASPECTS OF DIAGNOSIS AND TREATMENT OF NON-PALPABLE BREAST LESIONS. IMPORTANT FACTOR AFFECTING QUALITY OF LIFE IN CANCER PATIENTS UNDERGOING SURGERY $\checkmark$ COVID-19 VACCINATION STRATEGY IN GERMANY

$\checkmark$ ECONOMIC AND SOCIAL ASPECTS OF SECONDARY LYMPHEDEMA FOLLOWING TREATMENT OF BREAST CANCER

$\checkmark$ ADVANTAGES OF THE INTRODUCTION OF ELECTRONIC HEALTHCARE PRESCRIPTIONS BEFORE COVID ERA EXPERIENCES IN PIONEER COUNTRIES ESTONIA AND FINLAND AND THE STATUS IN GERMANY

$\checkmark$ DELIVERY OF BLISTERED MEDICINES AS AN IMPORTANT FACTOR IN MEDICATION SAFETY AND MAINTAINING PATIENT HEALTH IN TIMES OF LOCKDOWN DUE TO COVID-19

$\checkmark$ USE OF APPS IN PHARMACY AS A COMMUNICATION TOOL

$\checkmark$ CRISIS MANAGEMENT IN THE PHARMACEUTICAL INDUSTRY

$\checkmark$ A STUDY ON THE TIMING OF HIV REPEAT TEST: A CASE STUDY OF MARY IMMACULATE VCT CENTER, NAIROBI, KENYA

$\checkmark$ THE COVID-19 PANDEMIC AS A STRESS TEST - ENSURING INDIVIDUAL MEDICAL RESPIRATORY CARE: ASPECTS TO OBJECTIFY THE DISCUSSION

$\checkmark$ KNOWLEDGE ON MARRIAGE AND REPRODUCTION IN ISLAM FOR MULTICULTURAL HEALTHCARE AND SOCIAL WORK NEEDS: RESULTS OF THE SURVEY AT FIVE PUBLIC UNIVERSITIES IN SLOVAKIA 


\section{Editors}

\section{Editor-in-Chief:}

Peter G. Fedor-Freybergh, MD, Dr. Phil, Ph.D, DSc,

Dr.h.c. mult. (Vienna, AT)

\section{Deputy Chief Editors:}

Prof. Dr. Dr. med. Clauss Muss, PhD

(I-GAP Zurich, CH)

\section{Editorial board and reviewers:}

Dr. Andrea Shahum, MD (University of North

Carolina at Chapel Hill School of Medicine, USA)

Dr. Vlastimil Kozon, PhD.

(Allgemeines Krankenhaus - Medizinischer

Universitätscampus, Vienna, AT)

Dr. Daniel J. West, Jr. Ph.D, FACHE

(University of Scranton, Department of Health

Administration and Human Resources, USA)

Dr. Stephen J. Szydlowski, MBA, MHA, DHA

(University of Scranton school of education, USA)

Dr. zw. dr hab. Pawel S. Czarnecki, Ph.D.

(Rector of the Warsaw Management University, PL)

Dr. Michael Costello, MA, MBA, J.D.

(University of Scranton school of education, USA)

Dr. Roberto Cauda, Ph.D.

(Institute of Infectious Diseases, Catholic University of the Sacred Heart, Rome, IT)

Dr. Tadeusz Bak, PhD.

(Instytut Ekonomii i Zarządzania PWSTE

Jarosław, $\mathrm{PL}$ )

\section{Contact}

International Gesellschaft für angewandte

Präventionsmedizin i-gap e.V.

(International Society of Applied Preventive Midicine i-gap)

Währinger Str. 63 A-1090

Vienna, Austria

Tel. : +49 - 176 - 24215020

Fax : +43 / 1408313129

Mail : office@i-gap.org

Web : www.i-gap.org
Dr. Daria Kimuli, Ph.D.

(Catholic university of Eastern Africa, Nairobi, KE)

Dr. Gabriela Lezcano, Ph.D.

(University of California, San Francisco, USA)

Dr. Jirina Kafkova, Ph.D. (MSF, Freetown, SL)

Prof. Dr. Arab Naz, Ph.D.

(University of Malakand Chakdara Khyber

Pakhtunkhwa PK)

Dr. Vitalis Okoth Odero, Ph.D.

(St. Philippe Neri Schools Joshka, KE)

Dr. Johnson Nzau Mavole, Ph.D.

(Catholic university of Eastern Africa, Nairobi, KE)

Prof. Dr. Selvaraj Subramanian, Ph.D.

(SAAaRMM, Kuala Lumpur, MY)

Dr. hab. Zofia Szarota, Ph.D.

(Pedagogical University of Cracow, PL)

\section{Commisioning and language editor:}

Prof. Dr. John Turner (Amsterdam, NL)

Whole-Self@quicknet.nl

\section{Submit manuscript:}

cswjournal@gmail.com

Photo:

Michal Olah: Testing for Covid 19 in Czech Borders.

\section{Visiting Editors}

Radi Francis, Bundzelova Katarina

Olah Michal, Muss Claus

\section{Impact factor}

1. november 2019

1,21

Subscription rates 2021, Vol. 12, No.2

Open Access Journal

Additional Information on Internet:

www.clinicalsocialwork.eu 


\section{Table of Contents}

\section{Original Articles}

Francis Radi, Katarina Bundzelova, Michal Olah, Claus Muss

Late Psychosocial Consequences of Pandemics, from HIV to Covid

Christian Damjanow, Milan Luliak

The need for Rapid Vaccination Coverage against

COVID in People with Neuromuscular Diseases

Ralf Oehlmann, Attila Czirfusz

Pharmacy Vaccinations

Sana Ullah, Arab Naz, Basit Ali, Aziz UI Hakim

Socio-cultural Factors and the Transmission of HIVIAIDS in

Malakand Division: A Qualitative Analysis

Marian Bakos, Tomas Jankovic, Vladimir Krcmery, Martina Dubovcova

Social Aspects of Diagnosis and Treatment of Non-palpable

Breast Lesions. Important Factor affecting Quality of Life in

Cancer Patients undergoing Surgery

Michael Pfeiffer-Ruiz, Vitali Schroder

COVID-19 Vaccination Strategy in Germany

Karel Pitr

Economic and Social Aspects of Secondary Lymphedema

following Treatment of Breast Cancer.

Christoph Racek, Attila Czirfusz

Advantages of the Introduction of Electronic Healthcare

Prescriptions before COVID Era Experiences in Pioneer

Countries Estonia and Finland and the Status in Germany

Mark Herold, Erich Kalavsky

Delivery of blistered Medicines as an Important Factor in Medication Safety and Maintaining Patient Health in

Times of Lockdown due to COVID-19 
Mohammad Hosseini, Milan Luliak

Use of Apps in Pharmacy as a Communication tool

Lukas Niemuth

Crisis Management in the Pharmaceutical Industry .53

Victor Otieno Okech, Victor Wanjala Namulanda, Daria Kimuli

A study on the timing of HIV repeat test: A case study of

Mary Immaculate VCT Center, Nairobi, Kenya .57

Peter Kremeier

The COVID-19 Pandemic as a Stress Test - ensuring Individual

Medical Respiratory Care: Aspects to Objectify the Discussion

Monika Zavis, Irina Evgenjevna Voronkova, Parimal Chandra Biswas,

Lujza Koldeova, Michal Olah, Vladimir Krcmery, Radovan Soltes,

Vladimir Juhas, Hedviga Tkacova, Michal Bizon, Jozef Lenc

Knowledge on Marriage and Reproduction in Islam for

Multicultural Healthcare and Social Work Needs: Results

of the Survey at Five Public Universities in Slovakia

Jan Bydzovsky, Maria Jackulikova, Suliman Ousman, Radwan Faashtol

Nutritional Behavior and Status of Unaccompanied Minor

Refugees in the Moria Camp, Lesbos, Greece . .73 


\section{Editorial}

\section{Late Psychosocial Consequences of Pandemics, from HIV to Covid}

CSWHI 2021; 12(2): 6 - 7; DOI: 10.22359/cswhi_12_2_15 C C Clinical Social Work and Health Intervention

Following Issue of Clinical Social work number 2.2021 appears just after one year after the onset of one of the worst pandemics within the last 40 years worldwide.

If we remember the onset of HIV epidemics originating in America and Africa, spreading worldwide in 1980, and now 2020 Covid pandemics, within those four decades several alert have been given by WHO but sometimes ignored by EU and North America, also because effective HIV treatments has been introduced in 1999 ,bringing the numbers after 2010 definitely down and decreasing mortality in those infected from 100 to 1 percent. Also mother to child transmission of HIV decreased from 20 to 1 percent within last 25 years.(1.2)

Unfortunately, winning the battle (but not was) with HIV bought the community to lethargy worldwide, ignoring other alerts which fortunately were not major killers as HIV TB and malaria, but were predictors for the uncontrolled streads, specially when air transport has been increased from 1980 to 2020 more than 10 times, enabling to bring the disease rapidly via all continents. So called ,small, epidemics such as SARS in 2002, Avian influenza in 1995, other zoonotic flu (swine origin) 2010, MERS 2014, Zika 2016, Ebola 2015, Yellow fever 2018, all those were transmitted by air travel but fortunately rapid cessation of air travel, draconic isolation and quarantine in focuses helped us not only to stop the epidemics early, but gave us impression that WHO and health care systems can prevent everything, protect everybody, and the scientific community has vaccines for all infectious diseases.

However last years showed us that this is not true and control of last 10 epidemics ameliorated completely our vigilance. The results is up to 4 million deaths and 300 
million infected, despite of fabulous success of vaccination development. Due to vaccines and quarantines, the second wawe as well as the first part of third epidemics is currently promising us better summer, however new variants must keep the health authorities awake. Deaths and collapse of economics is an immediate visible relict (we hope) of this pandemic. This issue of CSW keeps our eyes more open in the late consequences: social and psychic trauma, including protcovid syndromes, related pandemics such as epidemy of depression, obesity, addictions, pharmacy and health care workers burnout syndromes, devastating effect due to isolation of elderly and mental health facilities etc. Despite we can predict many times first or second wawes of infectious diseases and deaths, or economy quakes ,we are afraid that we still cannot predict the psychosocial consequences of all those small (Ebola, MERS, SARS) or large epidemics such as HIV and Covid, which may take us decades.

\section{Radi Francis}

Bundzelova Katarina

Bl Max Kolbe House of Hope Phnompenh SEU Social work Trop programme, Kingdom of Cambodia

Olah Michal

Muss Claus

IGAP Vienna Austria and SEU Training Ctr Zurich Switzerland

\section{Contact address:}

e-mail: mussprof@yahoo.fr

\section{References:}

1. WHO Annual Report. 2018. Geneva, WHO. wwww.aho.org

2. United Nations AIDS office. UN New York. www.unaids.org 


\title{
The need for Rapid Vaccination Coverage against COVID in People with Neuromuscular Diseases
}

\author{
Ch. Damjanow (Christian Damjanow), M. Luliak (Milan Luliak)
}

SEUC PhD program in Health management and public health, Germany.

\section{E-mail address:}

christiandamjanow@yahoo.de

\section{Reprint address:}

Christian Damjanow

SEUC PhD program in Health management and public health

Health Center, Hohenzollernstr. 8

90475 Nurnberg

Germany

Source: Clinical Social Work and Health Intervention

Volume: 12

Issue: 2

Pages: $8-11$

Cited references: 16

\section{Reviewers:}

Daria Kimuli

Catholic university of Eastern Africa, Nairobi, KE

Roberto Cauda

Institute of Infectious Diseases, Catholic University of the Sacred Heart, Rome, IT

\section{Keywords:}

Neuromuscular Disorder. Immunosuppression. Immunization. COVID-19. Vaccine Against Infection.

\section{Publisher:}

International Society of Applied Preventive Medicine i-gap

CSWHI 2021; 12(2): 8 - 11; DOI: 10.22359/cswhi_12_2_01 C Clinical Social Work and Health Intervention

\section{Abstract:}

Infections may affect the therapeutic course of neuromuscular disorders, both in immunocompetent individuals and in those with reduced immunocompetence due to immunomodulating/ /immunosuppressive therapies. Infections can also cause NMDs as well. In patients with diminished immunocompetence, there is a risk for decreased effectiveness of immunizations. Countries across Europe have started considering vaccination roll-out plans in recent months, which are widely seen as a means of addressing high mortality rates and extensive lockdowns over the course of 2020. Vaccines are not compulsory in most European countries, and so the population's ability to be vaccinated against COVID-19 must be high in order to meet the high targets of obtaining herd immunity from the virus. This article examines emerging vaccination rollout co- 
ordination methods in many European countries: the Switzerland, Sweden, Germany, France and UK. It centered on the need for rapid vaccination in patients with NMD and the protection and effectiveness of immunization in NMD patients, with a focus on COVID-19 vaccination.

\section{Introduction}

More than 13 million COVID-19 cases have now occurred across the UK and the EU/EEA, resulting in over 320,000 deaths. Several politicians including World Health Organization DirectorGeneral have aligned COVID-19 vaccinations with a 'light at the end of the tunnel' in order to resolve COVID-19 infection rates and eliminate potential lockdowns (1). For this to be done, a high consumption of any safe and effective vaccine is required. Many concerns about the treatment of people with neuromuscular conditions have arisen from the coronavirus disease pandemic-2019. For the most recent two COVID-19 vaccines (PfizerBioNTech and Moderna) and more in the pipeline were granted emergency use clearance by the U.S Food and Drug Administration (2). The development of NMDs varies based on the underlying etiology and pathophysiology and can be determined by concomitant diseases and infections. The risk of aspiration is due to: dysphagia; impaired ability to take a deep breath; impaired cough reflex; and poor airway clearance of secretions with resulting atelectasis and pneumonia; respiratory or bulbar muscle weakness (3). In some of these conditions, the use of immunosuppressive and immunomodulating agents which can increase susceptibility to infections and at the same time reduce the humoral response to immunizations, is of special concern.

Immunization against a disease can be given by natural infection or vaccines against a certain agent or agents. The aim of vaccination is to create an immune response against a particular antigen and to shield vulnerable populations from communicable diseases. This can be achieved by adding a living manipulated agent ('live vaccine'; e.g. yellow fever vaccine), suspending killed animals (e.g. pertussis vaccine), antigen expressed in a heterologous organism (e.g. hepatitis B vaccine), or inactivated toxin (e.g. tetanus) (4). In this Practice Subject we use the terms immunization and vaccination interchangeably to refer to immunity gained in relation to vaccines.

\section{Infections and Underlying NMDS}

In terms of symptom severity and patient experience, the wide spectrum of neuromuscular disorders differ but typically include the peripheral nervous system resulting in gradual muscle weakness involving both skeletal muscles and internal organ muscles. The hallmarks of neuromuscular disorders, including: ALS; muscular dystrophies; SMA; along with certain myopathies; and mitochondrial diseases, among others; are mobility difficulties as well as cardiac, respiratory and intestinal complications. Our elderly patients and those with cardiorespiratory issues are at extremely high risk and the highest priority should be given. A multisystem influence of their disorders is faced by most people dealing with neuromuscular diseases. If they develop, these illnesses can weaken the pulmonary muscles and diaphragm raising the risk of significant pulmonary infection. There are also underlying coronary disorders of many neuromuscular patients. Research is gradually finding that, during the duration of their disease, these patients are at high risk of acute heart injury. For their future COVID-related effects; these variables do not bode well. To prevent muscle weakness, people with neuromuscular conditions are also administered corticosteroids. The $\mathrm{CDC}$ has reported that because of the resulting weakening of the immune system, people who take corticosteroids "may be at increased risk." Immunosuppressive therapy is needed for individuals with certain neuromuscular disorders such as myasthenia gravis and Lambert-Eaton myasthenia syndrome leaving them more prone to extreme COVID-19.

\section{Risk of Infections in Individuals with NMDS}

In the treatment of autoimmune neuromuscular conditions, Immunosuppressive /Immunomodulatory agents are commonly used and vaccines play a significant role in minimizing the morbidity associated with vaccine-preventable infections in this population (5). There is a general belief that both typical and atypical Immunosuppressive 
agents increase the risk of infections. A systematic study of 631 patients who were on Immunosuppressive/immunomodulatory agents with myasthenia gravis, chronic inflammatory demyelinating polyneuropathy, and dermatomyositis showed a $19 \%$ infection rate in all three diseases, with the most common being pneumonia. In multivariate studies, there has been an important independent correlation between infections and the use of plasmapheresis, mycophenolate mofetil, and corticosteroids. In retrospective analysis, line infections due to plasmapheresis were not analyzed separately (6). An elevated risk of illnesses, including the reactivation of latent tuberculosis, is associated with corticosteroids (7). HBV infections can be reactivated by B-cell depleting therapies, such as rituximab. For rituximab or highdose corticosteroid treatment, the chance of reactivation is estimated at over $10 \%$ (8). It is calculated that the chance of HBV reactivation with azathioprine, methotrexate, or low-dose corticosteroids is less than $1 \%$ (8). Through the use of rituximab, reactivation of varicella zoster virus infections has also been reported (9). The most serious infectious complication of immunosuppressive therapy, for which no appropriate vaccination or cure is presently available, is progressive multifocal leukoencephalopathy due to reactivation of infection with the John Cunningham virus (10). The risk of Pneumocystis jirovecii pneumonia is increased by immunosuppressive agents. In patients taking corticosteroids in conjunction with other immunosuppressive agents, the risk of Pneumocystis jirovecii pneumonia is higher (11). A chance of severe meningococcal infections is linked with eculizumab. It binds to the protein $\mathrm{C} 5$ complement to inhibit the cleavage of $\mathrm{C} 5 \mathrm{a}$ and $\mathrm{C} 5 \mathrm{~b}$, thus preventing the combination of $\mathrm{C} 5 \mathrm{~b}$ with the $\mathrm{C} 6$ to $\mathrm{C} 9$ complement proteins that form the membrane attack complex. Due to the absence of sufficient serum bactericidal action and compromised opsonization with decreased phagocytic degradation of the encapsulated organism, the lack of membrane attack complex prevents the capacity of the immune system to respond effectively to acquire Neisseria infections (12).

\section{Effectiveness of Vaccinations in NMDS Patients}

The benefits of vaccines can be diminished by altered immunocompetence. There is insufficient evidence, however, on the efficacy of vac- cines in people that are on IS/IM agents (13). Methotrexate reduces the humoral response to pneumococcal vaccine (14). CD19+ B cells, preplasma cell bursts, and interferon- $\gamma$-secreting $\mathrm{T}$ cells are depleted by rituximab. After rituximab, antibody responses may be compromised for at least 6 months (15). It appears that this medication has the most significant effect on the immune response to vaccinations, including vaccines against influenza and pneumococcal vaccines. It is also expected to affect the effectiveness of other vaccines (14). High-dose immunosuppression is more likely than low-dose immunosuppression (prednisone $>20 \mathrm{mg}$ /day for $>14$ straight days, azathioprine $>3 \mathrm{mg} / \mathrm{kg} /$ day, methotrexate $>0.4 \mathrm{mg} / \mathrm{kg} /$ week) to influence vaccine reaction (16).

\section{Vaccination and Infection Prophylaxis in Individuals with NMDS}

NMDs, which influence all age ranges, are complex. Two fairly distinct classes of NMDs arise from the viewpoint of diseases and immunizations: 1) those that are allergic and often treated with IS/IM agents, and 2) those that are inherited/degenerative and treated mostly with supportive management. It is likely that the risk of infection in people with NMD undergoing long-term IS/IM treatments could be higher than in people with NMD who do not undergo these treatments, but there is no evidence to support this. Furthermore, in these two classes, separate concerns about immunization emerge. Underlying heart and respiratory failure puts people with NMD at greater risk of severe complications and increased mortality, independent of treatment with IS/IM agents, from infections such as influenza. Vaccine-related deterioration of the underlying condition, activation of new autoimmune NMDs, and suboptimal vaccine effectiveness provide additional concerns in patients infected with NMD on IS/IM agents.

\section{Conclusion}

People with neuromuscular conditions, health care professionals and patients and employees at long-term care facilities should be among the first to receive COVID-19 vaccines. Finally, a single neuromuscular disorder is found to be rare (fewer than 100,000 cases in the US and Germany). There is little or no study on the im- 
pact of COVID-19 on these patients due to this "rare" status. This suggests that we might be unaware of additional risk factors that improve vulnerability to serious COVID-19 infection.

The MDA is urging the CDC and state and local governments to assign high priority to vaccinating persons with neuromuscular diseases against COVID-19 for all of these reasons.

\section{References}

1. WARREN GW, LOFSTEDT R. (2021) COVID-19 vaccine rollout risk communication strategies in Europe: a rapid response. Journal of Risk Research. 2021:111.

2. ZIVKOVIC SA, GRUENER G, NARAYANASWAMI P, QUALITY A, COMMITTEE PS, NARAYANASWAMI $\mathrm{P}$, et al. Doctor-Should I get the COVID-19 vaccine? Infection and Immunization in Individuals with Neuromuscular Disorders. Muscle \& nerve.

3. PANITCH HB (2017) Respiratory implications of pediatric neuromuscular disease. Respiratory care. 2017;62(6):82648.

4. KIMBRELL DA, BEUTLER B (2001) The evolution and genetics of innate immunity. Nature. Reviews Genetics. 2001;2(4):25667.

5. CARTWRIGHT SL, CARTWRIGHT MS (2019) Health maintenance for adults with neuromuscular diseases on immunosuppression. Muscle \& nerve. 2019;59(4): 397-403.

6. PRIOR DE, NURRE E, ROLLER SL, KLINE D, PANARA R, STINO AM, et al. (2018) Infections and the relationship to treatment in neuromuscular autoimmunity. Muscle \& nerve. 2018;57(6):927-31.

7. MALPICA L, MOLL S (2020) Practical approach to monitoring and prevention of infectious complications associated with systemic corticosteroids, antimetabolites, cyclosporine, and cyclophosphamide in nonmalignant hematologic diseases. Hematology 2014, the American Society of Hematology Education Program Book. 2020;2020(1):319-27.

8. SMALLS DJ, KIGER RE, NORRIS LB, BENNETT CL, LOVE BL (2019) Hepati- tis $B$ virus reactivation: \risk factors and current management strategies. Pharmacotherapy: The Journal of Human Pharmacology and Drug Therapy. 2019; 39(12): 1190-203.

9. AKSOY S, HARPUTLUOGLU H, KILICKAP S, DEDE DS, DIZDAR O, ALTUNDAG K, et al. (2007) Rituximab-related viral infections in lymphoma patients. Leukemia \& lymphoma. 2007;48(7):1307-12.

10. CORTESE I, REICH DS, NATH A (2020) Progressive multifocal leukoencephalopathy and the spectrum of JC virus-related disease. Nature Reviews Neurology. 2020: 1-15.

11. AVINO LJ, NAYLOR SM, ROECKER AM (2016) Pneumocystis jirovecii pneumonia in the non-HIV-infected population. Annals of Pharmacotherapy. 2016; 50(8): 673-9.

12. KONAR M, GRANOFF DM (2017) Eculizumab treatment and impaired opsonophagocytic killing of meningococci by whole blood from immunized adults. Blood, The Journal of the American Society of Hematology. 2017;130(7):891-9.

13. RUBIN LG, LEVIN MJ, LJUNGMAN P, DAVIES EG, AVERY R, TOMBLYN M, et al. (2013) IDSA clinical practice guideline for vaccination of the immunocompromised host. Clinical infectious diseases. 2014;58(3):e44-e100.

14. HUA C, BARNETCHE T, COMBE B, MOREL J (2014) Effect of Methotrexate, Anti-Tumor Necrosis Factor $\alpha$, and Rituximab on the Immune Response to Influenza and Pneumococcal Vaccines in Patients With Rheumatoid Arthritis: A Systematic Review and Meta-Analysis. Arthritis care \& research. 2014;66(7):1016-26.

15. NAZI I, KELTON JG, LARCHE M, SNIDER DP, HEDDLE NM, CROWTHER MA, et al. (2013) The effect of rituximab on vaccine responses in patients with immune thrombocytopenia. Blood. 2013;122(11):1946-53.

16. ESPOSITO S, BRUNO C, BERARDINELLI A, FILOSTO M, MONGINI T, MORANDI L, et al. (2014) Vaccination recommendations for patients with neuromuscular disease. Vaccine. 2014; 32(45): 5893-900. 


\section{Pharmacy Vaccinations}

\section{R. Oehlmann (Ralf Oehlmann), A. Czirfusz (Attila Czirfusz)}

SEUC PhD program in Health management and public health, Germany.

\section{E-mail address:}

ralf.oehlmann@web.de

\section{Reprint address:}

Ralf Oehlmann

SEUC PhD program in Health management and public health

Pharmacist, Abbentorswallstr. 52

28195 Bremen

Germany

Source: Clinical Social Work and Health Intervention

Volume: 12

Issue: 2

Pages: $12-16$

Cited references: 17

\section{Reviewers:}

Daria Kimuli

Catholic university of Eastern Africa, Nairobi, KE

Roberto Cauda

Institute of Infectious Diseases, Catholic University of the Sacred Heart, Rome, IT

\section{Keywords:}

Anti-vaccination Movements. Vaccinations. Pharmacists. Pandemics. Healthcare Access.

Disease T.ransmission.

\section{Publisher:}

International Society of Applied Preventive Medicine i-gap

CSWHI 2021; 12(2): 12 - 16; DOI: 10.22359/cswhi_12_2_02 (C) Clinical Social Work and Health Intervention

\section{Abstract:}

The vaccination rate is on the decline as parents avoid making frequent visits to healthcare facilities to visit doctors. The high cost of healthcare access in Germany, the United States, and other parts of the world has resulted in many people remaining under vaccinated or unvaccinated. The rate of pandemic outbreaks in Europe has highlighted the significance of improved communication and education about the safety and the efficacy of vaccinations alongside effective strategies of reducing the rate of disease transmission ${ }^{1}$. Pandemics have unprecedented impacts on the families' health and pressure on healthcare systems in Europe. During pandemics, there is widespread fear in families concerning how the pandemics will affect families and communities more especially to the compromised people in society, such as pregnant women and people with chronic illnesses. Although pharmaceutical practices are under intensive 
scrutiny, pharmacies' vaccinations comprise an important element in the healthcare system for pandemic diseases.

\section{Pharmacy vaccinations}

Throughout the history of public health, vaccinations play a critical role during an outbreak of pandemics helping to reduce transmission and eradication of pandemics. Europe has experienced many pandemics with detrimental impacts on the healthcare system and economies of many countries. During such pandemics, there is intense pressure on the existing healthcare systems, especially a shortage of critical equipment such as respirators and limitation in bed capacity during respiration related pandemics ${ }^{2}$. This makes pharmacists very essential in facilitating the supply of vaccinations during pandemics.

Pharmacies are considered to be the most accessible healthcare providers. The increasing number of pharmacies in Europe and other parts of the world makes them easily accessible by many people compared to the public and private healthcare access facilities ${ }^{3}$. Before, during, and after pandemics, the interaction between people and pharmacists is high. Pharmacists are better positioned to provide the public health with appropriate information regarding the minimization of transmissions, appropriate treatments and vaccinations. Pharmacists are central in the healthcare system in Germany and many parts of Europe. They advocate for improved and proper vaccination during the outbreak of pandemics. In some instances, community pharmacists execute programs that help to reach out and vaccinate many patients within their communities. They also recommend the diagnosis, appropriate vac- cinations, and advice on hospital admission. Pharmacists provide continuous vaccination education to members of the public, equipping them with enough information about the significance of taking vaccinations during pandemics and the benefits to the families and communities $^{4}$. Pharmacists ensure that patients complete routine vaccination programs during pandemics by being more proactive in their role.

Pharmacists play an essential role in countering anti-vaccination campaigns, which act as a major hindrance to vaccination programs. For instance, in 1998, The Lancet published a Wakefield and colleagues investigation which associated health complications such as autism to measles vaccination ${ }^{5}$. This comprised of a major anti-vaccination movement. Pharmacists at The Lancet were able to disapprove the assertions made by their colleagues in their published reports terming them as incorrect assertions. Since then, pharmacists have played a central role in measles vaccinations; eventually, measles was reduced significantly reduced and eradicated in many parts of Europe. As anti-vaccination movements rise, measles resurges in Europe.

During pandemic outbreaks, pharmacists play an essential role in ensuring that individuals identified receive timely vaccination and are isolated in good time, preventing further transmissions. This happens through close collaboration with other public health and government authorities and international health organizations such as the world health organization ${ }^{6}$. During pandemics,

\footnotetext{
${ }^{1}$ Centers for Disease Control and Prevention. (2007). Key facts about seasonal influenza (flu). The Influenza. http://www.CDC.gov/flu/key facts. htm (accessed November 28, 2008).

${ }^{2}$ Burson, R. C., Buttenheim, A. M., Armstrong, A., \& Feemster, K. A. (2016). Community pharmacies as sites of adult vaccination: A systematic review. Human vaccines \& immunotherapeutics, 12(12), 3146-3159.

${ }^{3}$ Patel, M. (2019). Increase in measles cases - United States, January 1-April 26, 2019. MMWR. Morbidity and mortality weekly report, 68 .

${ }^{4}$ Guerci, J., Campbell, C. T., \& Curtis, S. D. (2019). The Pharmacists' Role in Disease Outbreaks: Navigating the Dynamics of Uncertainty Before, During, and After Disease Outbreaks.

${ }^{5}$ Eggertson, L. (2010). The Lancet retracts 12-year-old article linking autism to MMR vaccines. Canadian Medical Association. Journal, 182(4), E199.

${ }^{6}$ Guerci, J., Campbell, C. T., \& Curtis, S. D. (2020). The Pharmacists' Role in Disease Outbreaks: Navigating the Dynamics of Uncertainty Before, During, and After Disease Outbreaks.
} 
many people feel insecure visiting healthcare facilities due to fear of contracting infections. This hinders government campaigns encouraging people to visit healthcare facilities for routine immunization and vaccinations against infectious diseases. This drops the rate of vaccination significantly. Pharmacists are vigilant learners during pandemics, which help track the performance of immunized patients while keeping track of the transmissions ${ }^{7}$. In the emergence of pandemics, pharmacists inform public health agencies for further action and vaccination programs. They also help to detect any resurgence during pandemics. Pharmacists play an essential role in educating communities on the role of vaccinations.

According to the Center for Disease Control, pharmacists comprise an essential source of vaccination information to the community members. Pharmacists frequently interact with the community. During the resurgence of the emergence of life threatening diseases and infections, vaccinations are critical in saving many lives ${ }^{8}$. For instance, in the United States in 2009, pharmacists from the 50 states were authorized to administer the influenza vaccine. Pharmacists in 46 states were allowed to administer all adult vaccines. There has been a significant rise in the number of pharmacists authorized to administer vaccinations in Europe ${ }^{9}$. For instance, the percentage of pharmacists allowed to immunize rose from $20 \%$ in 2010-2011 to $25 \%$ in $2014-2015$. The rise comprises an indication of the benefits of engaging pharmacists in vaccination programs during pandemics. Alongside the vaccination, pharmacists provide time information to the public and give reports to the public health agencies. The feedback collected from the pharmacists can be used to improve the vaccination programs making them more effective.

A meta-analysis study in 2016 indicated a rise in the number of vaccinations when the pharmacists were involved as facilitators and administrators compared to programs that failed to involve the pharmacists in vaccination programs. In other studies, Drodze et al. found that many countries in Europe were amending their legislation to allow pharmacists to administer vaccinations. After the amendment in the legislation, the percentage of immunized adults increased from $32.2 \%$ in 2003 to 40.3 in the year $2013^{10}$. In another survey in 2014 on the availability and accessibility of pharmacists administered vaccinations, one-third of the sample population during the study reported they could not have received vaccinations if the pharmacist administered vaccinations were not available. Pandemics have unprecedented impacts on the economies and healthcare systems of many countries ${ }^{11}$. This created the need for cheap and convenient vaccine administration programs. The pharmacists' vaccination administration programs are convenient and involve lower costs for the public's vulnerable members, such as those with low income.

During pandemics, the society's vulnerable members are at a bigger risk, especially people with limited income to access diagnosis and treatment. In such instances, pharmacists provide lower-cost vaccinations helping to save many lives during pandemics ${ }^{12}$. Pharmacists engage in multidisciplinary teams that help evaluate the history of patient vaccinations and provide further details on vaccination before making patient discharge.

\footnotetext{
${ }^{7}$ Patel, M. (2019). Increase in measles cases-United States, January 1-April 26, 2019. MMWR. Morbidity and mortality weekly report, 68 .

${ }^{8}$ Hussain, A., Ali, S., Ahmed, M., \& Hussain, S. (2018). The anti-vaccination movement: a regression in modern medicine. Cureus, 10(7).

${ }^{9}$ Centers for Disease Control and Prevention. (2007). Key facts about seasonal influenza (flu). The Influenza. http://www.CDC.gov/flu/key facts.htm (accessed November 28, 2008).

${ }^{10}$ Tsuyuki, R. T., Beahm, N. P., Okada, H., \& Al Hamarneh, Y. N. (2018). Pharmacists as accessible primary health care providers: review of the evidence. Canadian Pharmacists Journal/Revue des pharmaciens du Canada, 151(1), 4-5.

${ }^{11}$ Isenor, J. E., Edwards, N. T., Alia, T. A., Slayter, K. L., MacDougall, D. M., McNeil, S. A., \& Bowles, S. K. (2016). Impact of pharmacists as immunizers on vaccination rates: a systematic review and meta-analysis. Vaccine, 34(47), 5708-5723.

${ }^{12}$ Hoffman, J. (2020). Vaccine rates drop dangerously as parents avoid doctor's visits; 2020.
} 
The outbreak of COVID-19 in Europe and the world has proved pharmacists essential members of the healthcare sector. According to a study conducted in 2020 , the prevailing COVID-19 pandemic has been the major factor causing the decline of childhood vaccinations in Europe. This puts Europe and other countries in the world at risk of the emergence of other outbreaks ${ }^{13}$. Besides the provision of vaccinations, pharmacists help provide these vaccinations while informing the community on the dangers of the failure to carry out routine vaccination programs for children and other people with chronic illnesses.

When carrying out their businesses, pharmacists adhere to the protocols and guidelines given by the world international health bodies such as the World Health Organization and the Center for Disease Control. Pharmacists provide critical information to patients on where they can access vaccinations. Pharmacists play a vital role in the mobilization of members of the community during pandemics. They also help keep the community members with information on the need for other eradicated diseases. As mentioned earlier, during pandemics, access to routine vaccinations is disrupted by the pandemic ${ }^{14}$. According to the American Academy of Pediatrics, there is a need to maintain vaccination schedules for eradicated communicable diseases to prevent their resurgence.

Pharmacists in Europe have a long history of patient vaccinations and immunization. However, there exist limits on the age groups and types of vaccines that these groups can receive. There is a high level of uncertainty during pandemics, especially regarding communication, the flow of information, and vaccinations ${ }^{15}$. The pharmacists are allowed to carry out immunization programs; members of the community can access the vaccinations at a cheap cost and more convenience. Pharmacists can also provide information on outbreak resurgence to public health government authorities for actions. The role of pharmacists in vaccination programs can be direct through administering the vaccination themselves or indirectly through provision of vaccination information to the public members and giving vaccination information feedback to the government health care agencies ${ }^{16}$. World health bodies such as the world health organizations and the Center for Disease Control recognize pharmacists as essential members of the healthcare system in Europe and the world, especially during pandemics.

Pharmacists need to exhibit high levels of diligence and accountability when involved in vaccination programs during pandemics ${ }^{17}$. They should also ensure that they act in a proactive approach to curb future outbreaks. Pharmacists comprise valuable members of the healthcare sector prior to, during, and after the pandemic outbreak; they comprise the easily accessible healthcare provider directly or indirectly. The pharmacists can play an active role during pandemics by alleviating public concerns and worries by engaging the communities on prevention of transmission techniques where to seek vaccinations and other critical vaccination information.

\section{References}

1. BURSON R C, BUTTENHEIM A M, ARMSTRONG A, FEEMSTER K A (2016) Community pharmacies as sites of adult vaccination: A systematic review. Human vaccines \& immunotherapeutics, 12(12), 3146-3159.

\footnotetext{
${ }^{13}$ Japsen, B. (2020). Rite Aid: Pharmacist Role Will Expand Amid Coronavirus Outbreak.

${ }^{14}$ Mcelaney, P., Iyanaga, M., Monks, S., \& Michelson, E. (2019). The quick and dirty: a tetanus case report. Clinical practice and cases in emergency medicine, 3(1), 55.

${ }^{15}$ Meyers, R., Weiland, J., Holmes, A., Girotto, JE, \& Advocacy Committee on behalf of the Pediatric Pharmacy Advocacy Group. (2018). Position paper: pharmacists and childhood vaccines. The Journal of Pediatric Pharmacology and Therapeutics, 23(4), 343-346.

${ }^{16} \mathrm{Ou}, \mathrm{HT}$, \& Yang, YH K. (2020). Community pharmacists in Taiwan at the frontline against the novel coronavirus pandemic: gatekeepers for the rationing of personal protective equipment.

${ }^{17}$ Papastergiou, J., Folkins, C., Li, W., \& Zervas, J. (2014). Community pharmacist-administered influenza immunization improves patient access to vaccination. Canadian Pharmacists Journal/Revue des pharmaciens du Canada, 147(6), 359-365.
} 
2. CENTERS FOR DISEASE CONTROL AND PREVENTION (2007) Key facts about seasonal influenza (flu). The Influenza. http://www.CDC.gov/flu/key facts.htm (accessed November 28, 2008).

3. DROZD EM, MILLER L, JOHNSRUD M (2017) Impact of pharmacist immunization authority on seasonal influenza immunization rates across states. Clinical therapeutics, 39(8), 1563-1580.

4. EGGERTSON L (2010) Lancet retracts 12year-old article linking autism to MMR vaccines. Canadian Medical Association. Journal, 182(4), E199.

5. GUERCI J, CAMPBELL CT, CURTIS SD (2020) The Pharmacists' Role in Disease Outbreaks: Navigating the Dynamics of Uncertainty Before, During, and After Disease Outbreaks.

6. GUERCI J, CAMPBELL CT, CURTIS SD (2019) The Pharmacists' Role in Disease Outbreaks: Navigating the Dynamics of Uncertainty Before, During, and After Disease Outbreaks.

7. HOFFMAN J (2020) Vaccine rates drop dangerously as parents avoid doctor's visits.

8. HUSSAIN A, ALI S, AHMED M, HUSSAIN S (2018) The anti-vaccination movement: a regression in modern medicine. Cureus, 10(7).

9. ISENOR JE, EDWARDS NE (2019) The quick and dirty: a tetanus case report. Clinical practice and cases in emergency medicine, 3(1), 55.

10. MEYERS R, WEILAND J, HOLMES A, GIROTTO JE, ADVOCACY COMMITTEE ON BEHALF OF THE PEDIATRIC PHARMACY ADVOCACY GROUP (2018) Position paper: pharmacists and childhood vaccines. The Journal of Pediatric Pharmacology and Therapeutics, 23(4), 343-346.

11. OMECENE NE, PATTERSON JA, BUCHEIT JD, ANDERSOT AN, ROGERS D, GOODE JV, CALDAS LM (2019). Implementation of pharmacist-administered pediatric vaccines in the United States: major barriers and potential solutions for the outpatient setting. Pharmacy Practice (Granada), $17(2)$.

12. OU HT, YANG YHK (2020) Community pharmacists in Taiwan at the frontline against the novel coronavirus pandemic: gatekeepers for the rationing of personal protective equipment.

13. PAPASTERGIOU J, FOLKINS C, LI W, ZERVAS J (2014) Community pharmacistadministered influenza immunization improves patient access to vaccination. Canadian Pharmacists Journal/Revue des pharmaciens du Canada, 147(6), 359-365.

14. PATEL M (2019) Increase in measles cases - United States, January 1-April 26, 2019. MMWR. Morbidity and mortality weekly report, 68 .

15. RUBIN LG, LEVIN MJ, LJUNGMAN P, DAVIES EG, AVERY R, TOMBLYN M, KANG I (2014) 2013 IDSA clinical practice guideline for vaccination of the immunocompromised host. Clinical infectious diseases, 58(3), e44-e100.

16. SANTOLI JM (2020) Effects of the COVID19 pandemic on routine pediatric vaccine ordering and administration - United States, 2020. MMWR. Morbidity and mortality weekly report, 69.

17. TSUYUKI RT, BEAHM NP, OKADA H, AL HAMARNEH YN (2018) Pharmacists as accessible primary health care providers: review of the evidence. Canadian Pharmacists Journal/Revue des pharmaciens du Canada, 151(1), 4-5. 


\section{Socio-cultural Factors and the Transmission of HIV/AIDS in Malakand Division: A Qualitative Analysis}

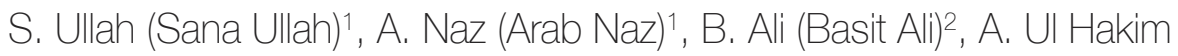

(Aziz UI Hakim) $^{1}$

${ }^{1}$ University of Malakand, Khyber Pakhtunkhwa, PK.

Original Article

${ }^{2}$ Abdul Wali Khan University Mardan, Khyber Pakhtunkhwa, PK.

\section{E-mail address:}

arab_naz@yahoo.com

\section{Reprint address:}

Arab Naz

Dean Social Sciences

University of Malakand

Khyber Pakhtunkhwa

Pakistan

Source: Clinical Social Work and Health Intervention

Volume: 12

Issue: 2

Pages: $17-24$

Cited references: 17

\section{Reviewers:}

Michael Costello

University of Scranton school of education, USA

Gabriela Lezcano

University of California, San Francisco, USA

\section{Keywords:}

Culture. HIV/AIDS. Cultural Norms. Gender Inequality. Information. Transmission.

\section{Publisher:}

International Society of Applied Preventive Medicine i-gap

CSWHI 2021; 12(2): 17 -24; DOI: 10.22359/cswhi_12_2_03 (C) Clinical Social Work and Health Intervention

\section{Abstract:}

The epidemic of HIV/AIDS has devastating impacts on many societal features of both urban and rural communities. Cultural factors have been played a significant role in human decision making and behavior around health. In simple terms, culture basically refers to the traditions and customs upheld by societies and communities because of their belief systems and values, which guide their decisions and shape their thinking, actions, attitudes and behaviors. The role of culture has been of particular significance both in the transmission of HIV/AIDS. Certain cultural practices such as: gender inequalities; unequal access to health care services; injectable drug users; unequal access to economic resources and opportunities; and male dominancy contribute to the spread of HIV/AIDS. The current 
study aims to investigate how various cultural factors contribute in the transmission of HIV/AIDS. The study was conducted in Malakand Division of Khyber Pakhtunkhwa province, while using a qualitative approach. Further, primary data was collected from 15 respondents through in-depth interview (using interview guide) while the selection of the sample was made through non-probability sampling using purposive sampling techniques. The collected information was qualitatively analyzed and a thematic discussion has been made for better understanding of the issue. The researchers also suggests some remedies.

\section{Introduction}

Historically, HIV/AIDS has been one of the worst diseases and the leading cause of death around the world. It is the most fear word in many societies of the world, and associated with many cultural myths and perceptions, and not discussed openly. The rapid increase in HIV has been the result of many different social webs and cultural practices of people. The stories of HIV patients are not their individual production, rather the sociocultural context other than individual is at its back. In a broader sense, culture means 'to cultivate' and is generally used when referring to patterns of human activity and the structures that give these activities meaning and importance (Linton, 2016). Culture is the source of formation of our attitudes and behaviors; influences our actions; and we cannot act outside of the culture in which we had been born and grown (Loosli, 2004). Culture also means the way of life for an entire society, which includes: codes of conduct; norms of behavior; dress; language; law; morality; religion; and systems of belief and practices (Jary \& Jary, 2008). Cultural norms and values influence a person's decision making including his/her decision regarding health (Guss, 2002). Moreover, culture is the learned, shared and transmitted values, beliefs, norms and life ways carried by groups of people that bind the individuals in society, guides their decisions, thinking and actions (Leninger, 1991). The role of culture has been of particular significance both in spread and fight against HIV/AIDS.

Certain cultural practices such as: gender inequalities; unequal access to health care services; injectable drug users; lack of HIV/AIDS related knowledge and information; unequal access to economic resources and opportunities; unequal power relations; male dominancy; and polygamy contribute to the spread of HIV/AIDS. The socio- cultural system influences one's knowledge and information about HIV as well as provides them opportunities of preventing themselves from the infection. Also socio-cultural factors determine and direct power relations between individuals in most societies around the world, which in turn form day to day life, influence one's social standing and access to resources including healthcare (Campbell, 2004).

Relevant literature shows that culturally driven gender inequalities have also contributed in the transmission of many diseases including deadly HIV/AIDS. Culturally produced unequal gender relations exist in matters related to sexual intercourse, and in many traditional cultures sex has been mainly practiced for the pleasure of men and in order to express masculinity (Reid \& Cornell, 2004). In such hierarchically structured unequal power and gender relations individuals have different levels of access to wealth, political influence, respect and social recognition, where resources are not collectively held, rather used by few in order to increase their influence, wealth and control others. In patriarchal societies, the husband exercises power within the household and gender is an important concept in discussing HIV/AIDS. Women subordination and the apparent sexual and economic superiority of men over women has been regarded the central factor in women's poverty and make them vulnerable to HIV infection (Schoepf, 1988 \& WHO, 1995). The disease (HIV/AIDS) has its roots in the socio-cultural fabric and this aspect needs be accessed properly in order to control further spread of the disease.

\section{Statement of the Problem}

HIV/AIDS have been regarded as the world's serious public health challenges and takes the lives of many individuals each day. In Pakistan, 
HIV/AIDS is spreading at an alarming speed both in rural and urban communities. HIV/AIDS is a much feared word in Pakistan, the infected people are looked on with suspicion, and the disease is viewed as deadly and not discussed openly. Pakistan has been regarded as a high risk country for HIV/AIDS (Baqi, Shah, Baig \& Mujeeb, 1997), while the government of Pakistan has been fighting against HIV/AIDS since the first case was reported in Pakistan in 1987. Most intervention for controlling HIV/AIDS is targeted on high risk populations and a wide range of other important factors are ignored. The present study was based on the premise that sociocultural factors are pivotal in the transmission of HIV/AIDS, and ignoring these factors is myopic vision in controlling the disease. It is further argued that the transmission of many infections including HIV/AIDS is interwoven in the social fabric and many strands work together in this regards. This study particularly accounts for factors like: culture and HIV related information; culture; power relations and HIV; gender inequality and HIV, culture; social stigma and HIV and culture; poverty and the transmission of HIV/AIDS. The study was conducted in District Dir Lower and Upper of Malakand Division, Khyber Pakhtunkhwa, province of Pakistan in order to investigate that the broader socio-cultural factors have an impact on people's lives, and perpetuate the spread of HIV/AIDS.

\section{Methods and Procedures}

The present study utilized qualitative research design. In this regard, the sample was taken from the total registered HIV-positive patients of District Dir Lower, District Dir Upper and District Swat (Pakistan National AIDS Control Program, 2019). Further, primary information wase collected from 15 respondents through in-depth interview using an interview guide. The selection of samples was taken through non-probability sampling using purposive sampling technique (Neuman, 2002; Babbie, 1998). For maintaining the anonymity of the respondents codes were used instead of names. In order to develop insight into the issue under study, detailed primary information was collected from the selected respondents using secondary information as a base. Keeping in consideration the nature of the study, the collected information was elaborated, inter- preted and thematically discussed under various themes and conclusions were drawn on its basis for clarification and understanding of the issue under study. For tackling ethical issues, prior consent (informed consent form) was signed from the respondent's explaining the study purpose, its nature, and objectives. The study and sampling technique were consistent with similar qualitative studies conducted by Delawala \& Ahmed, 1995; Comption, 2006 \& Mlobeli, 2007.

\section{Results and Discussion}

\section{General and Demographic Characteristics of the Respondents}

Demographic information shows that respondents who were interviewed belong to different age groups. In this regard, 05 (33.3\%) respondents were in an age group from 25 to $35 ; 07$ $(46.6 \%)$ were in the age group of $36-45$; while the remaining $03(20 \%)$ were in age group from 46 to 55 . Further, information also shows that most of the respondents $07(46.6 \%)$ belong to a joint family system; 03(20\%) were from an extended family; and the rest, 05 (33.3\%) were from a nuclear family system. In addition, on the basis of education level, 06 (40\%) of respondents were illiterate; $05(33.3 \%)$ were educated up to primary level; while $2(13.3 \%)$ each were educated up to middle school and above level. On the basis of marital status, respondents were distributed into married, unmarried categories i.e. married 12 (80\%; unmarried 3 (20\%). Demographic information is important and indicates the type of study participants, their social, economic and educational background along their social settings. It also shows the maturity level of research participants, their diversity and thus validity of data collected. 
Table. 1: General and Demographic Characteristics of the Respondents

\begin{tabular}{|l|l|l|l|}
\hline Age Group & Frequency & Percentage & Total \\
\hline $25-35$ & 05 & 33.3 & 05 \\
\hline $36-45$ & 07 & 46.6 & 07 \\
\hline $46-55$ & 03 & 20 & 03 \\
\hline Total & 15 & 100 & 15 \\
\hline Family Type & Frequency & Percentage & Total \\
\hline Joint Family & 07 & 46.6 & 07 \\
\hline $\begin{array}{l}\text { Extended } \\
\text { Family }\end{array}$ & 03 & 20 & 03 \\
\hline $\begin{array}{l}\text { Nuclear } \\
\text { Family }\end{array}$ & 05 & 33.3 & 05 \\
\hline Total & 15 & 100 & 15 \\
\hline Education & Frequency & Percentage & Total \\
\hline Illiterate & 06 & 40 & 06 \\
\hline Primary & 05 & 33.3 & 05 \\
\hline Middle & 02 & 13.3 & 02 \\
\hline $\begin{array}{l}\text { Matric \& } \\
\text { Above }\end{array}$ & 02 & 13.3 & 02 \\
\hline Total & 15 & 100 & 15 \\
\hline $\begin{array}{l}\text { Marital } \\
\text { Status }\end{array}$ & Frequency & Percentage & Total \\
\hline Married & 12 & 80 & 12 \\
\hline Unmarried & 03 & 20 & 03 \\
\hline Total & 15 & 100 & 15 \\
\hline
\end{tabular}

\section{Culture, HIV/AIDS Related Knowledge and Transmission of the Disease}

HIV/AIDS related knowledge and information influence the possibility of people engaging in unsafe sexual practices (Quine \& Rutter, 2002). Hoosen \& Collins (2004) \& Perkel (1992) argued that HIV related knowledge is necessary for making people informed about the disease and provide them an opportunity of preventing the virus from spreading further. During this research the respondents were asked 15 specific questions in a face to face interview about their basic knowledge regarding HIV/AIDS; it was revealed that most of them have no in-depth understanding of these words. While most of these respondents used the terms HIV and AIDS synonymously. In this regard, respondent's HIV/AIDS related knowledge was not satisfactory and many believed that HIV/AIDS cannot be cured or prevented and they regarded HIV/AIDS is a syn- onym for death. This was substantiated during field interview and a respondent shared similar views:

,...HIV/AIDS are synonymous to death and these are not curable. It transmits from one individual to another through eating together, sharing bed, and shaking hands. In my opinion HIV/AIDS simply means fatal disease..."

Similarly, majority of the respondents also believed that a person with HIV will show symptoms of illness soon after contracting the virus and that HIV is not a curable disease. Most of the respondents also did not know or understand the difficult names of other infections related to HIV/AIDS and therefore did not understand what healthcare providers tell them regarding the diagnoses of the illness.

„....He is an illiterate person, and for him it is not easy to understand the complicated names of HIV related infections. It is also difficult to know about the proper diagnosis, treatment and prevention of the disease..."

Relevant research studies shows that HIV related knowledge and information is important in the fight against the disease and poor knowledge about the disease promote the spread of the infection. Individual factors such as knowledge and confidence without a doubt, plays a key role in sexual behavior and thus contributes in the spread of HIV (Hook, 2004), while these factors are shaped by a person's social context in which he is living.

\section{Culture, Imbalance Power Relations and HIV/AIDS Transmission}

The power relations can be defined as the relations between groups or individuals in a hierarchically structured society. Traditional cultural practices, such as gender-role expectations, power-relations and hierarchical structures, form a very important part of the community's day to day life (Campbell, 2004). Various research studies indicate that in any society socio-economic inequalities have been contributing in the transmission of sexually transmitted diseases including HIV/AIDS. In socially constructed power relations, individuals have different levels of access to wealth, influence, respect and social recognition, while few accumulated social and economic resources. Primary information also indicates 
similar results and during an interview a respondents told that:

„...Poor people's access is barred to social and economic resources and majority of the sick people are the poor people. As the poor have no power; are most vulnerable to disease; so HIVIAIDS mostly infect the poor..."

Analyzing the field information, it is evident that excessive numbers of the respondents were poor They have lesser access to productive resources and health care services. The public issue like HIV/AIDS was interpreted with bias and disguise, while the poor were looking to the rich class for its solution.

„...In our culture the poor are looked upon with disgust and they are considered as the vectors of the infection. While the rich people blame the poor for HIVIAIDS transmission and they decide and define daily good and bad from their own point of view ignoring their wrong doing..."

Literary evidences indicate that HIV/AIDS mostly flourish in marginalized social groups having no access to economic power and resources (Barnett \& Whiteside, 2001). And they could not promote healthy a society and a healthenabling environment because of the broader socio-cultural determinants of the society (Campbell, 2004 \& Craddock, 1991). In this way it is important to look at the social, economic, cultural, political, gender and environmental factors along with the biological causes (Kalipeni et al, 2007). The spread of HIV is determined by the wider social context within which communities are located (Campbell, 2004), and the existing gulf between rich and poor significantly contributes to the spread of this deadly disease.

\section{Culture, Gender Relations and Transmission of HIV/AIDS}

In patriarchal societies men are seen as more intelligent, independent and superior to women. In these societies gender remains an important concept in HIV/AIDS related discussion. Further, men are seen as powerful in the family and in society and they make major decisions, while women are supposed to respect and accept men's decisions (Shefer \& Boonzaier, 2003) Such dependency keep women poor and make them vulnerable to various health issues (McFadden,
1992, Schoepf, 1988). Field information indicates imbalance in gender relation between men and women, where men enjoyed economic superiority and made major decisions, while women's role was limited to indoor activities: An extract from the field interview:

„...Yes, in our culture men are dominant, and they are regarded as superior and decision makers. Men accumulate and spend money according to their own will, while women are deprived of economic opportunities and decision making process..."

Relevant studies also found that power relations between a man and woman also occur in their sexual relations, and it is men who decide what will happen in such relationships, and thus put themselves and their partners at risk by having multiple sexual partners and in majority of situations refuse to use condoms (Collins, 2003). In this regard a respondent during interview explained:

„...In our society women are always at the mercy of men (fathers and husbands). Men are sexually and economically stronger than women, and have several wives, while women choices are restrained. Women's access to health services are also decided by the males in society..."

Generally, womens' unemployment, lack of education, and worst paid jobs, make men more powerful, and subjugate women. In most parts of the world women are dependent on men and thus forced to tolerate their dictates without considering the consequences of these on their lives (Shefer, 2003), while men in order to show their masculinity are not willing to use condoms (Collins, 2003). Women are seen as objects for men's sexual pleasure, and it is expected of them to accept sex without condoms in order to satisfy her male partner. It was explained by a respondent during a field interview that:

„,...In our society women are dependent on men and accept their decisions in life. Decision about sex, and the use of condoms is also made by men not women..."

In this context, women accept unprotected sex because of the belief that 1) accepting unprotected sex is an evidence of trust, 2) desires for using a condom can be understood as a sign of disloyalty or 3) that the person making the request is HIV positive (Willig, 1999 \& Guardian, 2006). Fur- 
ther, sex by using contraceptives is also regarded as unreligious and it is regarded as controlling the population. Similar opinions were also expressed by a respondent during an interview:

„...Using a condom is un-Islamic and contrary to religious teaching of producing more children. Nothing happens without the will of Allah. The use of contraceptive could not control disease..."

In this sense, men's demonstration to maintain their status quo and their vested interests would bring harm to many in the world (Baaylies $\&$ Bujrra, 2007). Thus, gender power relations aggravate the problem of HIV/AIDS, and many educated mothers thus avoid providing sex education to their adult daughters (Mbugua, 2007). In the present context too, men's dominance and economic superiority kept women deprived of their rights and most of the women are poor because of their lesser access to economic resources. It also leads men to exercise their power in sexual relations and thus expose both men and women to infections and diseases including HIV/AIDS.

\section{Culture, Poverty and the Transmission of HIV/AIDS}

Culture determines the socio-economic status especially access to economic resources and opportunities (Singer, 1993), and multiple social factors which determine individuals' health-related behavior are linked to the unequal distribution of economic power (Campbell, 2004). Poor people often lack adequate food, nutrition, shelter, and have lesser access to productive resources; education and they are extremely vulnerable to illness like HIV (Thelen, 2003). Field information also shows similar results and it was revealed by a respondent during an interview:

„,...Poverty compelled him to work at early age of 13 in an auto mechanic workshop. Behavior of the owner was intolerable and harsh, and thus, he fled to Lahore where he worked in a hotel. He was exposed to many risks and unhealthy practices there..." In this regard, the poor will at first work towards fulfilling their most basic needs before they will satisfy their need for health, safety, etc. (More, 2003). Similar studies also show that there is a close interrelatedness between culture and poverty as well as between poverty and
HIV/AIDS. Halperin (2001) \& Coovadia (2000) argue that it is a fact that poverty has contributed to the spread of the disease. The analysis further supports the literature that poverty also exacerbates the risks of HIV/AIDS in many direct and indirect ways. In the given context a respondent explained during an interview:

„,...He is a poor man, and because of his poverty he migrated to many parts of the country as well as abroad for earning a livelihood. He added that he also went to Malaysia, and it was during his stay abroad that he acquired the infection..."

Because people of rural areas are of low socio-economic position, and having far fewer work opportunities these men leave their homes in order to find employment elsewhere. Different research has shown that migrant workers often participate in high risk sexual behaviors during the times they spent away from home and infection rates among such workers is thus higher than the general population (United Nations, 2005). An extract from an field interview:

„...Actually, people of rural areas are poor having no economic opportunities. We migrate to big cities for finding a job, where we also found different situations. Away from home sometimes compel you to engage in unsafe sexual practices..."

The need for money and economic survival many times force people to behave in manners that might increase the risk of HIV, and satisfying basic needs of food, water, and shelter look to be the greater priority of the poor than the potential long-term consequences of risky health behaviors including unsafe sex (Halatshwayo \& Stein, 1997). People's level of economic freedom are associated with high-risk behaviors i.e. a woman whose sexual partner economically supporting her and her children, will have less freedom to refuse sex without a condom, but a woman who can support her family economically on her own can resist sex without a condom (Campbell, 2004). Women in order to improve their economic situation and to support her children might also have concurrent partners.

\section{Conclusion}

The study concluded that culture plays a significant role in shaping people's lives including their health. Culture is a source of knowledge and 
information, and these in turn are vital in promotion and prevention of various diseases including HIV/AIDS. Further, culture determines the streams and dimensions of interactions between males and females and influences their power relations. Such relations are considered significant in decisions related to health and accessing health. Furthermore, cultural settings and many social strands also shape our behavior and attitudes, particularly our health related behavior. It also determines the male and female different access to economic resources and accumulation of property which in turn is regarded as a decisive factor in controlling various diseases including HIV/AIDS.

\section{Recommendations}

HIV/AIDS is not only a medical issue but it is interwoven in the socio-cultural fabric of society. The spread as well as control of the infection could be found in social context and cultural factors and the study suggests redefining of certain cultural myths and perceptions that prevent HIV/AIDS patients from seeking prevention and treatment. Further, as HIV/AIDS is a taboo word and not openly discussed in our society, this issue should be discussed in all its forms and manifestation, in order to prevent its transmission. Moreover, as HIV/AIDS related knowledge and its disseminations is culturally defined and determined, the study thus recommends promotion of HIV/AIDS related information and education for both men and women, and increases their access to information and HIV prevention methods in order to reduce HIV/AIDS. In order to effectively fight the menace of HIV/AIDS, there is a need for specifying the role and place of the various religious leaders and institution to help the country's HIV response program and provide spiritual counseling to individuals living with HIV/AIDS. Furthermore, the fight against the disease is impossible without behavioral change and thus it is a necessary to tackle those sociocultural behaviors and values that expose individuals to the risk of HIV.

\section{References}

1. LEHNINGER AL (1982).In, Principles of Biochemistry, A.L.Lehninger (ed.), CBS Publishers \& Distributors.Pvt.Ltd., New Delhi, p. 531 .
2. BABBIE, EARL (1998) The practice of social research $\left(5^{\text {th }} \mathrm{ed}\right)$. Belmont, $\mathrm{CA}$.

3. WASDWORTH BAQI S (1995) HIV Seroprevalence and Risk Factors in Drug Abusers in Karachi. Presented at the 2nd National Symposium on Basic and Applied Research for Health Care and Social Development, Karachi.

4. BARNETT T, WHITESIDEA, DESMOND C (2001) The social and economic impact of HIVIAIDS in poor countries: a review of studies and lessons. Progress in Development Studies. Vol (2) pp. 151-170.

5. BARNETT T, A WHITESIDE (2000) Guidelines for Studies of the Social and Economic Impact of HIVIAIDS. Geneva: UNAIDS.

6. COLLINS C, COATES TJ (1997) Outside the Prevention Vacuum: Issues in HIV Prevention for Youth in the next Decade' The Aids Reader. Vol (5) pp. 149-154.

7. CAMPBELL C, FOULIS C, MAIMANE S, SIBIYA Z (2005) I have an evil child at my house: Stigma and HIVIAIDS management in a South African community. American Journal of Public Health, 9(5), pp. 808-815.

8. DELAWALA G, AHMED (1995) Treating sexually transmitted diseases to control HIV transmission. Current Option in Infectious Diseases, 10, 22-25.

9. HOOK D (2004) Critical psychology: The basic coordinates. In Hook, D (ed) Critical psychology. Cape Town: University of Cape Town Press.

10. KALIPENI E (2008) HIVIAIDS in women: Stigma and gender empowerment in Africa. Future-HIV Therapy Journal, 2(2), pp. 147153.

11. NEUMAN W LAWRENCE (2000) Social research methods: Qualitative and quantitative approaches (4th ed.). Boston: Allyn and Bacon. Pakistan National AIDS Control Program. http://www.nacp.gov.pk/index.html (accessed June 8, 2019).

12. PERKEL A, STREBEL A, JOUBERT G (1991) The psychology of AIDS transmission-issues for intervention. South African Journal of Psychology, 21, pp. 148-152.

13. SCHOEPF (1988) Women, AIDS and Economic Crisis in Zaire. Canadian Journal of African Studies 22(3): pp. 625-644.

14. SCHAFER J, GRAHAM J (2002) Missing 
data: our view of the state of the articulating. Psychiological Methods, 7(2), p. 147.

15. UNAIDS (2004) HIV/AIDS Prevention Indicator Survey, Knowledge, and Attitude and Sexual

Behavior.

16. WORLD HEALTH ORGANIZATION (1995) Acquired immunodeficiency syndrome (AIDS). Weekly Epidemiology Record. Vol (70) pp. 353-360.

17. WORLD HEALTH ORGANIZATION (1995) Global Program on AIDS, Progress Report. 


\title{
Social Aspects of Diagnosis and Treatment of Non-palpable Breast Lesions. Important Factor affecting Quality of Life in Cancer Patients undergoing Surgery
}

\author{
M. Bakos (Marian Bakos)1', T. Jankovic (Tomas Jankovic)ㄱ, V. Krcmery \\ (Mladimir Krcmery)2 ${ }^{2}$ M. Dubovcova (Martina Dubovcova) ${ }^{3}$
}

${ }^{1}$ Department of Surgery Faculty Hospital Nitra, Slovakia

Original Article

${ }^{2}$ University of Health and Social Work St. Elizabeth and Institute of tropical

Medicine Slovak Medical University Bratislava, Bratislava, Slovakia

${ }^{3}$ University of Health and Social Work St. Elizabeth, St. Lesley College, Nove Zamky, Slovakia

\section{E-mail address:}

bamamedchirurgia@gmail.com

\section{Reprint address:}

Marian Bakos

Faculty Hospital Nitra

Department of Surgery

Nitra

Slovakia

Source: Clinical Social Work and Health Intervention

Volume: 12

Issue: 2

Pages: $25-30$

Cited references: 25

\section{Reviewers:}

Jirina Kafkova

MSF, Freetown, SL

Roberto Cauda

Institute of Infectious Diseases, Catholic University of the Sacred Heart, Rome, IT

\section{Keywords:}

Breast Cancer. Non-palpable Lesion. SNOLL. Social Aspect. Quality of Life.

\section{Publisher:}

International Society of Applied Preventive Medicine i-gap

CSWHI 2021; 12(2): 25 - 30; DOI: 10.22359/cswhi_12_2_04 CC Clinical Social Work and Health Intervention

\section{Abstract:}

Introduction: The social aspect of breast cancer presents a serious problem all the time. Quality of women's life after surgery must be compared to life before it. Breast cancer treatments today are likely to cause less physical deformity from surgery than two decades ago but are more complex and extend over a longer period of time. Non-palpable breast lesions are findings with non-biologically specified importance, which can be responsible for development of cancer. The authors present the diagnosis and the results of the treatment of patients with non-palpable breast lesions. They were hospitalized at the Department of Surgery in Nitra from Jan- 
uary 2014 until July 2017 and we used the SNOLL method or wire guided excision under ultrasound control or digital stereotaxic.

Results: From January 2014 until July 2017 there were 122 patients diagnosed with non-palpable breast lesions at the Department of Surgery at our hospital. $76(62.3 \%)$ of these patients were diagnosed with carcinoma. Wire Guided Localization was performed in $99(81.1 \%)$ patients; sentinel node was found in 41 (33.6\%) patients using the SNOLL method. From all the patients a reoperation was conducted in 4 cases $(3.3 \%)$ for close or positive margin status and in 3 cases $(2.5 \%)$ for false negative perioperative sentinel biopsy.

Conclusion: The technique combining 99mTc-MAA (albuminmacro aggregate marked by 99 Technecium) and nanocoloid is a reliable localization method for non-palpable lesions and sentinel nodes. SNOLL is a practical and oncological safe technique of excision of a subclinical lesion in combination with sentinel biopsy. This technique brings new visions for the future, especially for quality of life after surgery, changes in body image and sexuality.

\section{Introduction}

Breast carcinoma presents as a serious diagnosis for every woman. The stress of breast cancer was described as arousing depression, anxiety, and anger. Breast cancer treatments today are likely to cause less physical deformity from surgery than two decades ago but are more complex and extend over a longer period. Women today are very well informed about the details of their cancer diagnosis and prognosis and are increasingly involved in shared decision-making regarding treatment. Although serious depression is not seen in most breast cancer patients and survivors, many will experience treatment-related distress, fear of recurrence, changes in body image and sexuality, as well as physical toxicities that result from adjuvant therapy. This paper discusses the importance of identifying early stage of cancer as an important factor of quality of life after surgery.

With premalignant non-palpable lesions, we understand the spectrum of morphological changes in the tissue of the breast. These changes are risk factors for the formation of cancer. We call them high res or precancerous lesions. These findings are unclear biological behavior as cells show malign architectural features, and the proliferation is different than the normal regulation mechanism of an organism. What is especially important, they have no invasion ability or ability to create metastasis. These lesions threaten patients with formation of cancer, but the extent of risk is necessary to connect with pre-existing individual risk factors of every patient $[1,2]$. In the last decades, the incidence of non-palpable lesions of the breast is increasing, because of mammography and other exact imaging methods. [3, $4,5]$. As a result of this fact, there is the decrease of number of neoplasia's and reduction of their spreading into the axillar lymphatic nodes [6]. The ratio of non-palpable lesions at the time of diagnosis is $25-30 \%$ in countries with function screening. [7]. With the increasing diagnosis of non-palpable lesions at an early stage, correct and complex treatment process is more important. Successful intraoperative localization of non-palpable lesion is necessary for surgeons because of complete excision during the single intervention without extensive excision of healthy tissue. This is important for a quality of life after surgery.

There are two types of pre-invasive carcinomas, which are different in their features and clinical meaning:

- Ductal carcinoma in situ (DCIS) - is the most common type of non-invasive breast cancer. During the months and years, it can progress into this malign form $(50 \%)$. The best treatment method is a surgical operation. Approximately half of cases of local relapse is presented as invasive carcinoma.

- Lobular carcinoma in situ (LCIS) - is an area (or areas) of abnormal cell growth that increases a person's risk of developing invasive 
breast cancer later on in life - both forms ductal or lobular. Treatment strategy is not only operative, but also in primary or secondary prevention [8].

\section{Material and Methods}

\section{Diagnostics and Treatment}

Imaging methods have decisive meaning in diagnoses of small non-palpable and clinical silent carcinomas. The method of choice is mammography. Mammography does not serve only for diagnosis of lesions in the breast, but it is useful in an intervention operation. Advantage of mammography is the ability to find micro-calcifications, which follow carcinoma in 30\%. With systematic mammography it is possible to decrease mortality [9].

Today the core-cut biopsy is the gold standard in preoperative diagnostics of non-palpable lesions of the breast. During the core-cut biopsy a roller of tissue is taken without damage to the architect of the tissue. It uses a special needle which is attached to a mechanical target unit. Today, there are many methods of preoperative localization of breast lesions. They must fulfill some basic conditions: the gold standard is localization of a non-palpable lesion with a wire (WGL - wire guided localization). By European guidelines for quality of screening and diagnosis of breast cancer the peak of wire must be in maximal $10 \mathrm{~mm}$ distance from the center of the lesions in a minimum of $90 \%$ of patients. In 1998 , at the Europe Oncological Institute, Luini introduced an alternative method of localization of a non-palpable lesion with the name ROLL (radio guided occult lesion localization) [9]. The principle of this technique is based on localization of a non-palpable lesion by radiopharmaceutical which is fixed on a carrier with a high molecular weight. Localization is conducted by ultrasonographic navigation, digital stereotaxic or magnetic resonance imaging. In patients with a non-palpable lesion of the breast evaluation of axillar lymphatic node is one of the most important factors, so the biopsy of sentinel node is very necessary. [10-14]. The combination of ROLL with a biopsy of the sentinel node is called SNOLL (sentinel occult lesion localization) and it was introduced by de Cicco in 2002 [15]. Localization is performed under ultrasonography navigation, digital stereotaxis or magnetic resonance imaging. It used the 99mTc-MAA (Technetium ${ }^{99 \mathrm{~m}} \mathrm{Tc}$ macro aggregated albumin), which is applied in a volume of $0.2 \mathrm{ml}$ with low activity. Indication is exact localization of small deep nonpalpable lesions of breast under $10 \mathrm{~mm}$ before surgery. Pregnancy and lactation are contraindications. The first phase of examination takes 1530 minutes and radiation load is minimal [16, 17]. Benefits of the ROLL/SNOLL method are: - it is more precise than the localization with wire, especially in a compact mammary gland - average time of operation is reduced

- lesions are in the resected tissue placed more in centre, they have wider resection border by the smaller volume of extirpation tissue

- increase in percent of non-pathological resection border

- decrease in the percent of require reoperations - diminish of operations wound and it is less traumatic [18, 19]

In our clinic, we proceed according to this two-days protocol:

1 First phase - indication - indication of the lesion by $99 \mathrm{mTc}-\mathrm{MAA}$, which is collected right in tumor without any extra-tumor spreading. Examination is possible to accompany with radionuclide detection of sentinel lymphatic node (SNOLL)

2 Second phase - perioperative localization - surgeons by the handy gamma probe localize the place with maximum radioactivity on the surface of the breast. Measurement of impulse of extirpation lesion and its border in the operation field is necessary for information about complete extirpation.

Imaging of the sentinel node is done by twodays protocol by application of nano nuclides with molecular weight $100-600 \mathrm{nM}$ and 99mTc subdermal peri-areolar in a dose of $60 \mathrm{MBq}$ patent blau. Control scintigraphy confirmed the locale and number of hot nodes. Localization of the nonpalpable lesion was done the day before surgery by the application of Technetium ${ }^{99 \mathrm{~m}} \mathrm{Tc}$ macro aggregated albumin with a molecular weight $10-$ $100 \mu \mathrm{m}$ in a radioactive dose of $20 \mathrm{MBq}$. Under USG control, respectively under digital stereotaxy. 94\% of lesions were marked at a distance of $10 \mathrm{~mm}$ from the center of the lesion. The non-palpable lesion and the sentinel node were detected by the gamma probe during the surgery. 
Operation preparation was subjected to an RTG examination for evidence of the lesion and width of a healthy resection border. In case the safety rim was under $10 \mathrm{~mm}$, the perioperative resection was done. Reoperation was conducted only if the safety rim was less than $3 \mathrm{~mm}$ in correlation of histopathological examination.

\section{Results}

From January 2014 to July 2017, we operated on 122 patients with non-palpable lesions of the breast. The carcinoma was confirmed for 76 patients $(62,3 \%)$. The average age of patients in our group was 63.5 years. Carcinoma was confirmed before surgery for 42 patients $(34.4 \%)$ by corecut biopsy and for 34 patients $(27.9 \%)$ the carcinoma was confirmed during the perioperative refrigeration. For 65 patients (53.3\%) after imaging non-palpable lesions core-cut biopsy was done (under the USG navigation and mammography). Image lesions were smaller than $1 \mathrm{~cm}$ or the cluster of micro-calcifications was detected. After the results of core-cut biopsy the carcinoma was confirmed for 42 patients (34.4\%) before surgery; for 23 patients $(18.9 \%)$ only benign lesion was detected). Localization of non-palpable lesion were done for 99 patients $(81.1 \%)$ with an identification wire. Altogether with localization of lesion with WGL we marked lesions with radiopharmaceutical for 87 patients $(71.3 \%)$. For 12 patients $(9.8 \%)$ we applied patent blau for visualization. We did lymphoscintigraphy for every patient who had suspicion of carcinoma - it means for 99 patients $(81.1 \%)$. At the beginning of surgery, we extirpated the suspect lesion and after this, the tissue was subjected to RTG because of the presence of clusters of micro-calcifications. After this, the histopathological examination was done. In case the safety rim was under $3 \mathrm{~mm}$ in correlation with the histopathological examination the re-resection was positive for 6 patients $(4.9 \%)$; for 35 patients $(28.37 \%)$ it was negative. The average amount of eliminated sentinel nodes for one surgery was 2.6.

After the confirmation of carcinoma from perioperative refrigeration, we indicated SNOLL for 41 patients $(33.6 \%)$. Non-palpable lesions were extirpated for 99 patients $(81.1 \%)$. If the result from core-cut biopsy was a benign lesion, we did not perform any surgery. We did reoperation for 7 patients $(5.7 \%)$; four times $(3.3 \%)$ it was because of insufficient border; three times $(2.5 \%)$ because of false negative result from perioperative histology of the sentinel node. Correlation of lesion's size in histopathological examination to number of reoperations is in table 1 .

Benign lesions we noticed in ages of 18-65 by $37.7 \%$ patients from the entire group. Malign lesions were characteristic for later incidence at ages 51-80 for $62.3 \%$ of patients. Occult, nonpalpable lesions, benign or malign are characterized by relative short anamnesis until surgery. Malign lesions were presented by a size of $10 \mathrm{~mm}$ in $94 \%$. Benign lesions were described connection with micro-calcifications in $55.8 \%$. It is important to do dispensing of these patients in specialized a an outpatient department. We found CIS for $14.8 \%$ patients in our group. CIS together with the T1 stage of carcinoma presented $46.05 \%$ from all malign cases $(76=100 \%)$.

\section{Discussion}

Examination of asymptomatic women increase capture of non-palpable lesions of the breast. Identification with guide wire remains standard for finding non-palpable lesions in many workplaces in Europe despite its deficiencies. These are, for example: difficulty for coordination of more specialists in delimited time, ac-

Tab. 1: Correlation of lesion size in histopathological examination to number of reoperations

\begin{tabular}{|c|c|c|c|c|c|}
\hline \multirow[b]{2}{*}{ pT } & \multirow[b]{2}{*}{$\mathrm{n}$} & \multirow[b]{2}{*}{$\begin{array}{l}\text { Verification of } \\
\text { SNL (SNOLL) }\end{array}$} & \multirow[b]{2}{*}{$\begin{array}{l}\text { identification } \\
\text { with WGL }\end{array}$} & \multicolumn{2}{|c|}{ Reoperation- (border < 3mm) } \\
\hline & & & & $\begin{array}{l}\text { Insufficient } \\
\text { border }\end{array}$ & $\begin{array}{c}\text { False negative } \\
\text { finding from } \\
\text { SNB }\end{array}$ \\
\hline Tis & 18 & 2 & 23 & & \\
\hline T1a & 17 & 7 & 26 & & \\
\hline T1b & 22 & 18 & 28 & 2 & 1 \\
\hline T1c & 19 & 14 & 22 & 2 & 2 \\
\hline overall & 76 & $41 / 122(33.6 \%)$ & $99 / 122(81.1 \%)$ & $4 / 122(3.3 \%)$ & $3 / 122(2.5 \%)$ \\
\hline
\end{tabular}


cumulation of stress factors because of more invasive processes on surgery day: vaso-vagal syncope during the localization; dislocation; migration; transection of a wire; thermic damage of skin during surgery; injury of surgeon or pathologist by processing of tissue [19].

In 1998, Luini introduced a new method with the name ROLL. Principle of this technique is based on localization of sentinel node by radiopharmaceutical which is fixed on a carrier with a high molecular weight. Some randomized studies were conducted with this method. De Cicco in a group of 227 patients combined two kinds of radio carriers with position variations of application of radiopharmacology. They have found that the most optimal for imaging of tumor is an intratumor application of Technetium ${ }^{99 \mathrm{~m}} \mathrm{Tc}$ macro aggregated albumin in combination of a subdermal peri-areolar ap-

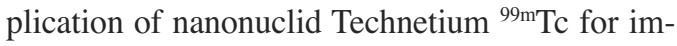
aging of a sentinel node. [15]. Verification of a node was demonstrated for $99 \%$ of patients. Monti et al. have publicized the most extensive study of 959 patients with carcinoma of the breast using the SNOLL. The study was focused for verification of the sentinel node and oncology radicality with using SNOLL [20]. Localization of a node was demonstrated in $99.6 \%$ of patients,; while negative borders were found in $91.9 \%$. A negative border was presented by a safety rim $>10 \mathrm{~mm}$. There were presented some studies with intratumor application of nanonuclid for simultaneously localization tumor and sentinel node [18]. Moreno has randomized a group of 120 patients into 2 groups [14]: ROLL a WGL. He identified: the safety of the resection border; cosmetic effect; and measure of postoperative pain in the first postoperative day. He defined safety borders of $10 \mathrm{~mm}$ for invasive carcinoma and $5 \mathrm{~mm}$ for DCIS. Both methods safely localized the non-palpable lesion. In the ROLL group a statistically significant higher number of clear borders $(p<0,05)$ was observed; better esthetic results; less postoperative pain which resulted in shorter hospitalization.

There is a new method for detection of a sentinel node which is called Sentimag. The Sentimag instrument uses the principle of magnetic susceptometry and generates an alternating magnetic field which transiently magnetizes the iron oxide particles in Sienna+. One of the benefits of Sienna+ is that this substance is not radioactive [21.22].
In concussions of overview studies, radiopharmacological navigated localization obtained many supporters. The reasons are a smaller number of reoperations and better cosmetic effect. Popularity of this method is enhanced with its combination of biopsy of sentinel node. Incidence of CIS dos does not reach $2 \%$ over a long term period in Slovakia, in screening programs its incidence raised [23]. Identification of nonpalpable lesions and micro-calcifications before surgery is important for breast carcinoma because early identification requires minimal surgery and minimal multimodal therapy. We can expect minimal incidence of local relapses, higher survival of patients and decrease of mortality. We expect more significant effect in survival of patients with non-palpable lesions of mammal gland (CIS, tumor in T1a) by using MRI with a contrast substance and follow-up marked by guide wire before surgery. SNOLL is a very practical modification of ROLL method in practice. With a combination of sentinel node detection, it is useful and oncological safety technique of excision of subclinical lesion [23. 24].

\section{Conclusion}

In pursuance of our study's results, we can state that detection of sentinel node using $99 \mathrm{mTc}-$ MAA presents a reliable method for localization of non-palpable lesions and sentinel node. SNOLL in combination with sentinel node detection is practical and an oncological safety technique of excision of a subclinical lesion. Alternative method of localization of sentinel node is method Senti-Mag. Benefit of this method is that substance Sienna+ is not radioactive.

Examination of asymptomatic women increases the number of non-palpable malign lesions of the breast. This technique brings new visions for the future, especially for: quality of life after surgery; changes in body image; and sexuality. Identification of a non-palpable lesion with a guide wire still the gold standard for its verification in many workplaces in Europe. Whether breast cancer patients are newly diagnosed, survivors, or at the end of life, attending to their psychological and social concerns will enhance the effectiveness of our treatments and palliation of symptoms. New techniques in diagnosis or in surgery are helpful for better quality of women's life with breast cancer. 


\section{References}

1. LEBEAU A (2010) Precancerous lesions of the breast. Breast Care. 5: pp 204-206.

2. SINN HP et al. (2010) Early breast cancer precursor lesions: Lessons learned from molecular and clinical studies. Breast Care. 5: pp 218-226.

3. KOHLER BA et al. (2015) Annual report to the nation on the status of cancer, 1975-2011, featuring incidence of breast cancer subtypes by race/ethnicity, poverty and state. J Natl Cancer Inst. 107:djv048.

4. HORTOBAGYI GN et al. (2005) The global breast cancer burden: variations in epidemiology and survival. Clin Breast Cancer. 6: pp 391-401.

5. DEFELICE C et al. (2012) The impact of presurgical magnetic resonance in early breast cancer: an observational study. Eur J Gynaecol Oncol. 33: pp193-9.

6. CADY B et al. (1996) The new era in breast cancer: invasion, size, and nodal involvement dramatically decreasing as a result of mammographic screening. ArchSurg. 131: pp 301-8.

7. BERRY DA et al. (2005) Effect of screening and adjuvant therapy on mortality from breast cancer. N. Eng J Med. 353:1784-92.

8. COUFAL O, FAIT V, EDITORS (2011) Surgical treatment of breast carcinoma. Grada. 76, 255, ISBN 978-80-247-3641-9. Grada. $76,255$.

9. LUINI A et al. (1998) Radio guided surgery of occult breast lesions. Eur J Cancer. 34: pp 204-205.

10. SAJID MS et al. (2012) Comparison of radio guided occult lesion localization and wire localization for non-palpable breast cancers: a meta-analysis. J Surg Oncol. 105:852-8.

11. LOVRICS PJ et al. (2011) Systematic review of radio guided surgery for non-palpable breast cancer. Eur J SurgOncol. 37: pp 38897.

12. MEDINA-FRANCO, H et.al. (2008) Radio guided occult lesion localization (ROLL) versus wire-guided lumpectomy for non-palpable breast lesions: a randomized prospective evaluation. J SurgOncol. 97: pp 108-11.

13. LOMBARDI A et al. (2015) High-resolution, hand held camera use for occult breast lesion localization plus sentinel node biopsy
(SNOLL): A single-institution experience with 186 patients. Surgeon. 13: pp 69-72.

14. MORENO M et al. (2008) Radio guided breast surgery for occult lesion localization: correlation between two methods. J ExpClinCancerRes. pp 27:29.

15. DECICCO C et al. (2002) Radio guided occult lesion localization (ROLL) and surgical biopsy in breast cancer. Technical aspects. Q J Nucl Med. 46: pp 145-151.

16. NURKO J, MICHAEL JE (2005). Imageguided breast surgery. Am J Surg. 190: pp 221-7.

17. GUTH A (2019) Operate or rehabilitate, Rehabilitation, Vol 56, No 4, 2019 , ISSN 03750922, p. 168-169.

18. GITTLEMAN MA (2003) Single - step ultrasound localization of breast lesions and lumpectomy procedure. Am J Surg._186: pp 386-90.

19. LAVOUE V et al. (2008) Simplified technique of radio guided occult lesion localization (ROLL) plus sentinel lymph node biopsy (SNOLL) in breast carcinoma. Ann Surg Oncol. 15: pp 2556-2561.

20. MILES DUA S, GRAY RJ, KESHTGAR M (2011) Strategies for localization of impalpable breast lesion. The Breast. 20: pp 246253.

21. MONTI S et al. (2007) Occult Breast lesion Localization plus Sentinel Node Biopsy (SNOLL): Experience with 959 Patient at the European Institute of Oncology. Ann Surg Oncol. 14: pp 2928-2931.

22. DOUEK M et al. (2014) Sentinel node biopsy using a magnetic tracer versus stardard technique: the SentiMAG Multicentre Trial. Ann Surg Oncol. 21: pp 1237-45.

23. COUFAL O et al. (2015) SentiMag--the magnetic detection system of sentinel lymph nodes in breast cancer SentiMag Rozhl Chir, 94: pp 283-288.

24. TURCAN I et al. (2013) Surgical treatment of non palpable breast cancer by SNOLL method. Slov. chir.10: pp 56-58.

25. CARRERA D et al. (2017) Use of the ROLL technique for lumpectomy in non-palpable breast lesions. Rev Esp Med Nucl Imagen Mol. 2017; 36(5): pp 285-291. 


\title{
COVID-19 Vaccination Strategy in Germany
}

\section{Pfeiffer-Ruiz (Michael Pfeiffer-Ruiz), V. Schroder (Vitali Schroder)}

SEUC PhDProgramme, Germany.

\section{E-mail address:}

m.pfeiffer-ruiz@web.de

\section{Reprint address:}

Michael Pfeiffer-Ruiz

SEU PhD Programme

Badstrasse 5

92318 Neumarkt

Bavaria, Germany

Source: Clinical Social Work and Health Intervention

Volume: 12

Issue: 2

Pages: $31-34$

Cited references: 8

\section{Reviewers:}

Clauss Muss

I-GAP Zurich, $\mathrm{CH}$

Roberto Cauda

Institute of Infectious Diseases, Catholic University of the Sacred Heart, Rome, IT

\section{Keywords:}

COVID-19 Vaccine. Safety and Efficacy COVID-19 Vaccines. Vaccine Development.

\section{Publisher:}

International Society of Applied Preventive Medicine i-gap

CSWHI 2021; 12(2): 31 - 34; DOI: 10.22359/cswhi_12_2_05 CC Clinical Social Work and Health Intervention

\section{Abstract:}

\begin{abstract}
Vaccines are needed to reduce the mortality and economic damage caused by COVID-19. To date there are three approved vaccines in the European Union created by BioNTech/Pfizer, Moderna and AstraZeneca, but due to the high demand globally there are still shortages, forcing governments to create strategies to immunize their population prioritizing their citizens according to their risk evaluation and their systemic relevance. This review specifies on the German vaccination strategy.
\end{abstract}

\section{Introduction}

The COVID-19 pandemic has been one of the greatest challenges of the century for the health industry considering the high mortality and rapid spread of the Coronavirus Disease 2019. Therefore the academic community, industry and government sectors are working tightly together to develop and test a variety of vaccines at an unprecedented pace
(1). This review is focused on the vaccines that have been approved by the European Union and the vaccination strategy established for Germany. So far there have been three vaccines that have passed the clinical trials and are approved by the European Commission to be distributed along the European population with the goal of reaching herd immunity and reducing the mortality rate. 


\section{Covid-19 vaccines approved by the European Union}

\section{1. BioNTech/Pfizer vaccine}

The BNT162b2 mRNA Covid-19 vaccine developed by the German biotechnology company BioNTech in cooperation with the American pharmaceutical corporation Pfizer is the first vaccine to have passed the clinical trials and to receive approval by the European Commission on 22. December 2020.

The BNT162b2 is a lipid nanoparticle-formulated, nucleoside-modified RNA vaccine that encodes a prefusion stabilized, membrane-anchored SARS-CoV-2 full-length spike protein. It is applied in a two dose regimen (30 $\mu \mathrm{g}$ per dose) which is administered 21 days apart and has been proven to be $95 \%$ effective in preventing a COVID-19. It is recommended for adults and adolescents 16 years of age or older and its safety profile was characterized by short-term, mild to moderate pain at the injection site, fatigue and headache.(2)

\section{2. Moderna vaccine}

The mRNA-1273 SARS-CoV-2 vaccine developed by the American pharmaceutical company Moderna was the second COVID-19 vaccine to receive approval by the European Commission on 6. January 2021.

It consists of a lipid-nanoparticle-encapsulated nucleoside modified mRNA vaccine expressing the prefusion-stabilized spike glycoprotein of SARS-CoV-2 and is applied in two doses (100 $\mu \mathrm{g}$ per dose) administered intramuscularly 28 days apart. It is recommended for adults (over 18 years) and has shown an efficacy of $94.1 \%$ and asides from transient local and systemic reactions no safety concerns were identified. $(3,4)$

\section{3. Oxford-AstraZeneca vaccine}

The chimpanzee adenovirus vectored vaccine ChAdOx1 nCoV-19 (AZD 1222) developed by the multinational pharmaceutical and biopharmaceutical company AstraZeneca with its headquarters in Cambridge, England is the latest vaccine to have received a green light by the European Commission on 29 January 2021, although its application has been restricted to the ages between 18 and 64 due to missing valid test data for an older population.
The vectored vaccine is administered in two doses containing $5 \times 10^{10}$ viral particles with 28 to 84 days between the two doses. It has been proven to have a vaccine efficacy of $70.4 \%$ after two doses and protection of $64.1 \%$ after at least one standard dose against symptomatic disease, with no safety concerns. $(5,6)$

\section{Vaccination strategy applied in Germany}

Due to the shortage of available vaccines in Germany and the European Union in general, the German Federal Health Administration was forced to elaborate a vaccination strategy in cooperation with the Robert Koch Institute to reduce the harm caused by this pandemic and prioritizing of individuals who:

- have an increased risk of a heavy or deadly course of COVID-19

- have a high exposition to the virus due to their work

- are in frequent contact with groups of people categorized as ,high risk“ with elevated probability of pathogen transmission.(7)

Currently there are six stages of vaccination in Germany:

\section{Stage 1:}

- Individuals over the age of 80

- Residents of nursing homes

- Medical staff with especially increased risk of exposition, including emergency wards, medical care of COVID-19 patients, emergency medical services and employees in medical sectors where aerosol-generating procedures are performed on COVID-19 patients (e.g. In- and extubation, bronchoscopy or laryngoscopy,...)

- Personnel in medical facilities with close contact to vulnerable groups, such as geriatric care facilities, institutions treating immunocompromised, oncologic, palliative patients and mobile vaccination teams.

- Nursing staff in ambulant or stationary care

- Other employees of residential care facilities for the elderly (7)

\section{Stage 2:}

- Individuals between the ages of 75 and 79

- People with trisomy 21 (Down’s syndrome)

- Institutional residents with dementia or mental disabilities

- Medical staff with high risk of exposition, like isolation wards, general doctor's/pediatricians offices, on duty emergency medical service, 
transport of emergency patients, ENT, ophthalmology or dental clinics, SARS-CoV-2 test centers and public health service.

- Employees in ambulant or stationary care of patients with dementia or mental disabilities (7)

\section{Stage 3:}

- Individuals between the ages 70 and 74

- Persons with pre-existing conditions considered high risk, such as chronic liver disease, cancer (not in remission), psychiatric illness (e.g. bipolar disorder, schizophrenia, severe depression), dementia, Diabetes mellitus (HbA1c $\geq 58 \mathrm{mmol} / \mathrm{mol}$ or $\geq 7.5 \%$ ), obesity (BMI $>30$ ), malignant haematological disorders and chronic renal failure

- Residents and staff in shared accommodations

- Close contact persons of pregnant women or persons with high risk

- Personnel in medical facilities with moderate risk of exposition like employees working with pregnant patients, blood donations or stationary vaccination centres, cleaning staff, relevant personnel for hospital infrastructure (7)

\section{Stage 4:}

- Individuals between the ages of 65 and 69 years

- Persons with pre-existing conditions considered moderate risk, including diseases of the heart or the central nervous system, diabetes mellitus $(\mathrm{HbA} 1 \mathrm{c}<58 \mathrm{mmol} / \mathrm{mol}$ or $<7,5 \%)$, cancer (in remission), rheumatic or autoimmune illnesses, hypertension and asthma

- Close contact persons of people with moderate risk

- Personnel in medical facilities with low risk of exposition like laboratory staff and workforce not dealing with patients with (suspected) infectious diseases and not performing aerosol generating procedures

- Teachers and childcare workers

- Persons with precarious working and/or living conditions (7)

\section{Stage 5:}

- Individuals between the ages of 60 and 64 years

- Previously not mentioned occupational groups, like personnel in key positions of the state and local government, retail workers, security and critical infrastructure personnel (7)

\section{Stage 6:}

- Remaining part of the population under the age of 60 (7)

\section{Materials and methods}

The main search engines used were PubMed, Google Scholar and Web of Science using the keywords: „,SARS-CoV-2 vaccine“, „COVID-19 vaccine“, „BioNTech/Pfizer vaccine“, ,Moderna vaccine“, „Astra-Zeneca vaccine“, „Safety and Efficacy COVID-19 vaccines“, ,Vaccine development".

Included in this review were articles, case studies, efficacy trials and systematic reviews as well as information gathered from the official website of the German Federal Government and the Robert-Koch Institute published on December 2020 or later. The exclusion criteria consisted in: articles not related to the topic; animal studies; articles published before December 2020 .

\section{Results}

The currently approved vaccinations have proven to be very efficient in short term prevention of a severe course of COVID-19, but so far there is not enough data to make viable statements about prevention of transmission and long term immunity.

Also due to the recent nature of events and Germany currently being between stages 1 and 2 of their vaccination plan it is yet too early to make any declaration about the efficiency of the applied strategies even though a decrease of the number of cases can be observed, but it is mostly attributed to the implemented measures of containment.

In some aspects of it there might still be some room for discussion as not all of the listed professions might feel they are being treated fairly, especially the teachers and childcare workers, because it is very hard to maintain the established measures of prevention in the schools and kindergartens and they are supposed to be reopened soon, yet they are categorized as a profession of low risk.

\section{Conclusion}

Even though there are vaccines available, there still are shortages, forcing the German government to implement a vaccination plan as well as a priority system to reduce the harm caused by the Coronavirus, meaning that the end of this pandemic remains yet to be seen. The vaccination strategy is not a fixed structure that can be changed and adapted to the needs of the current situation. 


\section{References}

1. LI YD, CHI WY, SU JH, FERRALL L, HUNG CF, WU TC (2020) Coronavirus vaccine development: from SARS and MERS to COVID-19. J Biomed Sci. 2020;27(1): p 104.

2. POLACK FP, THOMAS SJ, KITCHIN N, ABSALON J, GURTMAN A, LOCKHART S et al. (2020) Safety and Efficacy of the BNT162b2 mRNA Covid-19 Vaccine. N Engl J Med. 2020;383(27): pp 2603-15.

3. OLIVER SE, GARGANO JW, MARIN M, WALLACE M, CURRAN KG, CHAMBERLAND M, et al. (2021) The Advisory Committee on Immunization Practices' Interim Recommendation for Use of $\backslash$ Moderna COVID19 Vaccine - United States, December 2020. MMWR Morb Mortal Wkly Rep. 2021;69(5152): pp 1653-6.

4. BADEN LR, EL SAHLY HM, ESSINK B, KOTLOFF K, FREY S, NOVAK R, et al. (2021) Efficacy and Safety of the mRNA-1273 SARS-CoV-2 Vaccine. N Engl J Med. 2021;384(5): pp 403-16.

5. VOYSEY M, CLEMENS SAC, MADHI SA, WECKX LY, FOLEGATTI PM, ALEY PK, et al. (2021) Safety and efficacy of the ChAdOxI $n C o V-19$ vaccine (AZD1222) against SARSCoV-2: an interim analysis of four randomised controlled trials in Brazil, South Africa, and the UK. Lancet. 2021;397(10269): pp 99-111.

6. KNOLL MD, WONODI C (2021) OxfordAstraZeneca COVID-19 vaccine efficacy. Lancet. 2021;397(10269): pp 72-4.

7. KOCH-INSTITUT R. STUFENPLAN DER STIKO ZUR PRIORISIERUNG DER COVID-19-IMPFUNG ROBERT KOCH-INSTITUT WEBSITE2021 [Available from: https://www.rki.de/DE/Content/Infekt/Impfen/ImpfungenAZ/COVID- 19/Stufenplan.htmlAvailable from: \jsessionid=696984FCEC459FB9DC34 A61D067CD1FC.internet061.

8. RADI F, BUDZELOVA K, OLAH M, MUSS C (2021) Late psychosocial consequencesfrom HIV to Covid. Clin Soc Work and Health Interv.12.2021.2.6-7.10.22359/cswhi_12_2_15. 


\section{Economic and Social Aspects of Secondary Lymphedema following Treatment of Breast Cancer}

K. Pitr (Karel Pitr)

SEU PhD. program and REHA-PITR s.r.o., Czech Republic.

\section{E-mail address:}

pitrk@volny.cz

\section{Reprint address:}

Karel Pitr

SEU PhD. program and REHA-PITR s.r.o.

Plaska 66a

Plzen

Czech Republic

Source: Clinical Social Work and Health Intervention

Pages: 35 - 38

\section{Reviewers:}

Juraj Benca

Clinic st. Maximiliana Kolbeho, House of family, Phnom Penh, Cambodia

P.Haj Ali

Erbil - Clinic bl. Zdenky Schellingovej, Irak

\section{Keywords:}

Breast Cancer. Economic Burden. Lymphedema. Qualitative Analysis.

\section{Publisher:}

International Society of Applied Preventive Medicine i-gap

CSWHI 2021; 12(2): 35 - 38; DOI: 10.22359/cswhi_12_2_06 CC Clinical Social Work and Health Intervention

\section{Abstract:}

\section{Introduction}

The quality of life of female patients who have undergone mentally and physically demanding treatment of cancer is often affected by the emergence of secondary lymphedema. The purpose of our work is to evaluate this complexity not only from an objective but also subjective point of view.

\section{Methods}

Qualitative focus study in 18 patients under 60 years of age conducted by way of a structured interview during 2019 at the lymphological workplace.

\section{Results}

The economic burden for patients is on the average CZK 683 per month (about $\$ 360$ USD per year), the treatment is paid for fully by health insurance companies. Lymphedema is a significant barrier in an occupation, more in women after treatment of the second grade of cancer than the first one. Lymphedema 
is a bigger obstacle for women with lower education, physically working. Family status does not have a significant effect on the treatment of cancer.

\section{Conclusions}

The study has confirmed the difficulty of treatment of secondary lymphedema after the treatment of breast cancer, both from financial and professional points of view. The medical staff should take into account these factors or expand the rehabilitation team and thus ensure better compliance in therapy.

\section{Introduction}

The secondary lymphedema is a common complication of breast cancer treatment. Its incidence increases in parallel with the increasing incidence of breast cancer and the improvement of the prognosis and thus the number of surviving patients. It is repeatedly demonstrated (1.2) that the quality of life of patients who have survived severely mentally and physically difficult treatment of cancer suffer from the development of subsequent lymphedema. The purpose of our work is to evaluate this complexity not only from an objective but also subjective point of view.

\section{Methods}

In view of the fact that our goal is to evaluate primarily the subjective burden of patients with secondary lymphedema and to understand the obstacles and facilitators for compliance, possibly adherence, we used a qualitative method of research. The study was conducted in 2019 in a department specialized in the rehabilitation of oncology patients. It included 18 women after treatment of breast cancer treated for secondary lymphedema after the first one. The conditions of acceptance to the study were following: Women had to be younger than 60 ; before the retirement age. So we evaluated a group of women aged from 27 to 56 years old, with an average age of 45.78 years, a median of 46 , a standard deviation of 8.07 .

As a method of qualitative research, a focus group was chosen and as a way of obtaining data was chosen a structured conversation which will allow to unify the data obtained from individuals and at the same time to evaluate the subjective perception of reality. This subjective perception of reality was converted into degrees of:

Subjective financial burden by treatment: 1 minimum 2 - medium 3 - high $\mathbf{4}$ - hard to manage Lymphedema as an obstacle in an occupation:
1 - not manifested $\mathbf{2}$ - mild 3 - severe 4-impossible to work

\section{Results}

Assessing family status: 10 women lived with family; 7 only with a partner; only lived alone. Family status did not affect the overall burden of lymphedema treatment, according to the opinion of the husbands. In relation to profession: 5 women worked physically, 1 was a housewife; 5 were permanently fully disabled; the other 7 worked mentally. All 5 women who were in full disability pension evaluated their lymphedema problems as serious, making it impossible to work because 2 of them originally worked as waitresses, 1 as a nurse and 2 as shop assistants.

The size of lymphedema was measured as the largest difference in circuits and was at least 5 and a maximum of $3 \mathrm{~cm}$, on average $1.5 \mathrm{~cm}$ (median 1.5, standard deviation 0.65). Lymphedema was rated as a barrier to work by more serious women after treatment for second grade cancer than the first one. Higher grades cannot be evaluated due to the low frequency.

Chart 1: seriousness of obstacle in occupation (1-4) in dependence on size of swelling

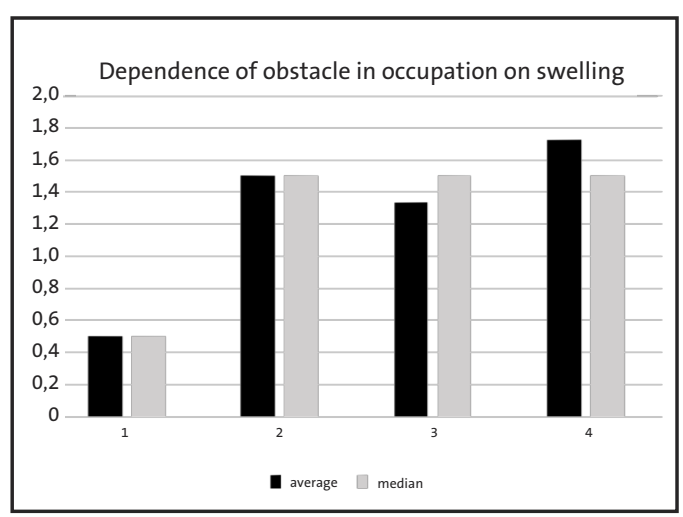


The average month cost of treatment for lymphedema in patients was CZK 683 (median 500, standard deviation 433). The treatment was covered by health insurance companies.

The financial difficulty of treatment with lymphedema objectively is slightly lower in women with second grade cancer than with the first one, but subjectively, the financial burden is perceived worse in the second grade than in the first one. Our patients showed a high quality of consumer credit, only two were credited, but not with high credit. The size of the swelling can be considered as an obstacle in occupation, as well as the lower the education, the greater the barrier in occupation.

\section{Chart 2: impact of education on seriousness of lymphedema as an obstacle in occupation}

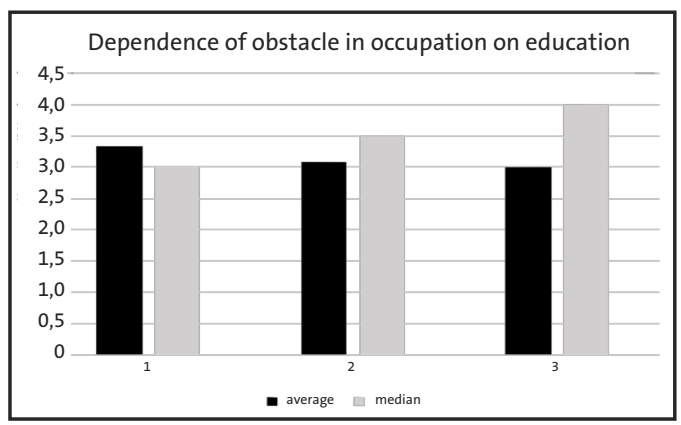

$1-$ primary + apprenticed

2 - secondary

3 - university

\section{Discussion}

In our study, according to the subjective observations of patients, family status does not have a significant effect on the overall burden of lymphedema treatment. According to other authors, this influence is significant (1) both in the field of occupation and in personal life (2). The reason is probably a different economic and cultural environment. The greater impact of lymphedema on women with lower education and therefore physically working our study shows a consensus (3).

The financial cost of treatment for our patients is significantly lower, i.e. $\$ 360$ per year compared to financial claims in the US, where it is $\$ 500$-\$1215 per year (4): Belgian authors report the cost of patient-bearing at $\$ 3,325$ to $\$ 5,545$, the cost of the company is $\$ 1,127$ to $\$ 3,165$ (5). According to the results of our study, lymphedema is usually a significant barrier to work, which is in conformity with most authors (1.6).

\section{Conclusions}

The study has confirmed the difficulty of treatment of secondary lymphedema after the treatment of breast cancer, both from the financial and professional points of view. The problem appears in patients with lower education which means working physically. The physicians, lymph therapists and physiotherapists should take into account these factors and cooperate with psychologists and social workers and provide better psychological and economic comfort for women treated for secondary lymphedema after treatment for breast cancer. In this way, better compliance and adherence in treatment can also be achieved, which is a necessary condition for its effectiveness.

The author was not supported by any company or sponsoring organization when creating the work, the work is not part of the grant. The author is not aware of a conflict of interest and has no direct or indirect interest in the production or sales results.

\section{References}

1. VIGNES S, FAU-PRUDHOMOT P, SIMON L, SANCHEZ- BRECHOT M L, ARRAULT M, LOCHER F (2020). Impact of breast cancer-related lymphedema on working women. Supportive Care in Cancer [online]., 28(1), 7985[cit. 2020-03-10]. DOI: 10.1007/s00520019-04804-2.ISSN 0941-4355. Available from:http://link.springer.com/10.1007/s00520019-04804-2.

2. BOING L, PEREIRA G S, DA CRUZ RAMOS DE ARAUJO C, SPERANDIO F F, DA SILVA GEVAERD LOCH M, BERGMANN A, BORGATTO A F, iana COUTINHO DE AZEVEDO GUIMARAES A (2019). Factors associated with depression symptoms in women after breast cancer. Revista de Saude Publica [online] 53 [cit. 202003-10]. DOI: 10.11606/S1518- 8787. 2019 053000786. ISSN 1518-8787. Available: https://www.revistas.usp.br/rsp/article/view/15 6159. 
3. PUGH S (2020) Importance of a collaborative approach to lymphoedema management. British Journal of Community Nursing [online]. 2019, 24 (Sup4), S30-S31 [cit. -03-10]. DOI: 10.12968/bjen.2019.24.Sup4.S30.ISSN 1462-4753. Available from: http://www.magonlinelibrary.com/doi/10.12968/bjen.2019.24 .Sup4.S30.

4. DEAN L T, MOSS S L, RANSOME Y, FRASSO-JARAMILLO L, ZHANG Y, VISVANATHAN $\mathrm{K}$, NICHOLAS $\mathrm{L} \mathrm{H}$, SCHMITZ K H (2020) It still affects our economic situation: long-term economic burden of breast cancer and lymphedema. Supportive Care in Cancer [online]. 2019, 27(5), 16971708 [cit. -03-09]. DOI: 10.1007/s00520-0184418-4. ISSN 0941-4355. Available from: http://link.springer.com/10.1007/s00520-0184418-4

5. DE VRIEZE,T, NEVELSTEEN I, THOMIS S, DE GROEF A, WIEBREN A. A.TJALMA, GEBRUERS N,DEVOOGDT N (2020) What are the economic burden and costs associated with the treatment of breast cancer-related lymphoedema? A systematic review. Supportive Care in Cancer [online]. 28(2), 439-449 [cit.2020-03-10]. DOI: 10.1007/s00520-01905101-8. ISSN 0941-4355. Available from: http://link.springer.com/10.1007/s00520-019 05101-8.

6. KALFA S, KOELMEYER L, TAKSA L, WINCH C, VIVEROS H, GOLLAN P J, MACKIE H, BOYAGES J (2018) Work experiences of Australian cancer survivors with lymphoedema: A qualitative study. Health \& Social Care in the Community [online].27(4), 848-855 [cit. 2020-03-10]. DOI: 10.1111/hsc. 12698. ISSN 0966-0410. Available from: https://onlinelibrary.wiley.com/doi/ abs/10. 1111/hsc.12698. 


\title{
Advantages of the Introduction of Electronic Healthcare Prescriptions before COVID Era Experiences in Pioneer Countries Estonia and Finland and the Status in Germany
}

\section{Ch. Racek (Christoph Racek), A. Czirfusz (Attila Czirfusz)}

SEUC PhD program in Health management and public health, Germany.

\section{E-mail address:}

christophracek@gmx.net

\section{Reprint address:}

Christoph Racek

SEUC PhD Program in Health Management and Public Health

Dentist

Winzerstr. 28

79227 Schallstadt

Germany

Source: Clinical Social Work and Health Intervention

Volume: 12

Issue: 2

Pages: 39 - 44

Cited references: 21

\section{Reviewers:}

Andrea Shahum,

University of North Carolina at Chapel Hill School of Medicine, USA

Steve Szydlowski

University of Scranton school of education, USA

\section{Keywords:}

Functions of e-prescription. eHealth. Benefits of e-prescription, e-prescription Implementation Barriers. Patients Safety.

\section{Publisher:}

International Society of Applied Preventive Medicine i-gap

CSWHI 2021; 12(2): 39 - 44; DOI: 10.22359/cswhi_12_2_07 (C) Clinical Social Work and Health Intervention

\section{Abstract:}

\begin{abstract}
As pointed out by previous studies, fragmentation of health information based on medical prescription is a prevalent health crisis across the globe. Several countries such as Finland, Estonia, and Germany have adopted the electronic health system to eradicate these medical errors ${ }^{1}$. As suggested by the health professionals, the major health concerns in modern healthcare are prescription error elimination and patients' safety. So, eprescription is proposed as the most effective health approach to provide long-term solutions by replacing manually written
\end{abstract}

\footnotetext{
${ }^{1}$ Greenhalgh, T., Stones, R. (2010). Theorizing big IT programs in healthcare: Strong structuration theory meets actor-network theory. Social Science and Medicine 70 (9), 1285-1294.
} 
prescriptions ${ }^{2}$. Electronic health is a computerized medical system with an expansive database of patients' information. Despite its speculated benefits on the health industry, e-prescription implementation has experienced various challenges such as patients and pharmacists resistance ${ }^{3}$. Therefore, this paper explores the health benefits of e-prescriptions in Estonia and Finland and their status in Germany.

\section{Function of the e-prescription}

\section{Capabilities of education}

Full details of the patients' medical history are provided by the e-prescription. Supplying the medical providers with knowledgeable information about the patients is easy for improving the quality of healthcare services. Additionally, eprescription is web-based and the patients and team of healthcare providers can interact and socialize online to educate patients on health issues.

\section{Improves efficiency}

As suggested by experts, the implementation of e-prescription is safe and faster ${ }^{4}$. Transition from the huge paperwork in issuing prescriptions to electronic print is more efficient and faster in retrieving the right medication for the patient. Besides, the long queuing at the health centers is minimized since services of e-prescription are much faster compared to physical handwriting 5 . More than that, reduced errors which could lead to health dangers are not embedded within the eprescription hence this justifies its efficiency.

\section{Expansion of patient medication adherence}

E-prescription frameworks can assist doctors with picking a minimal effort choice that might be clinically better for the patient. This is practical by eliminating inclination increased adherence to prescription treatment can advance better health results and diminish costs. At the drug store, the entering of solutions is more smoothed out when programming takes into consideration robotized preparation $^{6}$. Alongside medicine adherence, the replacement of non-exclusive meds or less exorbitant model options can decrease the expense to patients and insurance agencies. An expansion ineffectiveness is seen in the wake of executing e-recommending, principally because of less administrative work and fewer issues waiting to be settled.

\section{Advantages of this digital form: Store and display full patient-specific considerations, patient demographics, and structured patient data}

Joining e-prescription during the time spent on medical care can improve the nature of care productively. A medical services association needs to enlist individuals for different jobs like recording or deciphering ${ }^{7}$. It fundamentally decreases the danger of blunders and false impressions that can antagonistically influence the nature of care. The degree of the nature of care has expanded altogether because of the utilization of e-prescription. Business costs can deplete income. Notwithstanding, with e-prescription, you can dispose of the greater part of the recording assignments. Specialists can in any event diminish them to a point where staff hours can be decreased $^{8}$. Electronic prescription is regularly simpler to peruse than a specialist's penmanship.

\footnotetext{
${ }^{2}$ Cornford, T., Hibberd, R., Barber, N. (2014). The evaluation of the electronic prescription service in primary care, Technical Report.

${ }^{3}$ Uemo. (2019). Finland And Estonia Pioneering Cross-Border Health Services - Uemo. Uemo. Eu.

${ }^{4}$ HIMSS Europe. (2018). HIMSS Analytics Annual European eHealth Survey 2018.

${ }^{5}$ Helsinki,.(2013). eHealth Strategy And Action Plan Of Finland In A European Context.

${ }^{6}$ Lillevali, A., Kond, K, (2019).E-Prescription Success In Estonia: The Journey From Paper To Pharmacogenomics.

${ }^{7}$ Tinyakov, S. (2018). The priorities for health and social care policy in Germany

${ }^{8}$ Noventi. (2019). We Are Ready For E-Prescription. NOVENTI. https://www.noventi.de/en/news/we-areready-for-e-prescription.
} 


\section{Quick and safe retrieval of patients' data}

Electronic prescription is faster in accessing patients' data compared to offline data. It essentially decreases the danger of blunders and false impressions that can unfavorably influence the nature of care. Joining e-prescription during the time spent on medical care can improve the nature of care effectively ${ }^{9}$. Also, record costs are typically decreased because the framework translates predefined notes or documentation made by the doctor during a patient visit by basically barring the requirement for a staff transcriptionist. The degree of nature of care has expanded essentially because of the utilization of e-prescription. Automated information is frequently simpler to peruse than a specialist's penmanship.

\section{Ability to recruit a new breed of physicians}

Young graduates from medical schools are familiar with the digital system, unlike the older medical professionals. Adopting the digital system within the healthcare sector will provide more opportunities for fresh graduates to fill these newly created spaces by the e-prescription ${ }^{10}$. Implementation intention of the e-prescription calls for the new breed of doctors who are more conversant with the digital world to replace the analogue generations in adopting the new changes within the medical sector. New specialists look for training to grow another way, and the innovation offered in an e-prescription is something they have become constant to in residency. Electronic prescription makes occupations simpler and more productive thus disclose to them that training is developing and staying aware of industry changes.

\section{Reduced bulky paperwork}

An Offline medical prescription involves extreme use of paperwork that accumulates over the years in the office. Electronic prescription disposes of the need to store reports in massive file organizers ${ }^{11}$. Not exclusively is restricted space currently utilized for another capacity of the workplace, however innumerable office supplies like paper, dividers, and graph costs are dispensed with. Paper outlines and notes can occupy a ton of room. What's more, as they develop, it gets urgent to discover substitute storerooms for more established outline volumes. In any case, with e-prescription, specialists can supplant paper outlines.

\section{Implementation in Estonia and Finland}

Implementation of e-prescription in Finland and Estonia has generated various health benefits to patients and health providers ${ }^{12}$. The absence of sufficient patients' information has been a great challenge in Estonia and Finland hence causing health dangers to patients. The introduction of electronic prescription in Finland and Estonia has offered medical providers and patients a better experience by providing a broad range of health information on a national scale. Elderly patients in Estonia and Finland are no longer exposed to health risks due to the fragmentation of health information. Now, other countries are in the process of e-prescription implementation to create a national electronic medical approach just like Finland and Estonia. Several countries like Germany which have faced dismantled implementation attempts at initial stages are intending to offer a flexible and accurate updated dispensed and prescribed medication for every patient ${ }^{13}$. However, even Finland and Estonia experienced the slow process of e-prescription just like in Germany. In all countries, the common hurdles like e-prescription acceptance between patients and healthcare providers were witnessed ${ }^{14}$.

9 TFHC. (2019).E-Health In Germany

${ }^{10}$ Kela. 2020. Estonian Citizens Can Now Purchase Medicines In Finland With An E-Prescription Issued In Their Own Country - News Archive For Customers.

${ }^{11}$ Helsinki,.(2013). eHealth Strategy And Action Plan Of Finland In A European Context

${ }^{12}$ Cripps, H., Standing, C., Prijatelj, V. (2011). The Implementation of Electronic Health Records: A Two Country Comparison. In: Proceedings of BLED 2011, paper 46.

${ }^{13}$ Gohlisch, J. (2018). Digital Health in Germany - 2018 and beyond . Opgehaald van Medium: https://medium.com/@jangohlisch/digital-health-in-germany-2018-and-beyond-2b2df6032688

${ }^{14}$ Boonstra, A., Boddy, D., Fischbacher, M. (2004). The limited acceptance of an electronic prescription system by general practitioners: reasons and practical implications. New Technology, Work and Employment 19 (2), 128-144. 


\section{Reasons for the delay of the introduction in Germany}

Despite Estonia and Finland enjoying numerous benefits of e-prescription, Germany had a rough course in the implementation process of eprescription. The process of digitizing Germany's healthcare has been in delay due to several factors. Implementation intention of the e-prescription in Germany faced numerous hurdles as indicated by the Federal Health Ministry of Germany. Finally, the establishment of e-prescription in Germany was stabilized in the year 2020 after having encountered several failure stages.

\section{Reasons for the delay of e-prescriptions introduction in Germany:}

System errors associated with e-prescription: In Germany, the system errors or e-prescription was visible very early within the test regions ${ }^{15}$. It caused distrust and criticisms among the patients and healthcare providers ${ }^{16}$ concerning its efficiency. This inaccurate experience with e-prescription in the initial stages demonstrates inflexibility connected with digital medical platform. More than that, patients and medical providers in the first phase of e-prescription implementation experienced delays in the process of rendering prescriptions.

Legal and privacy issues: Most of the health recipients in Germany were opposed to the e-prescriptions due to the fear of legal and privacy issues. In Germany, most of the patients are used to offline prescriptions and the use of e-prescriptions demanded too much of their information including the bank details which triggered the uneasiness. For example, the e-prescriptions is web- based as it entails wires transmission of information $^{17}$. But as cyber-crimes are a prevalent issue with the digital platform, German citizens massively were against the implementation of the eprescription. Electronic prescription is open to information leakages at various points and if intrusion and firewall prevention systems are not properly installed, the privacy of patients' information is at risk. Several attempts of e-prescriptions tests in Germany proved to be insecure due to various errors hence the patients preferred to use offline prescription.

Inadequate time-frame for implementation: The Federal Health Ministry for Germany under-estimated the time process to transition from the analogue to digital medical prescription $^{18}$. As suggested by the research experts, medical providers and patients were not given enough time to adjust that quickly to e-prescriptions ${ }^{19}$. In most cases, the delays and errors witnessed through the e-prescription implementation process proved to be a result of improper timing for the program. Additionally, the scope of attitude change between health providers and patients was not taken seriously as the government thought the process of implementation could smooth just like in other countries like Finland and Estonia. Patients in Germany are used to the paperwork way of medical prescription hence eprescription was not popular ${ }^{20}$.

Lack of an integrated system accommodating various designs of healthcare departments: A potential stepwise acknowledgment of the general engineering - with putting away information just on the card in the initial step and the telematics foundation in a second was de-

${ }^{15}$ Engberg, Anna. 2019. German Health Minister Spahn Promotes Use Of Eprescriptions At The DMEA 2019. Healthcare IT News. https://www.healthcareitnews.com/news/emea/german-health-minister-spahn-promotes-use-eprescriptions-dmea-2019.

${ }^{16}$ Bastholm Rahmner, P. et al. (1994). Physicians' perceptions of possibilities and obstacles prior to implementing a computerized drug prescribing support system. International Journal of Health Care Quality Assurance 17(4), 173-179.

${ }^{17}$ Eversana. 2020. Germany To Mandate E-Prescriptions By 2022 I EVERSANA. Eversana. https://www.eversana.com/2020/04/02/germany-eprescriptions/.

${ }^{18}$ Dwivedi, Y. K. et al. (2014). Research on information systems failures and successes: status update and future directions. Information Systems Frontiers

${ }^{19}$ Duennebeil, S. et al. (2009). Integration of Patient Health Portals into the German Healthcare Telematics Infrastructure. In: Proceedings of AMCIS 2009, paper 754.

${ }^{20}$ Taylor Wessing. (2016, March). E-Health Law in Germany. Opgehaald van Synapse Law for Life Science 
serted or not considered ${ }^{21}$. The general design additionally might have been stepwise enhanced by point by point project results. During the intercession's advancement, it might have served to educate about changes in the to-be engineering because of postponements or different challenges. These means required complex parts and the inclusion of different equal advancement projects performed by countless sellers. Toward the end, the stepwise acknowledgment was important because of deferrals in understanding the telematics framework. The general design might have had a managing and recognizing capacity for every one of the many after tasks, advising similarly sellers and wellbeing suppliers.

\section{Conclusion}

Globally, healthcare organizations are shifting gradually from manually written prescriptions to e-prescription. The evolution of the modern healthcare system is gravitating towards the benefits of e-prescription due to reduce patients' information errors. For instance, in Finland, Estonia, and Germany, e-prescription is currently rated as the primary objective within their electronic health approaches ${ }^{22}$. However, the implementation process in all countries has been slower than expected due to resistance from patients and a team of healthcare providers. Besides, political interests, security, and privacy requirements are pointed out as the root to the implementation barriers.

\section{References}

1. BASTHOLM RAHMNER P et al. (1994) Physicians' perceptions of possibilities and obstacles prior to implementing a computerized drug prescribing support system. International Journal of Health Care Quality Assurance 17(4), pp 173-179.

2. BOONSTRA A, BODDY D, FISCHBACHER M (2004) The limited acceptance of an electronic prescription system by general practitioners: reasons and practical implications. New Technology, Work and Employment 19 (2), pp 128-144.
3. COMMONWEALTH FUND (2014) Germany: Health System Review. Health Systems in Transition, 20.

4. CRIPPS H, STANDING C, PRIJATELJ V (2011) The Implementation of Electronic Health Records: A Two Country Comparison. In: Proceedings of BLED 2011, paper 46.

5. CORNFORD T, HIBBERD R, BARBER N (2014). The evaluation of the electronic prescription service in primary care, Technical Report.

6. DUENNEBEIL S et al. (2009) Integration of Patient Health Portals into the German Healthcare Telematics Infrastructure. In: Proceedings of AMCIS 2009, paper 754.

7. DWIVEDI Y K et al. (2014) Research on information systems failures and successes: status update and future directions. Information Systems Frontiers.

8. ENGBERG A (2019) German Health Minister Spahn Promotes Use Of E-prescriptions At The DMEA 2019. Healthcare IT News. https://www.healthcareitnews.com/news/eme a/german-health-minister-spahn-promotesuse-eprescriptions-dmea-2019.

9. EVERSANA (2020). Germany To Mandate E-Prescriptions By 2022 / EVERSANA. Eversana.

https://www.eversana.com/2020/04/02/germany-eprescriptions/.

10. GOHLISCH J (2018) Digital Health in Germany-2018 and beyond. Opgehaald van Medium: https://medium.com/@jangohlisch/digital-health-in-germany-2018-andbeyond-2b2df6032688.

11. GREENHALGH T, STONES R (2010) Theorizing big IT program in healthcare: Strong structuration theory meets actor-network theory. Social Science and Medicine 70 (9), pp 1285-1294.

12. HELSINKI, (2013) eHealth Strategy And Action Plan Of Finland In A European Context. Retrievable from:https://www.google.com/ url?sa $=\mathrm{t} \& \mathrm{rct}=\mathrm{j} \& \mathrm{q}=\& \mathrm{esrc}=\mathrm{s} \&$ source $=$ web $\& \mathrm{c}$ $\mathrm{d}=\& \mathrm{cad}=$ rja\&uact $=8 \&$ ved $=2$ ahUKEwjRi JeZ-87uAhVTUBUIHciIBEkQFjAGegQI-

\footnotetext{
${ }^{21}$ Commonwealth Fund. (2014). Germany: Health System Review. Health Systems in Transition, 20.

${ }^{22}$ HIMSS Europe. (2018). HIMSS Analytics Annual European eHealth Survey 2018. Opgehaald van HIMSS Europe
} 
BRAC\&url=https $\% 3 \mathrm{~A} \% 2 \mathrm{~F} \% 2 \mathrm{Fjulkaisut} . v a l t$ ioneuvosto.fi $\% 2$ Fbitstream $\% 2$ Fhandle $\% 2 \mathrm{~F} 1$ 0024\%2F74720\%2FRAP2013_11_EHTEL_ verkko.pdf\%3Fsequence\%3D1\&usg=AOvVaw1eKRGFiLDrovuq37jZfaWl.

13. HIMSS EUROPE (2018) HIMSS Analytics Annual European eHealth Survey 2018. Opgehaald van HIMSS Europe: https://www. himss.eu/himss-analytics-annual-europeanehealth-survey-2018\#2018-form.

14. KELA (2020) Estonian Citizens Can Now Purchase Medicines In Finland With An EPrescription Issued In Their Own Country News Archive For Customers. Kela. En. https://www.kela.fi/web/en/news-archive//asset_publisher/1N08GY2nIrZo/content/estonian-citizens-can-now-purchase-medicines-in-finland-with-an-e-prescription-issuedin-their-own-country.

15. NOVENTI (2019) We Are Ready For E-Prescription. NOVENTI. https://www.noventi. de/en/news/we-are-ready-for-e-prescription .

16. LILLEVALI A, KOND K (2019) E-Prescription Success In Estonia: The Journey From Paper To Pharmacogenomics. Retrievable from: https://www.google.com/url?sa=t\&rct $=\mathrm{j} \& \mathrm{q}=\&$ esrc $=\mathrm{s} \&$ source $=$ web $\& \mathrm{~cd}=\& \mathrm{cad}=\mathrm{rja}$ \&uact $=8 \&$ ved $=2$ ahUKEwjA6pPU5c7uAhU M8hoKHYRAADYQFjACegQIARAC\&url $=$ https $\% 3 \mathrm{~A} \% 2 \mathrm{~F} \% 2 \mathrm{Fapps}$.who.int $\% 2$ Firis $\% 2$ Fbitstream $\% 2$ Fhandle $\% 2 F 10665 \% 2 F 332593$ \%2FEurohealth-25-2-18-20-eng.pdf\&usg= AOvVaw1FVsGYyKctO-tTqrUjkmdD.

17. WESSING T (2016) E-Health Law in Germany. Opgehaald van Synapse Law for Life Science: https://united-kingdom.taylorwessing.com/synapse/ti-ehealth-law-germany. html

18. TFHC (2019) E-Health In Germany. Retrievable from::https:/www.google.com/url? $\mathrm{sa}=\mathrm{t} \& \mathrm{rct}=\mathrm{j} \& \mathrm{q}=\& \mathrm{esrc}=\mathrm{s} \&$ source $=$ web $\& \mathrm{~cd}=$ $\&$ cad $=$ rja\&uact $=8 \& v e d=2$ ahUKEwj4kKjw8 c7uAhUSSxUIHezzCLEQFjACegQIB-

BAC\&url=https $\% 3 \mathrm{~A} \% 2 \mathrm{~F} \% 2 \mathrm{Fwww} . \mathrm{tfhc} . \mathrm{nl} \%$ 2Fwp-content $\% 2$ Fuploads $\% 2 F 2019 \% 2 \mathrm{~F} 08$ $\% 2 \mathrm{FeHealth}$-in-Germany-barriers-and-opportunities.pdf\&usg=AOvVaw27A9bPI8FuNz157aR2oiI.

19. TINYAKOV S (2018) The priorities for health and social care policy in Germany. Retrievable from:https://www.openaccess- government.org/health-and-social-care-germany $/ 52305 /$.

20. RADI F, BUDZELOVA K, OLAH M, MUSS C (2021) Late psychosocial consequencesfrom HIV to Covid. Clin Soc Work and Health Interv.12.2021.2.6-7.10.22359/cswhi_12_2_15.

21. UEMO (2019) Finland And Estonia Pioneering Cross-Border Health Services - Uemo. Uemo. Eu. Retrievable from: https://www. uemo.eu/finland-and-estonia-pioneeringcross-border-health-services/. 


\title{
Delivery of blistered Medicines as an Important Factor in Medication Safety and Maintaining Patient Health in Times of Lockdown due to COVID-19
}

\author{
M. Herold (Mark Herold), E. Kalavsky (Erich Kalavsky)
}

St. Elisabeth University PhD Program and ARKAPO Center Munich, Germany. Original Article

\section{E-mail address:}

herold@arkapo.de

\section{Reprint address:}

Mark Herold

St. Elisabeth University PhD Program and ARKAPO Center Munich

FR Germany, Health Management

Munich

Germany

Source: Clinical Social Work and Health Intervention

Pages: $45-48$

Volume: 12

Issue: 2

\section{Reviewers:}

Steve Szydlowski

University of Scranton school of education, USA

Pawel S. Czarnecki

Rector of the Warsaw Management University, PL

\section{Keywords:}

Blistering. Packaging. Medication Safety. Lockdown. Covid-19.

\section{Publisher:}

International Society of Applied Preventive Medicine i-gap

CSWHI 2021; 12(2): 45 - 48; DOI: 10.22359/cswhi_12_2_08 CC Clinical Social Work and Health Intervention

\section{Abstract:}

The whole world is holding its breath and has fallen into a kind of paralysis of shock: the Corona pandemic is affecting the lives of every single person on Earth. Many have fallen ill, many have died, almost everyone is in lockdown. But everyday processes must continue, under special conditions, yet they must continue to function. Among them is the supply of medicines to the population. Here the question arises as to whether a higher level of medication safety, especially in a situation with an extremely stressed external environment, can be provided by blistering. In this context, it is relevant what exactly blistering means, which advantages and disadvantages are associated with it, for which reasons blistering is used and whether more safety for medication can be achieved through it. This is the subject of the following remarks. 
In December 2019, the first infections with a previously unknown virus became known in the Chinese city of Wuhan. ${ }^{1}$ This novel virus comes from the coronavirus family of viruses. It got its name from the summary of its lineage (coronaviruses) and the year of discovery (2019). The official name of the virus is SARS-CoV-2, the disease caused by the virus is called COVID-19. Here, SARS stands for „Severe Acute Respiratory Syndrome“ and COVID for „Corona Virus Disease". Due to the global impact and spread of COVID-19, this disease was declared a pandemic by the World Health Organization on 11 March 2020. If one considers only the current number of cases in Germany, COVID-19 can be described as an epidemic.

A variety of measures were taken to combat the pandemic in Germany, as in all other countries around the world. ${ }^{2}$ These measures are - depending on the infection event - differently pronounced, but in essence they all have the same goal: to reduce or even interrupt infection chains; to reduce the infection event; respectively the infection speed; thus to maintain the health care system and the care of the infected persons. Examples of measures taken to combat the Corona pandemic include the obligation to wear mouthnose protection, closures of individual industries and even the entire lockdown of German social life.

The Corona pandemic also has an impact on nursing homes and other medical facilities. The Robert Koch Institute has published special recommendations for the prevention and management of COVID-19 in old people's and nursing homes $^{3}$. These recommendations include both preventive and reactive measures related to Corona. First of all, it is relevant for the nursing homes to implement extended hygiene and infection control measures. This includes protective equipment and disinfection as well as waste disposal or the handling of laundry and other textiles. Of particular relevance in terms of prevention are all measures related to visitor regulations.
The Corona pandemic has thus created a particularly challenging and above all stressful situation in nursing homes. This exists both for the staff and for the patients and their (possibly also non-permitted) visitors. Nevertheless, medical care is relevant to the system and must be ensured without restriction even in these special situations. One possibility to increase safety in the dispensing of medicines is the so-called blistering, which is described in the following.

First of all, it must be explained what exactly is meant by the term blistering. „It can describe the pharmaceutical-technological process of primary packaging of a (usually solid oral) pharmaceutical form by temperature-regulated deepdrawing of a polyethylene (PE) or polypropylene film with the formation of blister cups and subsequent welding with a thin aluminum layer. Often, however, the „blistering“ of medicinal products by pharmacies in connection with home care will merely be a matter of ,portioning“ and packing various oral medicinal products previously removed from their original packaging and individually combined for individual patients into PE endless tubular bags. " ${ }^{\text {In }}$ the following, the term blistering is used exclusively for the repackaging and portioning of medicinal products.

A large number of framework conditions apply to blistering, which must be complied with to ensure the quality of the medicinal products. First of all, the legal framework conditions must be mentioned. ${ }^{5}$ Since blistering is a step in the manufacture of a medicinal product, the legal basis is the Medicines Act (germ. Arzneimittelgesetz (AMG)). Section 21 of the AMG stipulates that blistered medicinal products are exempt from the authorization requirement. This exemption from the authorization requirement is limited by the fact that it only applies to blistering in a pharmacy or on behalf of a pharmacy, according to the wording of the article ,for pharmacies“. „With the blistering of medicinal products taken from packages of various finished medici-

\footnotetext{
${ }^{1}$ Federal Ministry of Health (2020a), n.pag.

${ }^{2}$ Federal Ministry of Health (2020b), n.pag.

${ }^{3}$ Cf. Robert Koch Institut (2021), n. pag.

${ }^{4}$ Diebold/Schmidt (2007), p. 54.

${ }^{5}$ Diebold/Schmidt (2007), p. 54ff.
} 
nal products, a new medicinal product is created which is individually tailored to the individual patient on request or order [...]. ${ }^{6}$ In turn, $\S 12 \mathrm{a}$ of the AMG stipulates that the portioning and blistering of medicinal products individually for each patient on the premises of the pharmacy by appropriately trained staff within the framework of home care contracts does not require a license, as this task is part of the ,usual pharmacy operations". 7 The above-mentioned regulations are supplemented by $\S 6$ of the Pharmacy Operations Ordinance. According to this, a medicinal product manufactured in or by a pharmacy must be of a quality required by pharmaceutical science and must be manufactured and tested in accordance with recognized pharmaceutical rules. This also includes the indication of a usability date, whereby it must be noted that the expiry date originally dated by the original manufacturer or the pharmaceutical company refers exclusively to an original packaging that has not yet been manipulated. However, blistering changes this, so that a new expiry date must be defined. According to $\S 17$ of the Pharmacy Operations Regulation, only those medicinal products may be used for blistering which have been prescribed by a doctor for the individual patient or which have been approved for the German market as finished medicinal products. This regulation prevents pharmacies from procuring large quantities of preliminary stages of the finished medicinal product from the manufacturers in advance and blistering larger quantities from these. This would require a real manufacturing authorization according to the Medicines Act. Section 10 of the Pharmacy Act regulates that pharmacies may not exclusively commit themselves to certain original manufacturers or certain finished medicinal products when blistering. Another important legal framework for blistering is $\S 14$ of the Pharmacy Operations Regulation, which stipulates which labeling must be applied to the portioned and newly blistered medicinal products: Name, strength and batch designation of the medicinal product used, a date of usability, type of application or instructions for use, name and address of the pharmacy as well as name and address of the pharmaceutical manufacturers of the original finished medicinal products. There are further legal framework conditions which cannot be discussed due to the scope of this paper.

In addition to the legal framework conditions, there are other requirements for blistering. These include, first of all, spatial environmental conditions. ${ }^{8}$ Baumaterialien: Lighting, the room air conditioning system (humidity, temperature and general air supply) must be planned in such a way that adverse influences on the blistered medicinal products are avoided as far as possible. From a hygienic point of view, too, with regard to careful cleaning and disinfection, the room layout must be designed accordingly already in the planning phase, e.g. as few corners, edges and crevices as possible.

Furthermore, the equipment determines the possibilities of blistering. ${ }^{9}$ So-called blistering machines are used for this purpose. Different medicines are introduced into these machines by means of individual canisters. Chips and corresponding software are used to determine exactly which finished drug is available in which canister. The blistering is then triggered by a fully automatic process. It must be taken into account that the finished medicines used are exposed to a „fall“ from a certain height and must survive this without parts splintering off. It must also be taken into account that the canisters of the automatic blistering machines do not offer good protection of the finished medicinal products from external influences, so that they should not be stored in the canisters for too long.

There are also specifications for quality control, so that this also represents a framework condition of blistering that must be adhered to. ${ }^{10} \mathrm{As}$ soon as a quality control has been carried out, it must be documented. Despite the qualification of the machines and adequate validation of the software, malfunctions cannot be ruled out. After the

\footnotetext{
${ }^{6}$ Diebold/Schmidt (2007), p. 55.

${ }^{7}$ Diebold/Schmidt (2007), p. $55 \mathrm{ff}$.

${ }^{8}$ Riesenberger (2007), p. 46.

${ }^{9}$ Riesenberger (2007), p. 49.

${ }^{10}$ Riesenberger (2007), p. 52.
} 
quality control has been carried out and documented, a release of the manufactured medicinal product must be issued by the holder of the pharmacy operating license.

A particularly important aspect in the blistering of medicinal products is hygiene..$^{11}$ All surfaces, equipment, materials and media that come into contact with the finished medicinal products must be integrated into a special cleaning process. First of all, cross-contamination of the medicinal products is to be prevented, but the special hygiene also serves the blistering staff and, above all, the protection of the patients. The area where blistering takes place must be separated from the rest of the premises by a lock. The staff must be hygienically dressed or equipped, e.g. gloves, hygienic suits, etc.

Patient-specific blistering is therefore not a new measure that has arisen from the special situation surrounding the corona virus, but has already existed for many years and the legal and other framework for blistering is basically very strictly defined. The question arises whether blistering can create additional safety in medical care.

The patient-specific packaging of medicines initially improves patients' compliance. ${ }^{12}$ If adherence is reduced, this can lead to increased morbidity and mortality. In this respect, blistering is a mitigating measure. Furthermore, blistering can also lead to an increase in drug therapy safety for patients at risk. Particularly in the case of high-risk patients, the risks of wrong dosage or wrong times of administration occur more frequently, so that this risk can also be counteracted by means of blistering. The patient group of elderly, chronically ill citizens, who often live in nursing homes, particularly benefits from higher safety through blistering. ${ }^{13}$ These patients are often prescribed a higher number of medicines to be taken at the same time and thus have a higher check for interactions and side effects due to blistering.

The many framework conditions for blistering described above ensure that trained staff create individually tailored blisters for each patient under the best possible conditions and label them carefully. For patients, this is always - not only in times of a pandemic - a helpful solution and a risk reduction in everyday medication. For the staff in German nursing homes, blistering can initially mean a saving of time, but above all a reduction of the task budget. In concrete terms, a particularly relevant task is eliminated, leaving more time and concentration for the preventive and reactive handling of the Corona pandemic. A special side effect of blistering is the reduction of contact points and thus possible contamination points. In corona times, blistering means a real win-win situation for all involved.

\section{References}

1. FEDERAL MINISTRY OF HEALTH (2020A). General information on coronavirus, https://www.zusammengegencorona.de/informieren/basiswissen-zum-coronavirus/allgemeine-informationen-zum-coronavirus/ ; Stand: 17.02.2021.

2. RADI F, BUDZELOVA K, OLAH M, MUSS C (2021) Late psychosocial consequencesfrom HIV to Covid. Clin Soc Work and Health Interv.12.2021.2.6-7.10.22359/cswhi_12_2_15.

3. DIEBOLD S, SCHMIDT M (2007) Patientspecific blistering, in: German Pharmacist Newspaper, Issue 35/2007, S. 54-60.

4. LAUFS U et al (2011) Strategies to improve adherence to medication, in: German Medical Weekly, Heft 136, S. 1616-1621.

5. LAUTERBACH K et al (2006) Effects of the use of individual blisters on the costs and quality of drug therapy.

6. RIESENBERGER M (2007) Patients' individual second blistering, in: German Pharmacist Newspaper, Issue 48/2007, pp. 48-54.

7. ROBERT KOCH INSTITUT (2021) Prevention and management of COVID-19 in old people's and nursing homes and facilities for people with impairments and disabilities, https://www.rki.de/DE/Content/InfAZ/N/Neua rtiges_Coronavirus/Alten_Pflegeeinrichtung_Empfehlung.pdf?_blob=publicationFile ; Status 18.02.2021.

\footnotetext{
${ }^{11}$ Riesenberger (2007), p. 53.

${ }^{12}$ Laufs et al (2011), p. 1620.

${ }^{13}$ Cf. Lauterbach et al (2006), p. 7.
} 


\title{
Use of Apps in Pharmacy as a Communication tool
}

\author{
M. Hosseini (Mohammad Hosseini), M. Luliak (Milan Luliak)
}

University of Health and Social Work St. Elizabeth, Bratislava, Slovakia.

\section{E-mail address:}

mh26041980@gmail.com

\section{Reprint address:}

Milan Luliak

University of Health and Social Work St. Elizabeth

Bratislava

Slovakia

Source: Clinical Social Work and Health Intervention

Pages: $49-52$

Volume: 12

Issue: 2

\section{Reviewers:}

Andrea Shahum,

University of North Carolina at Chapel Hill School of Medicine, USA

Steve Szydlowski

University of Scranton school of education, USA

\section{Keywords:}

Digitalization. Communication Tool. Patients. Medicines. Health.

\section{Publisher:}

International Society of Applied Preventive Medicine i-gap

CSWHI 2021; 12(2): 49 - 52; DOI: 10.22359/cswhi_12_2_09 (C) Clinical Social Work and Health Intervention

\section{Abstract:}

In Germany, around 58 million people currently use a smartphone. ${ }^{1}$ Not to use this communicative access to potential customers on the part of the health market would not only be negligent, but also unrealistic. Digitalization in the health sector has developed strongly in many areas in recent years and is described with different terms. These include 'e-health', 'digital health' or 'health 2.0 '. However, all these terms mean the same thing: techniques and digital applications for preventing, improving and maintaining the health of the population. The tools of this technology are websites, portals, forums and, above all, apps. They are all intended to support people in actively shaping their health. ${ }^{2}$

\footnotetext{
${ }^{1}$ Source: Statista, statistics on smartphone usage in Germany, published on 8.2.21.

${ }^{2}$ Knoppler \& Stendera, 2019, p. 83.
} 


\section{Digital applications in the health sector}

In the category 'Health and Fitness' there are currently over 100,000 different apps available. In the category 'Medicine' there are another 46,000 apps $^{3}$ The offer is diverse and partly confusing. In a Bertelsmann study from 2016, Knöppler et al. derived a systematization of digital health applications and divided them into seven application types. This subdivision facilitates the overview and is structured as follows: ${ }^{4}$

Group 1: Basic application with a medical purpose such as prevention or therapy:

- Type 1 'Strengthening health literacy': The user is provided with general health-related knowledge in order to be able to act in a self-determined healthy way.

- Type 2 'Analysis and insight': The user receives health information with a specific personal context.

- Type 3 'Indirect intervention': Promoting selfefficacy, adherence \& safety': monitoring of the patient with continuous personal context.

- Type 4 'Direct Intervention': Changing skills, behaviors \& states': Therapy apps are used in addition to therapy to bring about long-term change.

Group 2: Complementary applications with administrative or service reference

- Type 5 'Documentation of health and medical history': Creation of a digital health record.

- Type 6 'Organization and administration': Digital contact with doctors' practices, hospitals or health insurance companies.

- Type 7 'Purchasing and supply': Digital purchase of medicines and medical devices.

The different types of applications classified in the Bertelsmann study each contribute to the digital evolution of the health sector. This evolution describes a networking of individual aspects of the health market into a complex structure of digital health solutions. It promises significantly improved efficiency, with at the same time greatly improved communication between the patient and the actors in the healthcare system and has the potential to bring about savings of almost 10 billion euros. ${ }^{5}$ To date, however, digital offerings in the medical sector are still isolated solutions that, although they bring many advantages in their own right, do not yet really exploit the benefits of a digital turnaround. ${ }^{6}$ It is therefore necessary to further expand these islands and to interconnect them in the course of digital evolution.

\section{The role of pharmacies in digitalized communication with patients}

Pharmacies play a decisive role in this network. They not only ensure the supply of medicines to the population, but are also an important link between doctor and patient. Earlier than many other areas of the health care system, pharmacies have digitalized a large part of their processes. Both ordering and stock management run digitally by default, as do data queries, invoicing or the application of discount agreements. ${ }^{7}$ Increasingly, the digitalization of contact with the customer is now also becoming the focus of technical progress.

In Google's current ranking of medical apps, an app with ordering functions for an online pharmacy is already in 4th place, followed by another in 6th place. They are each credited with over 500,000 downloads. ${ }^{8}$ These figures show all too obviously that even on-site pharmacies have to compete for customers in the digital app market in order to keep up with the growing online competition.

For a partial digitalization of the interaction with the customer, a whole range of apps already offers numerous interesting possibilities for the care and retention of customers by the local pharmacy on site.

The main functions here are:

- Pre-ordering of medicines and pharmacy products

- Easy contact for personal advice

\footnotetext{
${ }^{3}$ Source: AppBrain.com, State 9.2.21.

${ }^{4}$ Cf. Knoppler et al., 2016, p. 13-15.

${ }^{5}$ Cf. Genter, 2016, p. 16.

${ }^{6} \mathrm{Cf}$. Kaindl, 2020.

${ }^{7}$ Cf. Benkert, 2020.

${ }^{8}$ Source: AppBrain, State: 11.2.21.
} 
- Overview of local branches and emergency services

The offer of a personal consultation already differentiates these apps from the pure sales platforms of online pharmacies. This shows that the service advantage of the local pharmacy must also be fully exploited in the digital framework of an app. Thus, these apps serve customer service and marketing in equal measure. Nevertheless, any development of digitalization should be consistently oriented towards patient welfare and not be a pure marketing tool. Their use only makes sense if the quality of care processes is improved and should never be an end in itself. ${ }^{9}$

The providers of the different pharmacy apps range from pharmacy cooperatives and wholesalers to marketing agencies and publishers. They all have different focuses, but basically function similarly. They offer two areas: 1) The customer area which is used with the app on the smartphone; 2) the pharmacy area which allows the employee to interact via a website. ${ }^{10}$

The most popular of these pharmacy apps is currently the app "Deine Apotheke" (engl. Your Pharmacy). It is currently in 14th place in the Google ranking of medicine apps and has over 100,000 downloads. ${ }^{11}$ The multi-channel concept "Deine Apotheke" comes from the Mannheimbased health service provider Phönix. The Phönix Group is at the European forefront as a pharmaceutical wholesaler and pharmacy operator and wants to use the concept to support local pharmacies in Germany, which are responsible for about one third of the group's turnover. ${ }^{12}$ The concept consists of the app and a customer magazine of the same name, which is published in cooperation with Funke Mediengruppe. ${ }^{13}$ Unique among pharmacy apps, "Deine Apotheke" also works with the bonus program Payback and thus provides an additional incentive for customers. The success of this large-scale cooperative proj- ect could point to a development that could also be observed in the digitization of other industries: over time, digital platforms are formed that network several areas and functions with each other. In the end, only a few large providers will be able to prevail due to the development of market concentration. ${ }^{14}$

\section{Perspectives and opportunities}

Already in 2014, a perspective paper was published at the German Pharmacists' Conference, which deals with the possible development of pharmaceutical care in the near future. It deals with the adaptation of pharmacies to scientific and technical progress and an expansion of the range of services..$^{15}$ Norbert Peter, Member of the Board of the Marketing Association of German Pharmacists (Marketingverein Deutsche Apotheker e.V.), concretized the future prospects for pharmacies in 2019, particularly from the aspect of digitalization. ${ }^{16} \mathrm{He}$ points out that especially in times of digitalization, the empathetic and personal bond with the local pharmacist in charge will still be essential. The pharmacist stands as a mediator between the digital and the analogue world of the patient. Nevertheless, the digital services of pharmacies will increase significantly in the next 10 years. According to Peters, these include:

- digitally networked medication plans and increased medication management

- digital therapy monitoring

- regular drug monitoring

- issuing of repeat prescriptions by the pharmacist

These points absolutely presuppose a digitalized health record and perfect networking of the necessary cooperation network of patient, doctor and pharmacist. They are the basic prerequisite for the digital networking of the healthcare system. Patients, doctors and pharmacists benefit

\footnotetext{
${ }^{9} \mathrm{Cf}$. Benkert, 2020.

${ }^{10} \mathrm{Cf}$. Wessinger, 2018.

${ }^{11}$ Source: AppBrain, State: 11.2.21.

${ }^{12}$ Cf. Edalat, 2020.

${ }^{13}$ Source: Funkemedien, Press release from 21.02.2020.

${ }^{14}$ Cf. Kaindl, 2020.

${ }^{15} \mathrm{Cf}$. ABDA, 2014.

${ }^{16} \mathrm{Cf}$. Peter, 2019.
} 
equally from this, as processes become more efficient and can be implemented much more quickly. The optimized processes become significantly leaner, more flexible and more individualized, which increases the overall quality of treatment. ${ }^{17}$ This is an important effect, especially in terms of adherence to therapy, medication safety and dosage safety, which will reduce follow-up treatments due to incorrect medication.

In principle, some of the points mentioned can already be technically implemented today through the isolated solutions mentioned in the form of different health apps. However, the applications are not networked and their use is largely based on the individual responsibility of the respective users. The technical possibilities are therefore given and must now be controlled and securely bundled in an adequate place.

For the best possible patient care, a comprehensive pharmacy app of the future should therefore have the following functions:

- Ordering medicines

- Overview of branches and emergency services

- personal advice

- personal medication plan

- personal health data (at least basic data)

- overview of treatments, therapies and attending physicians

In addition, service aspects, such as a magazine, discount promotions or similar, could be introduced to further strengthen the local pharmacy. All this can be possible via an app.

Even though most pharmacy customers tend to be older people, their use of smartphones should not be underestimated. A survey from 2020 shows that just under half $(48 \%)$ of respondents over the age of 65 would use a health app if asked to do so by a doctor, for example..$^{18}$ In younger years, the acceptance of apps is also much greater in the health sector. Therefore, apps will also be an important tool for on-site pharmacies to communicate with their customers in the future.

\section{References}

1. ABDA-FEDERAL ASSOCIATION (2014). Pharmacy 2030 - Perspectives on Pharmaceutical Supply in Germany.
2. BENKERT T (2020) Basics for digitized pharmacies. In: Rückert \& Pförringer (ed.): With excellent health? Germany in e-health in check-up - future platform Bavaria: digital health system.

3. EDALAT A (2020) Phoenix: 50.000 Orders per month via "Your Pharmacy" app. DAZonline, Stuttgart May 10th, 2020.

4. GENTER A (2014) E-Health perspective consumer solutions as the key to success?, Deloitte study series "Intelligent Networks".

5. KAINDL A (2020). Digitization is the key to better health care. In: Rückert \& Pförringer (Ed.): In the best of health? Germany in ehealth in check-up - future platform Bavaria: digital health system 2020.

6. KNOPPLER K., NEISECKE T, NOLKE L (2016). Digital-Health-Anwendungen für Bürger - Kontext, Typologie und Relevanz aus Public-Health-Perspektive. Bertelsmann Foundation.

7. KNOPPLER K, STENDERA P (2019) Transfer of digital health into everyday care. In: Haring, R. (Ed.), (2019), Health digital Perspectives on digitization in health care, Springer.

8. PETER N (2019) Is that the breakthrough? The BMG's digital plans from a pharmacy's point of view - opportunities and potential for better care. In: The breakthrough? - The digital plans of the BMG from the perspective of the actors. Discussion on health policy forum, April 2019.

9. WESSINGER S (2018) Which mobile phone apps are there for pharmacists and their customers? DAZ.online, Stuttgart - March 13, 2018.

${ }^{17}$ Cf. Ganter, 2014, p. 18.

${ }^{18}$ Source: Statista, Juli 2020Can you imagine using apps on prescription? 


\section{Crisis Management in the Pharmaceutical Industry}

\section{Niemuth (Lukas Niemuth)}

Pharmacy, SEUC PhD program in Health Management and Public Health, Munich, Germany.

\section{E-mail address:}

1.niemuth@gmx.de

\section{Reprint address:}

Lukas Niemuth

Pharmacy, SEUC PhD program in Health Management and Public Health

Waltherstr. 27

80337 Munich

Germany

Source: Clinical Social Work and Health Intervention

Volume: 12

Issue: 2

Pages: 53 - 56

Cited references: 12

\section{Reviewers:}

Erich Kalavsky

IGAP Vienna, AT

Selvaraj Subramanian

SAARM Kuala Lumpur, MY

\section{Keywords:}

Pharmaceutical. Management. Process. Crises.

\section{Publisher:}

International Society of Applied Preventive Medicine i-gap

CSWHI 2021; 12(2): 53 - 56; DOI: 10.22359/cswhi_12_2_10 CC Clinical Social Work and Health Intervention

\section{Abstract:}

The first step of management functions is planning. It is the starting point of a process. It asks what needs to be done and how it should be done in order to achieve business objectives. The planning phase also defines the goals, policies, programs and procedures for program implementation for the company or individual departments. Planning is also considered a primary function. This phase is designed to avoid errors as far as possible, as they can affect all other management functions.

\section{Introduction}

Difficult times - especially economic ones also present management with new challenges and demands. Many managers are therefore not only busy running companies, but are also simultaneously involved in drawing up plans in emergency situations. Constantly rising insolvency figures show that these companies are increasingly in crisis situations. As a result of this development, the area of crisis management is taking up an ever greater part of the management's responsibilities. This is also shown by surveys: $61 \%$ of the 2,575 top managers surveyed consider it an essential success factor to make crisis or restruc- 
turing management the task of top management. ${ }^{1}$

However, management in times of crisis consists not only of leading and acting in times of crisis, but also includes proactive actions including early detection of crises. ${ }^{2}$

Managers therefore have the task of formulating and realizing the goals of the employees. This also includes regulating the behavior of the employees or overcoming crises. ${ }^{3}$ Leadership is especially necessary where people have a common goal. Each individual should be used accordingly with regard to their strengths and abilities. The individual activities or work steps of the employees in a company must be coordinated $^{4}$. This is achieved through management measures:

\section{„Leading, being led, letting oneself be led}

and leading oneself is a consequence of the division of labor and role differentiation. "5

Accordingly, a manager fills the position of a senior executive in a company and has personnel responsibility towards other employees. This results in various management functions. They are used to simplify the tasks of managers and make them clearer. A distinction is mainly made between five classic management functions by Koontz and O'Donell (1955). The subdivision of the management functions can therefore also be described as a classic canon of five. ${ }^{6}$

\section{Planning in crisis management}

The first step of management functions is planning. It is the starting point of a process. It asks what needs to be done and how it should be done in order to achieve the business objectives. The planning phase also defines the goals, policies, programs and procedures for program implementation for the company or individual departments. Planning is also considered a primary function. This phase is designed to avoid errors as far as possible, as they can affect all other management functions. This helps to minimize the occurrence of additional costs. Once the planning is done, the phase of the organization can begin. In this phase, the planned is implemented. The process flow is analyzed and aligned with the specified goals. This is done by the process organization. To ensure the process flow, new departments, areas and work centers are created within the organizational plan. Tasks, competencies and responsibilities are also assigned. The process flow is planned to determine how the individual units work together. To ensure that the process runs smoothly and that employees are provided with the information they need to perform their tasks, it is very important to clarify how communication is to take place within the enterprise. The positions created in the organizational plan must now be filled. The demands placed on the employee play a major role here. Qualified employees must be found and, if necessary, trained. You must also ensure that employee motivation and remuneration match the job requirements. ${ }^{7,8}$

Once the plan and the organization have been defined and the staff have been recruited, the management function of leadership comes into play. The manager comes into action when complications, errors, delays, crises and frictional losses occur. It is also an important aspect is that the manager must always be present and close to the employees. Then mistakes can be noticed and decisions can be made. Because if the manager only looks at the reports, it is difficult or impossible to determine whether there are communication problems. This can also affect the results, although it is not initially reflected in the key figures. Managers are also responsible for resolving any conflicts that arise and making decisions. This includes problems with employees, feedback from customers, and problems in working with suppliers.

\section{Control of the crisis management}

The final phase of the management process is control. In this phase, a target/actual comparison is determined, analyzed and carried out in order to be

\footnotetext{
${ }^{1}$ See Hutzschenreuter, 2004, corporate development, p. 5

${ }^{2}$ See. Hutzschenreuter, 2004, a.a.O.

${ }^{3}$ Gudemann, 1995, Leadership. Lexikon of Psychology, p.132

${ }^{4}$ Comelli et al., 2014, Leadership through Motivation, p.83

${ }^{5}$ Hentze et al., 2005, Leadership apprenticeships, p.4

${ }^{6}$ See Seiler 2012, p. 19.

${ }^{7}$ See Schreyogg/Koch 2010, p. 10.

${ }^{8}$ See Seiler 2012, p. 19.
} 
able to judge whether there is a deviation or whether the plans have been put into practice. If deviations have occurred, it must be checked whether corrective measures should be implemented. This control also helps to improve new planning. Thus future processes can be better planned and started. ${ }^{9}$

A corporate crisis is understood as ,unplanned and unwanted, temporary processes that are capable of substantially endangering the continued existence of the company or even making it impossible ${ }^{\text {"10 }}$, understood. Personnel company crises, on the other hand, refer in particular to shortages of skilled workers or waves of redundancies..$^{11}$ Among the central characteristics of the corporate crisis are

- Endangerment of existence by endangering essential goals

- Metamorphosis or destruction of a company due to uncertain outcomes from the crisis

- Process character of a time limitation of the crisis

- Control problems due to loss of control over influence able processes

- Inability to act ${ }^{12}$

\section{Corporate crises}

Disasters are a special case of corporate crises, as they are one-sidedly negative and offer no way out. Disruptions, on the other hand, are characterized by problems in the operating process or set-up. They thus relate more to the functionality of the company's material potential. Conflicts always point to problems within human relationships with persons or groups of persons. Risks, on the other hand, are inseparably linked to entrepreneurial activities and are therefore always present. In general, they characterize dangers of not reaching goals. Issues are mainly topics that affect the company but are of interest to the public. Such topics include, for example, the values of companies, expectations or views. Increasingly, issues can also grow into scandals. For example, when a company tries to cover up illegal activities. In contrast to issues, scandals have only a one-sided focus on annoyances in public life..$^{13}$ This is where crisis management comes in. Because it is concerned with understanding and solving all these problems. ${ }^{14}$ However, it depends on how a crisis unfolds, as it is usually divided into four phases:

Phase 1: Potential corporate crisis

Phase 2: Latent corporate crisis

Phase 3: Acute/controllable corporate crisis

Phase 4: Acute/unmanageable corporate crisis ${ }^{15}$

Depending on the phase, a crisis can lead to an actual collapse and thus also to the abandonment of the company. However, it is also possible to restructure the company, for example if it is in the first three phases of the crisis. ${ }^{16}$ The first two phases can be summarized under the term active crisis management. The companies are eager not to get into an emergency situation. Therefore, they actively try to anticipate crises and prevent their development into an acute crisis by precaution and avoidance. If this does not succeed, reactive crisis management describes how to deal with the last two phases of a crisis. A smooth communication process is important to manage crises. Communication is primarily understood to mean actions that are perceived differently depending on the situation and the individual. Crisis management is considered a process in which communication is primarily a matter of. ${ }^{17}$

\section{Conclusions}

The process of identification, however, does not begin at the point in time when the problem - for

\footnotetext{
${ }^{9}$ See Schreyogg/Koch ,2010, Fundamentals of Management, p. 11.

${ }^{10}$ Gabler Wirtschaftslexikon (14.02.2018), p.1, https://wirtschaftslexikon.gabler.de/definition/ unternehmungskrise-49331/version-272567

Revision of corporate crisis from 14.02.2018 [28.03.2020]

${ }^{11}$ Gabler Wirtschaftslexikon (14.02.2018), a.a.O.

${ }^{12}$ Krystek/ Lentz, 2013, Unternehmenskrisen, p.35f.

${ }^{13}$ See Krystek/Lentz, 2013, Unternehmenskrisen, 34f.

${ }^{14}$ See Krystek/Lentz, 2013, Unternehmenskrisen, p.6f.

${ }^{15}$ See Gabler Wirtschaftslexikon (14.02.2018), p.1, https://wirtschaftslexikon.gabler.de/definition/ unternehmungskrise-49331/version-272567

Revision of corporate crisis from 14.02.2018 [28.03.2020]

${ }^{16}$ Coombs et al., 2012, The Handbook of Crisis Communication, S.3
} 
example a lack of medication - is objectively recognized, but only when it is perceived as such. This can be the case, for example, if certain ingredients for medicines are not or no longer available and as a result medicines become scarce. Or resources such as breathing masks or disinfectants become scarce due to increased demand. „If corporate crises are not identified in good time, the scope for effective crisis management is continuously narrowed down due to the destruction of alternatives over time. " ${ }^{18}$ However, the German Act on Control and Transparency in the Corporate Sector (KonTraG) in $\S 91$ II of the German Stock Corporation Act $(\mathrm{AktG})$ requires the early detection of corporate crises, as well as developments that could endanger the continued existence of the company. If crises are detected early on, processes can still be controlled, company goals planned and control of the company maintained. With reference to the abovementioned example, a corporate crisis could be averted, for example, if the stock level is increased at an early stage or the necessary ingredients for which needed drugs could be procured. If all parties involved in crisis management turn to the crisis, the crisis can be overcome and the company saved. If this is not possible, then damage limitation in the crisis is necessary to ensure a new start after the crisis, „The strategy of the company and the guidelines of communication must be corrected, because the new start must have absolute priority. ${ }^{* 19}$

Should the crisis, despite the commitment of all those involved, develop into an uncontrollable crisis, the only option left to the management is an „orderly withdrawal“. By liquidating the company as planned, the losses can be limited for everyone. The liquidation can take place within the framework of insolvency proceedings or outside of them.

\section{References}

1. COOMBS TIMOTHY W, HOLLADAY SHERRY J (2012) The Handbook of Crisis Communication. John Wiley \& Sons, Hoboken, New Jersey, United States.

2. COMELLI G, ROSENSTIEL LUTZ VON NERDINGER, FRIEDEMANN W (2014)
Tour through Motivation: Winning employees for the company's goals, 5th, revised edition. Franz Vahlen Verlag, Munich.

3. GUDEMANN W LEADERSHIP (1995) Lexicon of Psychology. Bertelsmann-Lexikon-Verlag, Gutersloh.

4. HENTZE J, GRAF A, KAMMEL A, LINDERT K (2005) Personnel Management. $4^{\text {th }}$ Ed. UTB Verlag, Bern, Stuttgart, Vienna.

5. HUTZSCHENREUTER T (2004) Corporate development. State of research and Development tendencies. Research papers of the scientific university for Corporate Management (WHU), No. 100, Vallendar.

6. KRYSTEK U, LENTZ M (2013) Corporate crises: description, causes, course and Effects of processes critical to survival in the company 13. In: Thießen, Ansgar (Ed.): Crisis management. Springer, Wiesbaden, 2nd edition.

7. SAILER U (2012) Management, systemic thinking, business modeling, fields of action sustainable success. Schaffer-Poeschel Verlag Stuttgart.

8. SCHREYOGG G, KOCH J (2010) Basics of management, basic knowledge for studies and practice, ( $2^{\text {nd }}$ Edition) Gabler Verlag Heidelberg.

9. TERNES D (2008) Communication - a key skill: Introduction to the essentials Areas of interpersonal communication. Junfermann Verlag, Paderborn.

10. GABLER WIRTSCHAFTSLEXIKON (02/ 14/2018) https://wirtschaftslexikon.gabler. de/definition/unternehmungskrise-49331/ version-272567 Revision of corporate crisis from 02/14/2018 [03/28/2020].

11. KRYSTEK (February 22, 2018) Crisis Management, https://wirtschaftslexikon. gabler.de/definition/krisenmanagement37353\#head2 [03/28/2020]

12. WENDLER MARKETING CONSULTING (01.01.2020) CRISIS MANAGEMENT, https://www.wemarcon.de/de/beratung/krisen management/ [03/22/2020]

\footnotetext{
${ }^{17}$ See Ternes, 2008, Communication - a key qualification, p. 20

${ }^{18}$ Krystek (22.02.2018), Crisis management, https://wirtschaftslexikon.gabler.de/definition/krisenmanagement-37353\#head2 [28.03.2020]

${ }^{19}$ Wendler Marketing Consulting, (01.01.2020), Crisis mangement, https://www.wemarcon.de/de/beratung/krisenmanagement/ [22.03.2020]
} 


\section{A study on the timing of HIV repeat test: A case study of Mary Immaculate VCT Center, Nairobi, Kenya}

\section{Otieno Okech (Victor Otieno Okech)1, V. Wanjala Namulanda Victor Wanjala Namulanda) ${ }^{2,3}$, D. Kimuli (Daria Kimuli)2}

${ }^{1}$ Comenius University in Bratislava, Faculty of Education, Department Original Article of Social Work, Slovakia.

${ }^{2}$ St. Elizabeth College of Health and Social Sciences, Bratislava, Slovakia.

${ }^{3}$ Mary Immaculate VCT Center, Nairobi, Kenya.

\section{E-mail address:}

okech1@uniba.sk

\section{Reprint address:}

Victor Otieno Okech

Department of Social Work

Comenius University in Bratislava

Soltesovej 4

81334 Bratislava

Slovakia

Source: Clinical Social Work and Health Intervention

Volume: 12

Issue: 2 Pages: $57-62$

Cited references: 19

\section{Reviewers:}

Pawel S. Czarnecki

Rector of the Warsaw Management University, PL

Roberto Cauda

Institute of Infectious Diseases, Catholic University of the Sacred Heart, Rome, IT

\section{Keywords:}

HIV Inter-test Interval. HIV Repeat-testing. HIV Testing,HIV Re-testing.

\section{Publisher:}

International Society of Applied Preventive Medicine i-gap

CSWHI 2021; 12(2): 57 -62; DOI: 10.22359/cswhi_12_2_11 (C) Clinical Social Work and Health Intervention

\section{Abstract:}

Population testing, especially those at risk, plays an important role in preventing and managing the HIV pandemic. It helps practitioners in identifying individuals who need to be counseled on behavior change as well as those who need to be enrolled in HIV care and treatment programs. Further still, policy makers also use outcomes of such tests in determining whether their strategies are bearing fruits or not. In this study, we sought to determine the time interval within which sexually active individuals seek HIV repeat tests in relation to their gender and marital statuses.

We observed that majority of the respondents $(39.8 \%, \mathrm{n}=47)$ 
sought HIV repeat test within a period of 7-12 months, which we considered as short interval that leads to early diagnosis. We also observed a section of the respondents were also seeking HIV repeat test after a period that exceeded 13 months. We considered the latter as long interval that leads to late diagnosis of HIV. We further observed that, a majority of the respondents who were either married or had never been married before, sought HIV repeat tests within a short interval compared to those who were either divorced or widowed.

We concluded that most widowed and divorced respondents were more likely to receive late diagnosis of HIV than those who were either married or had never been married before. Most studies have indicated that people who are unaware of their HIV status carry a higher risk of infecting others.

\section{Introduction}

HIV testing is an essential component of HIV prevention and management strategy. Its results help practitioners make informed decisions when enrolling patients into the HIV care and treatment programs. Equally, outcomes of such testing also help policy makers in determining effectiveness of their HIV prevention strategies, such as proportions of the diagnosed and undiagnosed populations (Subramanian, et al., 2018). Undiagnosed populations, especially those that comprise individuals who have been infected but are unaware, remains a major challenge in the fight against HIV. According to Marks, Crepaz, \& Janssen (2006), approximately 50-70\% of people who newly get infected with HIV, acquire it from people who were unaware of their serostatus. Thus, HIV testing, especially a repeat test, plays an important role in nipping at its bud, the spread of HIV. Scientific studies have had mixed outcomes on the effectiveness of HIV repeat tests in reducing if not preventing the spread of this infectious virus. Some studies have pointed out that HIV repeat tests lead to irresponsible sexual behaviors, especially among those who return HIV negative results (Hoenigl, et al., 2015) while others have shown that HIV repeat tests play significant roles in suppressing its spread, through behavior change.

Early identification of HIV infection has been associated with benefits such as timed treatment that ensures maximum gains and reduction in HIV transmission among populations at risk (Šebestová \& Plavčan, 2018; Tuma \& Ondrusova; Kopinec, 2015; Castilla, et al., 2002; Shahum, et al., 2017). The optimal time for initiating HIV treatment is still an ongoing debate with most guidelines recommending that it should be initiated before the symptomatic phase. Though, this is the case, a good proportion of individuals get enrolled into the HIV care and treatment programs when they have reached the symptomatic phase of the disease due to late diagnosis (Girardi, et al., 2000). According to Fisher (2008), late diagnosis of HIV, defined as $\mathrm{CD}^{+}{ }^{+} \mathrm{T}$ cell count less than 200 cells $/ \mathrm{mm}^{3}$ or with AIDS-defining illnesses, has been associated with increased mortality rate among patients who test positive for the virus. In addition, in developed countries heterosexual people tend to be diagnosed late for HIV compared to men who have sex with other men and those who use intravenous drugs.

Our aim in this study was to determine the time interval within which sexually active individuals seek HIV repeat tests in relation to their gender and marital statuses. This study was carried-out, between 2019 and 2020 at the Mary Immaculate Voluntary Counseling and Testing (VCT) Center, in Nairobi-Kenya.

\section{Methods}

\section{Study participants}

This study enrolled a total of 118 participants, aged between 18 and 64 years, who had sought HIV repeat-test services at the Mary Immaculate Voluntary Counseling and Testing (VCT) Center in Nairobi, Kenya.

\section{Study design and data collection}

This is study examined the behaviors of respondents in relation to HIV repeat where only 
those who were seeking HIV repeat tests were enrolled. A standardized questionnaire that masked identity of the respondents was used in collecting data. Respondents who could not fill in the questionnaires on their own for various reasons were assisted by research assistants. The questionnaire collected the following information from the respondents: i) sociodemographic information; ii) reason for the seeking the test; iii) HIV tests interval i.e., date last tested before the current one. Informed consent was also obtained from all the respondents.

\section{Statistical analysis}

This study employed two levels of analysis. The fist level comprised of analyzing demographic data using descriptive statistical procedures. The $2^{\text {nd }}$ level involved the use of Pearson's chi square $\left(X^{2}\right)$ to analyze the HIV testing intervals. Cross tabulation was used in comparing HIV test intervals with marital status and gender of the respondents. SPSS version 23 was used in conducting the analysis.
Table 1: HIV testing interval and reasons for HIV tests

\section{Results: b) HIV Repeat Tests}

\begin{tabular}{lc}
\hline HIV repeat & $\begin{array}{c}\text { Total number } \\
\text { of respondents } \\
(\mathbf{n}=118)\end{array}$ \\
tests & $\begin{array}{c}\mathbf{n}(\%) \text { of the } \\
\text { respondents }\end{array}$ \\
\hline HIV Tests & \\
Interval & $29(24.6 \%)$ \\
$1-6$ Months & $47(39.8 \%)$ \\
$7-12$ Months & $10(8.5 \%)$ \\
$13-18$ Months & $13(11.0 \%)$ \\
$19-24$ Months & $19(16.1 \%)$ \\
$\geq 25$ Months &
\end{tabular}

\section{Discussions}

In this study we sought to determine the time interval within which sexually active individuals seek HIV repeat tests in relation to their gender and marital statuses. We defined HIV testing interval as the length of time, in months, which in-

Table 2: Cross tabulation of gender and HIV testing intervals

\begin{tabular}{|l|c|c|c|c|c|c|}
\hline \multirow{3}{*}{ Gender } & \multicolumn{7}{|c|}{ HIV Testing Intervals (Months) } \\
\cline { 2 - 7 } & $\begin{array}{c}\mathbf{1 - 6} \\
\text { months } \\
\mathbf{n}(\%)\end{array}$ & $\begin{array}{c}\mathbf{7 - 1 2} \\
\text { months } \\
\mathbf{n}(\%)\end{array}$ & $\begin{array}{c}\mathbf{1 3 - 1 8} \\
\text { months } \\
\mathbf{n}(\%)\end{array}$ & $\begin{array}{c}\mathbf{1 9 - 2 4} \\
\text { months } \\
\mathbf{n}(\%)\end{array}$ & $\begin{array}{c}\mathbf{2 2 5} \\
\text { months } \\
\mathbf{n}(\%)\end{array}$ & Totals \\
\hline Male & $10(32.3 \%)$ & $10(32.3 \%)$ & $4(12.9 \%)$ & $3(9.7 \%)$ & $4(12.9 \%)$ & $31(100 \%)$ \\
\hline Female & $19(21.8 \%)$ & $37(42.5 \%)$ & $6(6.9 \%)$ & $10(11.5 \%)$ & $15(17.2 \%)$ & $87(100 \%)$ \\
\hline Total & $29(24.6 \%)$ & $47(39.8 \%)$ & $10(8.5 \%)$ & $13(11.0 \%)$ & $19(16.1 \%)$ & $118(100 \%)$ \\
\hline $\mathrm{X}^{2}=\mathbf{0 . 5 7 1}$ & & & & & \\
\hline
\end{tabular}

Table 3: Cross tabulation of marital and HIV testing intervals

\begin{tabular}{|l|c|c|c|c|c|c|}
\hline \multirow{3}{*}{$\begin{array}{l}\text { Marita } \\
\text { Status }\end{array}$} & $\begin{array}{c}\mathbf{1 - 6} \\
\text { months } \\
\mathbf{n}(\%)\end{array}$ & $\begin{array}{c}\mathbf{7 - 1 2} \\
\text { months } \\
\mathbf{n}(\%)\end{array}$ & $\begin{array}{c}\mathbf{1 3 - 1 8} \\
\text { months } \\
\mathbf{n}(\%)\end{array}$ & $\begin{array}{c}\mathbf{1 9 - 2 4} \\
\text { months } \\
\mathbf{n}(\%)\end{array}$ & $\begin{array}{c}\mathbf{2 2 5} \\
\text { months } \\
\mathbf{n}(\%)\end{array}$ & Totals \\
\hline Unmarried & $10(26.3 \%)$ & $15(39.5 \%)$ & $2(5.3 \%)$ & $6(15.8 \%)$ & $5(13.2)$ & $38(100 \%)$ \\
\hline Married & $14(24.6)$ & $25(43.9 \%)$ & $5(8.8 \%)$ & $4(7.0 \%)$ & $9(15.8 \%)$ & $57(100 \%)$ \\
\hline Divorced & $5(25.0 \%)$ & $6(30.0 \%)$ & $3(15.0 \%)$ & $3(15.0 \%)$ & $3(15.0 \%)$ & $20(100 \%)$ \\
\hline Widow/ed & $0(0.0 \%)$ & $1(33.3 \%)$ & $0(0.0 \%)$ & $0(0.0 \%)$ & $2(66.7 \%)$ & $3(100 \%)$ \\
\hline Total & $29(24.6 \%)$ & $47(39.8)$ & $10(8.5 \%)$ & $13(11.0 \%)$ & $19(16.1)$ & $118(100 \%)$ \\
\hline$X^{2}=\mathbf{0 . 5 7 4}$ & \multicolumn{7}{|c|}{} & & \\
\hline
\end{tabular}


dividuals take between two tests. In comparing the HIV testing intervals with gender, we observed that $64.4 \%(n=76)$ of the respondents took HIV repeat-test within a period of 12 months which we considered as a short interval that leads to early diagnosis; while $35.6 \%(n=42)$ took HIV repeat-test after a period that exceeded 13 months which we considered as long interval which on the other hand leads to late diagnosis of HIV. Late diagnosis of HIV has been associated with risk of HIV related morbidities and mortalities; increased direct cost of the disease management (such cost of drugs, laboratory tests, outpatient care and home care) and increased risk of HIV transmission (Fisher, 2008; Krentz, et al., 2004; Horvathiva, et al., 2011). Studies have also pointed out factors that lead to late diagnosis include denial of HIV positive status; poor selfcare; communication breakdown between healthcare workers and their patients; and barriers associated with accessibility to the test sites such as cost and distance from health facilities (Krentz, et al., 2004; Fisher, 2008; Sharma, et al., 2018). In this study we observed that very few men $26.3 \%(n=31)$ compared to women $73.7 \%$ $(\mathrm{n}=87)$ were turning up for HIV repeat tests. Though in this study we did not examine factors that hinder them from seeking HIV repeat tests, we suspect that work-related commitments could be one of the factors that keeps them away from seeking HIV repeat tests. Most VCTs, in Kenya, operate only during weekdays, from 8 am to 5 $\mathrm{pm}$. This makes it hard for those who are employed to access the VCT services.

We also examined effects of marital status on the length of time individuals take to seek HIV repeat tests. We observed that more married respondents $48.3 \%(n=57)$ than widowed respondents $2.5 \%(n=3)$ sought HIV repeat-tests. This is because married respondents encounter more pull and push factors associated with HIV repeat tests than their counterparts who are widowed (Neszméry, 2020). In Kenya, for instance, one of such pull and push factors is the inclusion of HIV test as part and parcel of antenatal care package. Thus, all pregnant women who attend antenatal care, in Kenya, at certain points get tested for HIV. In one study done by Nzioki, et al., (2015) in Mwingi, a district in Kenya, observed that a majority $(73.6 \%)$ of the women who attend Antenatal Clinics (ANC) are married compared to
$5.8 \%$ who are widowed. Their findings show that married women have higher chances of being tested for HIV than their counterparts who are widowed. We further observed that a majority of the widowed respondents $(66.7 \%, \mathrm{n}=2)$ sought HIV repeat tests after a period that exceeded 25 months compared to the majority of the married ones $(43.9 \%, \mathrm{n}=25)$ who get tested within a period of 7-12 months. We also observed that a widowed who took a repeat HIV test was a result of referral by health workers when they had gone to seek treatment for other medical conditions. Though widowed individuals rarely seek HIV repeat tests, a study done in Kenya and Malawi by Anand, et al., (2009), found that they were sexually active. This makes them part of the unaware population that could be contributing to the spread of HIV.

We also examined factors that motivated respondents to seek HIV repeat tests. We observed that most of them, $44.1 \%(n=52)$, took it as a 'routine' test for the purpose of either initiating new intimate relationships with their partners or modifying risky behaviors that could predispose them to contracting HIV. We further observed that $25.4 \%(n=30)$ of the respondents took the repeat test as result of being referred by healthcare professionals. This group comprised of respondents who had gone to the clinic specifically for treatment of other medical conditions such as tuberculosis but ended up being referred to the VCT for HIV test. We also noticed another group of respondents, $23.7 \%(\mathrm{n}=28)$, who were taking repeat tests for the purpose of confirming results of their previous HIV tests. This group was comprised of respondents who were living in denial over their HIV status. Psychological processes due to loss, in this case loss of health, and stigma associated with HIV are some of the factors that push people into denial (Mikolasova, et al., 2018; Li, Wong, et al., 2016; Krentz, et al., 2004). We also observed that only a small proportion of pregnant women $(6.8 \%, \mathrm{n}=8)$ who were seeking HIV repeat tests. This was because the VCT center where we did this research does not provide labor and maternity services to pregnant women making pregnant women to opt for repeat tests in other facilities when their due dates edges closer. In addition, some women also begin their antenatal care very late in their pregnancies, making it hard for them to attend HIV repeat tests. Most 
studies have documented the importance of HIV repeat tests in eliminating risks associated with transmission of the virus during pregnancy, labor and breastfeeding. In one study done in South Africa by Moodley, et al. (2009) on pregnant women, found that at least $3 \%(n=72)$ of 2,377 pregnant women who had tested negative in the first HIV test, returned positive results in their repeat tests.

\section{Conclusions}

We conclude that most respondents prefer to seek HIV repeat tests within 12 months while men and widowed individuals rarely seek repeat HIV tests. We recommend that VCT services should be availed over the weekend so those with busy schedule, during weekday, can also access them.

\section{References}

1. ANAND A, SHIRAISHI R W, BUNNELL R E, JACOBS K, SOLEHDIN N, ABDULQUADER A S, . . . DIAZ T (2009) Knowledge of HIV status, sexual risk behaviors and contraceptive need among people living with HIV in Kenya and Malawi. AIDS, 23(12), pp 1565-1573. doi:10.1097/QAD.0b013e32832cb10c.

2. CASTILLA J, SOBRINO P, LUIS D L, NOGUER I, GUERRA L, PARRAS F (2002) Late diagnosis of HIV infection in the era of highly active antiretroviral therapy: consequences for AIDS incidence. AIDS, 16(14), 1945-1951.

3. FISHER M (2008) Late diagnosis of HIV infection: major consequences and missed opportunities. Current Opinion in Infectious Diseases, 21(1), pp 1-3. doi:10.1097/QCO.0b013e3282f2d8fb.

4. GIRARDI E, SAMPAOLESI A, GENTILE M, NURRA G, IPPOLITO G (2000). Increasing Proportion of Late Diagnosis of HIV Infection Among Patients With AIDS in Italy Following Introduction of Combination Antiretroviral Therapy. J of Acquired Immune Deficiency Syndromes, 25(1), pp 7176.

5. HOENIGL M, ANDERSON M C, GREEN N, MEHTA R S, SMITH M D, LITTLE J S (2015) Repeat HIV-testing is associated with an increase in behavioral risk among men who have sex with men: a cohort study. BMC Medicine, 13(218), pp 1-10. doi:10.1186/ s12916-015-0458-5.

6. HORVATHOVA E, MACKINOVA M P, RUSNAKOVA V, DOKTOROV A, KRCMERY V, FIALA P, . . PHILIPPE M (2011) News in AIDS social work with HIV positive management and prevention. Clinical Social Work, 2(4), pp 49-60.

7. KOPINEC P (2015) Jaroslav Janos prison Governor, Corps of Prison and Court Guard, Slovak Republic. In M. H. Hurley, KD. Das, Trends in Corrections: Interviews with Corrections Leaders Around the World (pp. 3555). Boca Raton. CRC Press.

8. KRENTZ H, AULD M, GILL M (2004) The high cost of medical care for patients who present late $(C D 4<200$ cells/ $\mu L)$ with HIV infection. HIV Medicine, 5(2), pp 93-98. doi:10.1111/j.1468-1293.2004.00193.x.

9. LI A T W, WONG J P H, CAIN R, FUNG K P L (2016) Engaging African-Caribbean, Asian, and Latino community leaders to address HIV stigma in Toronto. International J of Migration, Health, and Social Care, 12(4), pp 288-300. doi:10.1108/IJMHSC-07-20140029

10. MARKS G, CREPAZ N, JANSSEN S R (2006) Estimating sexual transmission of $H I V$ from persons aware and unaware that they are infected with the virus in the USA. AIDS, 20(10), pp 1447-1450.

11. MIKOLASOVA G, SETA S, HOIN H, OTRUBOVA J, BENCA J, BARTKOVJAK M (2018) Improved Adherence to ART in Children-Orphans with AIDS Results in the Decreasing Occurrence of Tuberculosis. Clinical Social Work and Health Intervention, 9(4), pp 81-83. doi:10.22359/cswhi_9_4_14.

12. MOODLEY D, ESTERHUIZEN M T, PATHER T, CHETTY V, NGALEKA L (2009) High HIV incidence during pregnancy: compelling reason for repeat HIV testing. AIDS, 23(10), 1255-1259.

13. NESZMERY S (2020). Divorce as a cause of disruption of interpersonal relationships. World Social Work Day. VI (pp 162-179). Sladkovicovo: University Danubius.

14. NZIOKI M J, ONYANGO O R, OMBAKA H J (2015). Socio-Demographic Factors Influencing Maternal and Child Health Service 
Utilization in Mwingi; A Rural Semi-Arid District in Kenya. American Journal of Public Health Research, 3(1), pp 21-30. doi:10.12691/ajphr-3-1-4.

15. SEBESTOVA P, PLAVCAN P (2018) Multidisciplinary approach in addiction treatment. Review of Social Sciences and Humanities, 6(4), pp 1-12.

16. RADI F, BUDZELOVA K, OLAH M, MUSS C (2021) Late psychosocial consequencesfrom HIV to Covid. Clin Soc Work and Health Interv.12.2021.2.6-7. 10.22359/cswhi_12_2_15.

17. SHARMA M, SMITH J A, FARQUHAR C, YING R, CHERUTICH P, GOLDEN M, . . . BARNABAS R V (2018) Assisted partner notification services are cost-effective for decreasing HIV burden in western Kenya. AIDS, 32(2), pp 233-241.

18. SUBRAMANIAN S, BELOVICOVA M, VANSAC P, PALUN M, RADKOVA L, OTRUBOVA J (2018) Rehabilitation and Nursing Homes with Elderly and Homeless Population, Lessons not only for Physiotherapy but also for Epidemiology? Clinical Social Work and Health Intervention, 9(3), pp 64-66. doi:10.22359/cswhi_9_3_08.

19. TUMA J, ONDRUSOVA Z (n.d.) Assisting families at Risk of Poverty in the Context of Social Services. Clinical Social Work and Health Intervention, 9(2), pp 101-105. doi: 10.22359/cswhi_9_2_15. 


\section{The COVID-19 Pandemic as a Stress Test - ensuring Individual Medical Respiratory Care: Aspects to Objectify the Discussion}

\section{P. Kremeier (Peter Kremeier)}

Simulation Center for Clinical Ventilation, Karlsruhe, DE.

\section{E-mail address:}

pk@respicode.de

\section{Reprint address:}

Peter Kremeier

Simulation Center for Clinical Ventilation

Karlsruhe

Germany

Source: Clinical Social Work and Health Intervention

Volume: 12

Issue: 2

Pages: $63-67$

Cited references: 5

\section{Reviewers:}

Clauss Muss

I-GAP Zurich, $\mathrm{CH}$

Peter Marks

London, GB

\section{Keywords:}

Stress test. COVID-19. Individual Medical Respiratory.

\section{Publisher:}

International Society of Applied Preventive Medicine i-gap

CSWHI 2021; 12(2): 63 - 67; DOI: 10.22359/cswhi_12_2_12 (C) Clinical Social Work and Health Intervention

\section{Abstract:}

The COVID-19 pandemic confronts intensive care medicine with a new clinical picture, which is manifested in various forms and which clearly differs from the classic acute respiratory distress syndrome (ARDS). Ventilation therapy for COVID-19 pneumonia is complex and, contrary to previous guidelines for the treatment of acute respiratory failure, an increasing number of these patients do not primarily receive invasive ventilation. High-flow $\mathrm{O}_{2}$ therapy and non-invasive ventilation by mask or ventilation helmet have become key treatment options. In endeavours to provide respiratory care to all segments of the population whenever necessary, other therapeutic devices may be employed. The fact that milder cases of these diseases can also be treated with less expensive out-of-hospital ventilators and HFOT devices and that a full-fledged intensive care ventilator may not be imperative must be considered in the 
final decision. Nevertheless, answers to the triage and allocation of ventilators must be found in a discussion involving society as a whole and the health sciences in particular. The health sciences are called upon to contribute to the public debate on the distribution of all necessary resources during the pandemic.

\section{Introduction}

In November 2019, a previously unknown virus emerged in Wuhan, China, and has since spread across the globe. This global pandemic also reached Germany with its first detected case in Gauting on 27 January 2020. The SARS-CoV2 virus responsible for the current pandemic is the causative agent of severe acute respiratory syndrome, and the resulting disease is known as COVID-19. Every day during the first wave of the infection, the media reported on the challenges faced by the public health care system. Despite massive national and international efforts the shortage of ventilation capacity was a daily topic in the media and discussions among experts revolved around which intensive care patients should be ventilated and which should not (or no longer) be treated in intensive care. It was not only in Italy that the media reported cases in which patients were triaged to decide on who could not receive intensive care because of the insufficient availability of ventilators. In this emotional situation, creative minds from various branches of industry tried to develop crisis ventilators, the basic principle of which was mechanically filling and squeezing a type of bag-valve mask. In Germany, the already high number of beds for ventilator-dependent patients per 100,000 inhabitants was also significantly increased, but there were supply bottlenecks. It was therefore also considered likely that within a short period of time and despite the gradual capacity increases, ICU beds for ventilator-dependent patients would not be available in Germany for all those who needed them.

The health sciences are called upon to discuss diverse questions regarding the provision of resources for all population groups and to develop proposals for solutions. These encompass not only ventilation capacities, but also preventive measures such as protective equipment, vaccines and vaccination categories. To objectify the often purely emotional discussions, individual aspects in connection with ventilation medicine will be examined below.

\section{COVID-19 between an asymptomatic course and severe respiratory failure}

According to a situation report provided by the World Health Organization (WHO), SARS$\mathrm{CoV}-2$ has an overall mortality rate of $1.4 \%$, with documented rates varying from $<1 \%$ to $>7 \%$ depending on the demographic composition of the study population (1). However, the results of studies conducted around the world have shown that the actual number of infected cases is much higher than the cumulative number of confirmed infections, probably due to a lack of screening among asymptomatic or mildly symptomatic individuals (2). Due to its widespread symptomatology, multi-organ involvement and broad spectrum of disease severity, ranging from asymptomatic to symptomatic, mild or moderate to severe cases necessitating intensive care treatment to fatal outcomes of the disease, COVID-19 has caught medical practitioners worldwide unawares. According to the WHO, approximately $80 \%$ of COVID-19 infections are mild to moderate or asymptomatic; $15 \%$ develop severe symptoms requiring supplemental oxygen; and $5 \%$ experience a critical illness with complications such as respiratory failure, acute respiratory distress syndrome (ARDS), sepsis and septic shock, acute kidney injury, thromboembolism and/or multiple organ failure. Other acute and life-threatening conditions that have been described in COVID-19 patients include acute pulmonary embolism, acute coronary syndrome, delirium and acute stroke.

\section{Ventilation of COVID-19 patients with severe respiratory failure}

ARDS caused by COVID-19 pneumonia does not correspond to "conventional" ARDS [(3). Although ARDS is also associated with inflammatory activation, endothelial cell damage and hypercoagulability in the pulmonary system, as well as with increased dead space, right ventricular dysfunction and decreased pulmonary compliance, COVID-19-induced ARDS has some specific, pathophysiological characteris- 
tics. In COVID pneumonia, there is an extremely inhomogeneously distributed pattern of damage that does not show the gravity-dependent distribution of hyperinflated, functional and atelectatic lung tissue of conventional ARDS. (Google defines Atelectasis (at-uh-LEK-tuh-sis) as a complete or partial collapse of the entire lung or area (lobe) of the lung. It occurs when the tiny air sacs (alveoli) within the lung become deflated or possibly filled with alveolar fluid). Due to this inhomogeneous lung damage, shear forces - which can reach values many times higher than the inspiratory pressure - develop between atelectatic and hyperinflated lung areas. These regional shear forces can also negatively affect adjacent, healthy areas in the lung. As these shear forces are significantly increased by controlled ventilation, we suspect this to be one of the reasons why controlled ventilation often considerably worsens the pulmonary situation in patients with COVID-19-related ARDS. Marini et al. defined different stages of COVID-19 pneumonia with types $\mathrm{L}$ and $\mathrm{H}$, which differ substantially in their pathophysiology. While, despite severe hypoxia and interstitial edema, the compliance of the probably non-recruitable lung tissue is still high; type $\mathrm{H}$ is characterized by low compliance with a high degree of right-to-left shunting due to progressive damage to the lungs. This stage requires a higher PEEP (positive endexpiratory pressure). Ventilated patients have a markedly poor outcome with a high mortality rate of over $50 \%$ [4]. Currently, there are hardly any promising pharmacological therapies to effectively influence the course of the disease. It has been repeatedly observed that patients with COVID-19 pneumonia often develop a pathologically increased respiratory drive, which very likely leads to further damage to the lungs. The extent to which the occurrence of atelectasis with an extremely inhomogeneous distribution pattern is related to this pathological respiratory drive is unclear. We can assume that, due to inhomogeneous lung injury, a normal or increased tidal volume meets a significantly lower functional lung volume depending on the lung region and can therefore result in P-SILI (Patient SelfInflicted Lung Injury). Accordingly, at this level of severity of COVID-19, a full intensive care ventilator with all functions for lung-protective ventilation must be provided.

\section{Ventilation of COVID-19 patients with lower COVID-19 severity}

In addition to the 5\% of COVID-19 patients with severe respiratory failure, a further $15 \%$ develop severe disease requiring at least oxygen or milder methods of "ventilation" or respiratory therapy. Besides non-invasive ventilation by means of a mask or ventilation helmet, the socalled high-flow $\mathrm{O}_{2}$ therapy (HFOT) is of particular importance. These milder treatment strategies are not only available in intensive care ventilators, but can also be implemented with less expensive out-of-hospital ventilators and HFOT systems. In high-flow $\mathrm{O}_{2}$ therapy combined with a respiratory humidifier, for example, heated and humidified oxygen is applied at high flow rates of up to 70 liters per minute via a special nasal cannula. It is often possible to successfully oxygenate patients with this type of acute hypoxemic respiratory failure, and this form of therapy is usually very well accepted by the patient. If HFOT no longer suffices to provide adequate oxygenation and decarboxylation with tolerable breathing effort, then non-invasive ventilation (NIV) is the next best level of escalation. In this case it is possible to provide the patient with pressure support and, even more crucially, with positive end-expiratory pressure (PEEP). With the onset of the current pandemic, both high-flow $\mathrm{O}_{2}$ therapy and mask ventilation became highly controversial due to the potential hazard associated with aerosol formation for the health care personnel. The spectrum ranged from the complete abandonment of HFOT and NIV (with early intubation) to the generous use of NIV (in some cases even on normal wards). First studies have shown that the increased aerosol formation of these procedures can be reduced to an acceptable level by appropriate protective measures such as filter systems and masks for medical staff.

\section{Patient's will versus indication for ventilation}

Particularly when resources are scarce, medical treatment teams must be provided with socially and ethically supported decision-making aids. When questioning the use of ventilation therapy, not only the number of available ventilators, but ultimately the overall situation must be assessed with the patient at the center of deliberations. In addition to the medical, legal and political discussions and in addition to the ethics 
Figure 1: modified according to the $S 1$ guideline „Decisions on the allocation of intensive care resources in the context of the COVID-19 pandemic". AWMF [The Association of the Scientific Medical Societies in Germany] registration number 040-013 dated 17.04.2020.

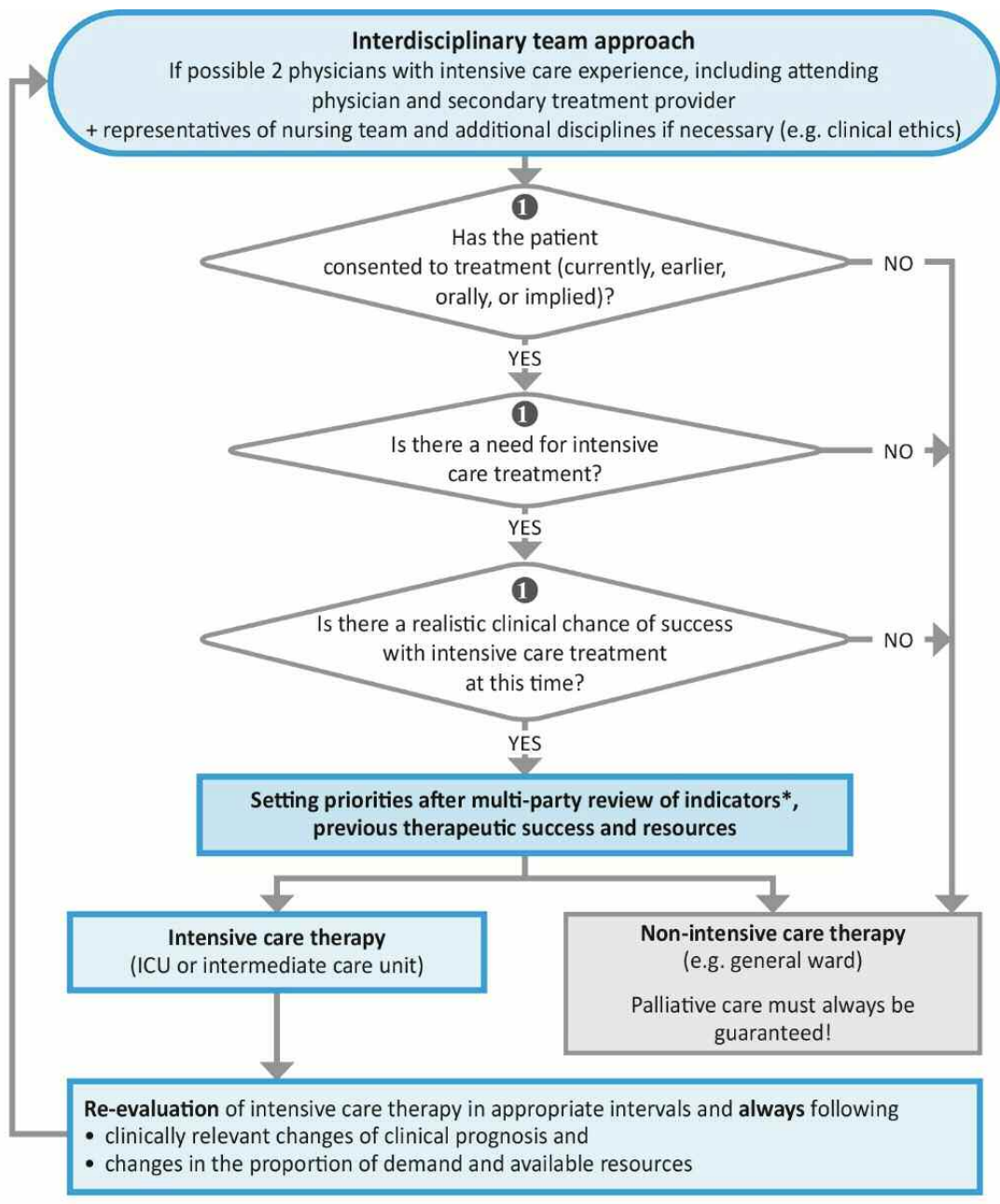

\begin{tabular}{|c|c|}
\hline \multicolumn{2}{|c|}{ Indicators of poor prognosis in initial assessment or re-evaluation } \\
\hline $\begin{array}{l}\text { Current condition } \\
\text { - Higher severity (e.g. acute respiratory distress } \\
\text { syndrome [ARDS]) } \\
\text { - Accompanying acute organ failure (e.g. SOFA } \\
\text { score > 11) } \\
\text { - If applicable, prognostic markers for COVID-19 } \\
\text { patients }\end{array}$ & $\begin{array}{l}\text { Comorbidities } \\
\text { Individual severe comorbidity with significant } \\
\text { impact on long-term prognosis: } \\
\text { - Chronic organ failure } \\
\text { - End-stage organ dysfunction } \\
\text { - Advanced neurological disease } \\
\text { - Advanced oncological disease }\end{array}$ \\
\hline $\begin{array}{l}\text { General health condition } \\
\text { - Advanced frailty (e.g. Clinical Frailty Scale, CFS) }\end{array}$ & $\begin{array}{l}\text { - Severe immune deficiency } \\
\text { - Multi-morbidity }\end{array}$ \\
\hline
\end{tabular}

(1) Prequisites for terminating intensive care therapy after re-evaluation
- Continuing the intensive care therapy runs counter to the patient's (declared,
presumed) will
- Therapeutic goal is no longer realistically achievable
- Treatment attempts have been unsuccessful after an observation period with
previously defined criteria
- Progressive multiple organ failure (e.g. significant increase of SOFA score [>2]
within 24 hours)


committees, the health sciences must also deal with questions of ensuring adequate health care for the individual and the need for a quota system for ICU beds and beds for ventilator-dependent patients.

The COVID-19 pandemic confronts intensive care medicine with a new clinical picture, which is manifested in various forms and which clearly differs from the classic acute respiratory distress syndrome (ARDS). Ventilation therapy for COVID-19 pneumonia is complex and, contrary to previous guidelines for the treatment of acute respiratory failure, an increasing number of these patients do not primarily receive invasive ventilation. High-flow $\mathrm{O}_{2}$ therapy and non-invasive ventilation by mask or ventilation helmet have become key treatment options. In endeavors to provide respiratory care to all segments of the population whenever necessary, other therapeutic devices may be employed. The fact that milder cases

of these diseases can also be treated with less expensive out-of-hospital ventilators and HFOT devices and that a full-fledged intensive care ventilator may not be imperative must be considered in the final decision. Nevertheless, answers to the triage and allocation of ventilators must be found in a discussion involving society as a whole and the health sciences in particular. The health sciences are called upon to contribute to the public debate on the distribution of all necessary resources during the pandemic.

\section{References}

1. WORLD HEALTH ORGANIZATION (2020) Clinical Management of COVID-19. Interim guidance. 27. Mai 2020.

2. POLLAN M, PEREZ-GOMEZ B, PASTORBARRIUSO R, et al. (2020) Prevalence of SARS-CoV-2 in Spain (ENE-COVID): a nationwide, population-based seroepidemiological study [published online ahead of print, 2020 Jul 3]. Lancet. pp 396:535-44. pii: S0140-6736(20)31483-5.

3. MARINI JJ, DELLINGER RP, BRODIE D (2020) Integrating the evidence: confronting the COVID-19 elephant. Intensive Care Med. 46: pp 1904-7. doi:10.1007/s00134-02006195-z.

4. KARAGIANNIDIS C, MOSTERT C, HENTSCHKER C, VOSHAAR T, MAL-
ZAHN J, SCHILLINGER G, et al. (2020)

Case characteristics, resource use, and outcomes of 10021 patients with COVID-19 admitted to 920 German hospitals: an observational study. The Lancet Respiratory Medicine. 8: pp 853-62.

5. BROCHARD L, SLUTSKY A, PESENTI A (2017) Mechanical Ventilation to Minimize Progression of Lung Injury in Acute Respiratory Failure. Am J Respir Crit Care Med. pp 195:438-42. doi:10.1164/rccm.201605$1081 \mathrm{CP}$. Further literature sources from the author. 


\section{Knowledge on Marriage and Reproduction in Islam for Multicultural Healthcare and Social Work Needs: Results of the Survey at Five Public Universities in Slovakia}

\section{Zavis (Monika Zavis)1', I. E. Voronkova (Irina Evgenjevna Voronkova)², P. Ch. Biswas (Parimal Chandra Biswas) ${ }^{3}$, L. Koldeova (Lujza Koldeova) $)^{1}$, M. Olah (Michal Olah)4, V. Krcmery (Vladimir Krcmery) ${ }^{5}$, R. Soltes (Radovan Soltes)' ${ }^{6}$, V. Juhas (Vladimir Juhas) H. Tkacova (Hedviga Tkacova) ${ }^{8}$, M. Bizon (Michal Bizon)') , J. Lenc (Jozef Lenc) ${ }^{10}$}

${ }^{1}$ Comenius University in Bratislava, Faculty of Education, Department of Original Article Pedagogy and Social Pedagogy, Slovakia.

${ }^{2}$ Oryol state University named after I. S. Turgenev, Oryol, Faculty of History, Dean of the faculty, Russian Federation.

${ }^{3}$ Adamas University, Kolkata, School of Economics and Business, Department of Management, India.

${ }^{4}$ University of Healthcare and Social Work of Ss. Elisabeth, n. o., Department of Social Work Jan Havlik Skalica, Slovakia.

${ }^{5}$ Comenius University in Bratislava, Faculty of Medicine, Department of Microbiology, Slovakia. University of Health and Social Work St. Elizabeth and Institute of tropical dis Slovak Medical University, School of Nursing,Bratisava

${ }^{6}$ University of Presov, Greek-Catholic Theological Faculty, Department of Philosophy and Religion, Slovakia.

${ }^{7}$ Catholic University in Ruzomberok, Faculty of Theology, Department of Systematic Theology, Slovakia.

${ }^{8}$ University of Zilina in Zilina, Faculty of Humanities, Department of Philosophy and Religious Studies, Slovakia.

${ }^{9}$ Comenius University in Bratislava, Faculty of Education, Department of Ethics and Civic Education, Slovakia.

${ }^{10}$ University of Ss. Cyril and Methodius in Trnava, Faculty of Arts, Department of Philosophy and Applied Philosophy, Slovakia.

\section{E-mail address:}

zavis@fedu.uniba.sk

\section{Reprint address:}

Monika Zavis

Comenius University in Bratislava

Faculty of Education

Department of Pedagogy and Social Pedagogy

Racianska 59

81334

Bratislava

Slovakia

Source: Clinical Social Work and Health Intervention Pages: $68-72$

\section{Reviewers:}

Selvaraj Subramanian

SAAaRMM, Kuala Lumpur, MY 
Roberto Cauda

Institute of Infectious Diseases, Catholic University of the Sacred Heart, Rome, IT

\section{Keywords:}

Islam. Marriage. Reproductive Health. Multicultural Healthcare. Multicultural Social Work.

\section{Publisher:}

International Society of Applied Preventive Medicine i-gap

CSWHI 2021; 12(2): 68 - 72; DOI: 10.22359/cswhi_12_2_13 (C) Clinical Social Work and Health Intervention

\section{Abstract:}

Objective: The aim of our research was to find out, if university students of humanities and social sciences at five Slovak public universities have theoretical prerequisites for intercultural competencies mainly needed in multicultural healthcare. These concrete theoretical prerequisites are dealing with knowledge regarding Islamic teachings on: family; female infanticide; reproduction; usage of assisted reproduction technologies; and induced abortion.

Design: Research study.

Participants: Overall 1000 students at 5 Slovak public universities (at each $n=200$ ).

Methods: Empirical research was done using our own questionnaire. Verification of our three hypotheses has been done using the method of statistical testing for testing hypotheses on equality of parameters of two alternative divisions with large selection ranges.

Results: Responses to questions concerning definition of marriage in Islam (Questions \#1 - 3) have shown, that both male and female students have proved better knowledge of this issue than in the case of the area concerning possibilities of use of reproductive medicine achievements in Islam. Responses to question (Question \#4) regarding Muhammad's attitude to feminine infanticide have shown that men, in comparison to women, have manifested more radical (more numerous) inclination to the answer that Muhammad entrusted fathers with decision on its performance. Responses to questions dealing with possibilities to use reproductive medicine achievements in Islam (Questions \#5-7) have shown that female, in comparison to male students, have manifested more radical (more numerous) rejective position.

Conclusion: Knowledge of marriage and reproductive issues in Islam among students stays at historical level, what causes a problem not to be able to understand and respect contemporary needs of Muslim patients in the frame of an holistic approach in multicultural healthcare and social work in Slovakia. Improvements in current curriculum concerning students' intercultural competencies mainly connected to an understanding of standpoints of Muslim believers concerning their social foundations, health and entire well-being are inevitable. 


\section{Introduction}

Although European and American society is now for almost a yearlong faced in a priority manner with COVID-19 pandemic which places high ethical and hygienic demands on professionals of diverse domains and both challenges ordinary people to act reasonable and responsible we shouldn't be approaching human dignity and overall well-being reducing them to numbers or statistic reports concerning the spread of the disease (WHO, 2020). Even in these times of virtual interpersonal relationships we have to be aware of the importance of our approach to the most inner values and religious worldview which are constitutional parts of everyone's existence. Regarding Islam, which is still often perceived as an exotic element to European culture, regardless to its historical cross connection with European culture, it is important to overcome ungrounded xenophobia (Dojcar, 2017) and authentically try to understand the most personal, intimate stands of believers (Zavis, Prochazka, 2020) who need our help dealing with health, social or educational issues.

\section{Methods}

This study presents chosen results of the research that was conducted in the frame of the project Bioethics of Reproductive Health in Islam: Basis, Discussion and Challenges, VEGA $\# 1 / 0585 / 18$, which is unique both regarding contemporary Slovak research; its past research; and that of an entire European context. Quantitative research on the topic of theoretical preparedness for intercultural or interreligious communication has been conducted at: Comenius University in Bratislava; University of Ss. Cyril and Methodius in Trnava; University of Zilina in Zilina; University of Presov in Presov; Catholic University in Ruzomberok; at each university $n=200$, totally $\mathrm{n}=1000$.

\section{Evaluation of Empirical Research}

Verification of 3 given research hypotheses has been done using the method of statistical testing for testing hypotheses on equality of parameters of two alternative divisions with large selection ranges. Our approach was based on following criteria given by statistical testing according to Markechova et al. (2011):

We assume that:
$\left(\mathrm{X}_{11}, \mathrm{X}_{12}, \ldots \ldots \ldots . . ., \mathrm{X}_{1 \mathrm{n} 1}\right)$ is a random pick from division of alternative $p_{1}\left(p_{1}\right.$ means probability of hypothesis $\mathrm{H} 0$ ),

$\left(\mathrm{X}_{21}, \mathrm{X}_{22}, \ldots \ldots \ldots, \mathrm{X}_{2 \mathrm{n} 2}\right)$ is a random pick from division of alternative $\mathrm{p}_{2}\left(\mathrm{p}_{2}\right.$ means probability of hypothesis $\mathrm{H} 1$ ).

The selections are independent:

$$
\mathrm{n}_{1}>50 \mathrm{a} \sum_{i=1}^{n_{1}} X_{1 i}+\sum_{i=1}^{n_{2}} X_{2 i}>5 \text {. }
$$

We are testing the problem:

H0: $p_{1}=p_{2}$ against H1: $p_{1}<p_{2} ; p_{1}>p_{2}$

$$
\begin{aligned}
& \overline{X_{1}}=\frac{1}{n_{1}} \sum_{i=1}^{n_{1}} X_{1 i} \\
& \overline{X_{2}}=\frac{1}{n_{2}} \sum_{i=1}^{n_{2}} X_{2 i} \\
& \bar{X}=\frac{n_{1} \overline{X_{1}}+n_{2} \overline{X_{2}}}{n_{1}+n_{2}}
\end{aligned}
$$

The value of testing criterion:

H0: $p_{1}=p_{2}$ against H1: $p_{1}<p_{2}$ :

Critical domain $\mathrm{W}_{0.05}=\left(-\infty ;-\mathrm{u}_{2.0 .05}\right)=(-\infty$; $\left.-\mathrm{u}_{0,1}\right) \mathrm{u}_{0.1}$ is critical value $\mathrm{N}(0.1)$ according to division of critical values of $u_{\alpha}$ division $N(0.1)$ in Table $1 \mathrm{u}_{0.1}=1.64$

$\mathrm{W}_{0,05}=(-\infty ;-1.64)$ Hypothesis testing:

$\mathrm{U} \in \mathrm{W}_{0.05}$, then we reject $\mathrm{H} 0$ and $\mathrm{H} 1$ is valid.

$\mathrm{U} \notin \mathrm{W}_{0.05}$, then $\mathrm{H} 0$ is valid and we reject $\mathrm{H} 1$.

H0: $\mathbf{p}_{1}=\mathbf{p}_{\mathbf{2}}$ against H1: $\mathbf{p}_{\mathbf{1}}>\mathbf{p}_{\mathbf{2}}$ :

Critical domain W0.05 $=(\mathrm{u} 2.0 .05 ; \infty)=$ $(\mathrm{u} 0.1 ; \infty) \mathrm{u}_{0,1}$ is critical value $\mathrm{N}(0.1)$ according to division of critical values of $\mathrm{u}_{\alpha}$ division $\mathrm{N}(0.1)$ in Table $1_{\mathrm{u} 0,1}=1.64$

W0.05 $=(1.64 ; \infty)$

Hypothesis testing:

$\mathrm{U} \in \mathrm{W}_{0.05}$, then we reject $\mathrm{H} 0$ and $\mathrm{H} 1$ is valid. $\mathrm{U} \notin \mathrm{W}_{0.05}$, then $\mathrm{H} 0$ is valid and we reject $\mathrm{H} 1$. Critical values of $\mathrm{u} \alpha$ division $\mathrm{N}(0.1)$;

$\mathrm{X} \sim \mathrm{N}(0.1), \mathrm{P}(|\mathrm{X}|>\mathrm{u} \alpha)=\alpha$

Table 1 Critical values of $\mathrm{u}$ division $\mathrm{N}(0,1)$

\begin{tabular}{|l|l|l|l|l|}
\hline$\alpha$ & 0.01 & 0.02 & 0.05 & 0.1 \\
\hline $\mathrm{u} \alpha$ & 2.5758 & 2.3263 & 1.9599 & 1.6448 \\
\hline
\end{tabular}




\section{The Results of Empirical Research}

\section{Hypothesis 1:}

Hypothesis 1.0: Both men and women won't manifest better knowledge of this issue than in the case of the area concerning possibilities of the use of reproductive medicine achievements in Islam.

Hypothesis 1.1: Both men and women will manifest better knowledge of this issue than in the case of area concerning possibilities of use of reproductive medicine achievements in Islam.

Statistical testing: $\mathrm{U}=-26.4$ where $\mathrm{U} \in \mathrm{W}=$ $(-\infty ; 1.64)$ while testing $\mathrm{H} 0: \mathrm{p}_{1}=\mathrm{p}_{2}$ against $\mathrm{H} 1$ : $\mathrm{p}_{1}<\mathrm{p}_{2}$ at the level of significance $\alpha=0.1$ we state that hypothesis 1.0 has not been confirmed and hypothesis 1.1 has been confirmed.

\section{Figure 1 Comparison of knowledge dealing with definition of marriage and reproductive medicine in Islam (\%)}

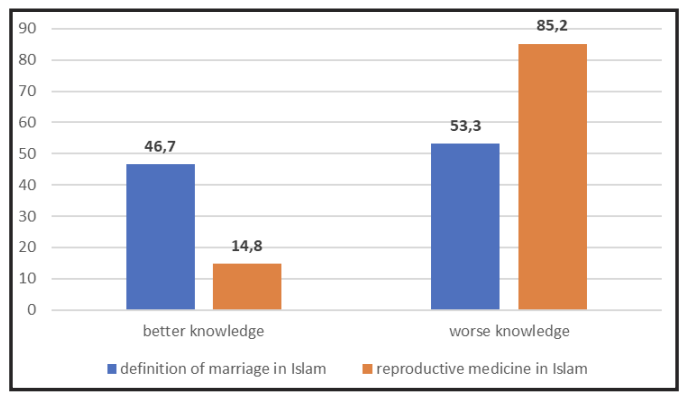

\section{Hypothesis 2:}

Hypothesis 2.0: Men, in comparison to women, will not manifest more radical (multiple) inclination to the answer that Muhammad entrusted fathers with decision on its performance.

Hypothesis 2.1: Men, in comparison to women, will manifest more radical (multiple) inclination to answer that Muhammad entrusted fathers with decision on its performance.

Statistical testing: $\mathrm{U}=2.88$ where $\mathrm{U} \in \mathrm{W}=$ $(\infty ; 1.64)$ while testing $\mathrm{H} 0: \mathrm{p}_{1}=\mathrm{p}_{2}$ against $\mathrm{H} 1$ : $\mathrm{p}_{1}>\mathrm{p}_{2}$ at the level of significance $\alpha=0.1$ we state that hypothesis 2.0 has not been confirmed whereas hypothesis 2.1 has been confirmed.
Figure 2 Positions of men and women on feminine infanticide in Islam (\%)

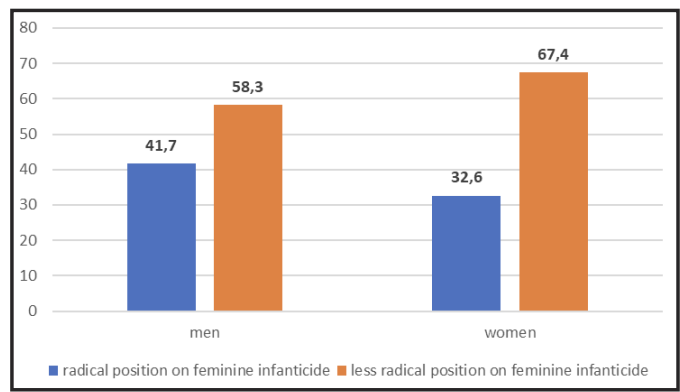

\section{Hypothesis 3:}

Hypothesis 3.0: Women, in comparison to men, won't manifest more radical (multiple) rejective position.

Hypothesis 3.1 Women, in comparison to men, will manifest more radical (multiple) rejective position.

Statistical testing: $\mathrm{U}=-6,493$, where $\mathrm{U} \in \mathrm{W}=$ $(-\infty ;-1.64)$ while testing $\mathrm{H} 0: \mathrm{p}_{1}=\mathrm{p}_{2}$ against $\mathrm{H} 1$ : $\mathrm{p}_{1}<\mathrm{p}_{2}$ at the level of significance $\alpha=0.1$ we state that hypothesis 3.0 has not been confirmed whereas hypothesis 3.1 has been confirmed.

Figure 3 Attitudes of men and women to reproductive medicine in Islam (\%)

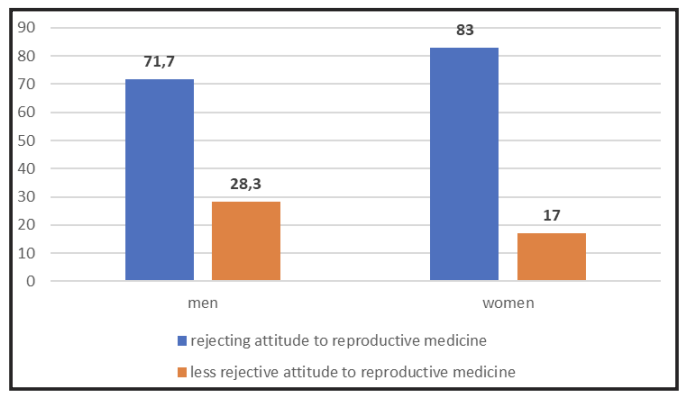

\section{Discussion and Conclusion}

The results of our quantitative research show that knowledge of marriage and reproductive issues in Islam among students stays at an historical level gained by lectures that in a reducing manner accentuate historically axiomatic individual and social principles in Islam what causes a problem not to be able to understand and respect contemporary needs of Muslim patients in the frame of holistic approach in multicultural healthcare and social work in Slovakia. Improvements in current curriculum concerning students' 
intercultural competencies mainly connected to understanding of standpoints of Muslim believers concerning their social foundations, health and entire well-being are inevitable. There is also an open question of preparedness of university lecturers and professors regarding the quality of their lectures, as the same as their empirical experience stemming from personal affinity to know deeper other cultures and religions as to be able to understand contemporary standpoints of believers professing other faiths; that means to be willing to go beyond ritual praxis and search for their spiritual motivation on an existential level. The present and the future of religions are of the same importance as their history. The fact that religions evolve both by their doctrines and praxis is also very important, and that means that for a teacher preparing students for interreligious communication or providing healthcare is inevitable to follow changes in particular religions and to communicate them to students with appropriate interpretation. Therefore, it is necessary to start to critically evaluate the current content of lectures regarding religions with a special emphasis on a place of the modern human, believer and his/her needs, issues, challenges in the frame of the religion he/she belongs to. It is considerably contra-productive to academically prepare future health workers, social workers, teachers or other professionals in humanities or social sciences exclusively by leading them to memorize particular quotations from the sacred scriptures regarding a particular topic and not to be able to apply their sense to needs and requests of contemporary patient or a person in whatever distress, emergency or need. Further research and identification of reasons or premises leading to unsatisfactory results regarding students' knowledge of current marital and reproductive issues of Muslim couples in the context of their religious background is needed.

\section{Declaration on Interest}

The authors declare that they have no conflict of interest.

\section{Acknowledgements}

The article is written within the frame of the VEGA project \#1/0585/18: Bioethics of Reproductive Health in Islam: Basis, Discussion and Challenges (2018 - 2019). The project was suc- cessfully finalized at Comenius University, Faculty of Education, Department of Pedagogy and Social Pedagogy and proclaimed by VEGA Commission at the Ministry of Education, Science, Research and Sport of the Slovak Republic to be one of projects with best research results.

\section{References:}

1. DOJCAR M (2017) Migration, Xenophobia and Dialogical Ethos. In Migration: Religions without Borders - European Perspective. Trnava: Trnava University.

2. MARKECHOVA D, STEHLIKOVA B, TIRPAKOVA A (2011) Statistical Methods and Their Application. Nitra: Constantine the Philosopher University in Nitra.

3. KUBA K, KUBOVA S, HARSA P, PAVLU S (2020) Linking psychology with physiotherapy within rehabilitation, Rehabilitation, Vol. 57, no. 4, 2020, ISSN 0375-0922, p. 307.

4. WORLD HEALTH ORGANIZATION (2020) WHO Coronavirus Disease (COVID19) Dashboard. [cited 2020 Oct. 12]. Available at: https://covid19.who.int/table.

5. ZAVIS M, PROCHAZKA P (2020) Studying Spirituality of Muslim Spouses Fighting Infertility: From Methodological Problems to Analysis of Everyday Practice. Spirituality Studies 6(2): pp 28-39. 


\title{
Nutritional Behavior and Status of Unaccompanied Minor Refugees in the Moria Camp, Lesbos, Greece
}

\author{
J. Bydzovsky (Jan Bydzovsky) 1, 2, 3, M. Jaclkulikova (Maria Jackulikova), 2, \\ S. Ousmann (Suliman Ousman)², R. Faashtol (Radwan Faashtol)²
}

${ }^{1}$ St. Elizabeth University of Healthcare and Social Work, Bratislava, Slovakia. Original Article ${ }^{2}$ NPHO SUPPORT MISSION Program, RIC Moria, Lesbos Island, Greece.

${ }^{3}$ Emergency Department, Hospital Ceske Budejovice, Czech Republic.

\section{E-mail address:}

bydzovsky@vszsp.cz

\section{Reprint address:}

Jan Bydzovsky

VSZaSP sv. Alzbety

Jiraskovy sady 240

26101 Pribram

Czech Republic

Source: Clinical Social Work and Health Intervention

Volume: 12

Issue: 2

Pages: $73-82$

Cited references: 16

\section{Reviewers:}

Dr. Johnson Nzau Mavole

Catholic University of Eastern Africa, Nairobi, KE

Zofia Szarota Pedagogical University of Cracow, PL

\section{Keywords:}

Nutritional Behavior. Unaccompanied and Separated Children. Refugees. Diet Program. Hygiene. Biological Needs. Psycho-social Needs.

\section{Publisher:}

International Society of Applied Preventive Medicine i-gap

CSWHI 2021; 12(2): 73 - 82; DOI: 10.22359/cswhi_12_2_14 (C) Clinical Social Work and Health Intervention

\section{Abstract:}

Greece faces a migration crisis caused by thousands of refugees coming from the Middle East and Africa to overwhelmed camps that try to fulfill at least their basic needs including diet as a humanitarian aid. The aim of the survey is to determine both the eating habits and possibilities and objective anthropometric parameters to evaluate the nutritional status of unaccompanied children under 18 years of age in the Moria refugee camp on the island of Lesbos, Greece. The survey has found that the respondents are completely dependent on the food provided by the camp. $87 \%$ of them reported starvation at least once a week, $24 \%$ are underweight. The energetic value of the provided food is insufficient as compared to their real needs. We have encountered serious complaints about the catering but 
have also found that more than half of the respondents state that they would be able to cook for themselves. These minor refugees are also at risk of starting with smoking cigarettes or drinking alcohol.

\section{Background}

The refugee crisis has been significantly affecting Europe since 2015. The mostly used form of their access to the European Union has been and still is a combination of land and sea routes, which are very risky for their lives. In 2016, approximately 362,000 refugees and migrants risked their lives by crossing the Mediterranean Sea, from whom around 173,450 people sailed to Greece as one of Europe's gateways.(2) In 2019, Europe recorded the entry of more than 123,663 refugees and migrants. There were at least 1,319 people missing or those who lost their lives when crossing the Mediterranean Sea. The migration was also affected by the Covid-19 pandemic in 2020. At the beginning of August 2020, the number of refugees and migrants arriving in Europe is estimated at 39,303.(3) High migration flows from Turkey to Greece during 2019 were also visibly reflected in the high number of unaccompanied minors. They were on their journey without family members or close relatives, putting themselves at high risk of various dangers including: violence; abuse and exploitation; uncertain access to food; drinking water; hygiene; health care. (5) Europe recorded the arrival of 33,200 children in 2019, of which 9,000 were unaccompanied and separated from their parents (unaccompanied and separated children, UASC). From January to December 2019, Greece records the number of arrivals by sea and land by 25,443 children, including 3,852 UASC, a huge increase in comparison with previous years. Most of them come from Afghanistan, Syria, Iraq or Congo.

Increased migratory movements were also proportionally reflected in the UASC standard of living, especially in reception and identification centers. In 2019, 2,781 UASC (more than half) remained out of suitable accommodation in Greece. The total number of UASC in Greece as of December 2019 is estimated at 3,852 children. Of these, 2,034 (42\%) were in suitable accommodation. Out of 3,852 UASC, $21 \%$ were aged 0-4 years and $79 \%$ of the UASC population accounted for aged 5-17 years. Overall, Europe has a predominance of boys over girls.(1)
The arrival of unaccompanied newly admitted children and children separated from their parents takes place in the first European contact countries. Children are usually accommodated in large accommodation centers and supervision is often minimal or totally absent. The situation of children on the Greek islands remains one of the most worrying. The camps are overcrowded, and the high population growth of UASC reception centers is difficult to cope with. Violence incident prevention and response (SGBV) is becoming increasingly challenging, especially in the islands of Lesbos and Samos, as well as in some mainland locations where UNHCR receives more reported incidents.

\section{Management of the Catering System in the Receiver, Registration and identification of the Moria Center on the Island of Lesbos}

UASC's health and mental health problems were not limited to poor housing conditions which were uncompromisingly complicated by the Covid-19 pandemic. The problems also concerned the lack of food and the quality of it that were criticized by most of the minors as well as adult refugees and migrants. Local staff and educators working directly in the sections for minors did not comment positively on the diet program in Moria refugee camp as well. It is true that it has been difficult to meet the unprecedented growing population of refugees and migrants in the First Income Center (KE.P.Y), also in the Registration and Identification Center (RIC) in Moria, Lesbos. As in similar centers, food was distributed in the form of catering and the Greek army was entrusted with the main responsibility for its provision. The following information on the functioning of the catering on Moria is drawn from the criteria of projects for which tenders were opened for those interested in providing catering services, published on the website of the Army General Staff (GES) of Greece. Several open offers for catering services in refugee centers, which were current in early 2020 , had the same criteria, the same budget and duration, and differed only in the date of imple- 
mentation, serial number and minor details.(6)

We describe the provision of food and catering services in Moria on the basis of a specific open offer of a contract for performing food preparation activities for refugees and migrants located in KE.PY also in RIC Moria, near the military camp "PARADELI" (hereinafter referred to as the camp / RIC Moria) on the island of Lesbos.(6) The contracting authority, appointed by the GES, was the 98th Battalion of the High Command of the National Guard of the DNSI Archipelago. Due to the exceptional crisis situation and the urgency of the needs, for RIC Moria, procurement for the catering service provider was carried out through a negotiated procedure without publication of a tender. Negotiation processes for the catering service provider and the acceptance of offers took place in early 2020 in several stages. The budget financed by the Army General Staff was 497,776 euros, including VAT, and covered the provision of catering services for a period of 4 days. In February and March 2020, it was a matter of providing food for 22,200 refugees and migrants living in the RIC Moria. Due to the specificity of the service provided and the fact that it was not possible to determine in advance the final number of daily meals, the catering provider unilaterally reserved the right to change the number of meals and thus the daily rations, in accordance with the procedure set out in the procurement document.

The daily distribution of ready meals in Moria camp could be in the maximum price of 5.46 euros, including 9\% VAT (5.01 euros without VAT) per person per day. According to the criteria stated in the document of the tender for the procurement of catering services, the all-day meal was divided into breakfast, lunch and dinner with the possibility of adding food. It also included a drinking regime and special meals for vulnerable groups of refugees and migrants. The special diet was divided into meals for diabetics, pregnant women, breastfeeding mothers and children. Children's meals were differentiated according to age categories 0-6 months, 6-12 months, 1-12 years. For the remaining population of asylum seekers, this was a common diet, which was also provided to UASC over the age of 12 .

According to the criteria in the procurement of catering services, the daily energy value of food in the regular diet for persons older than 12 years was approximately 2,000 calories $( \pm 100$ kcal) per person; in diabetics 1,800 calories $( \pm$ $100 \mathrm{kcal})$ per person; in children from 1 to 12 years 2,400 calories $( \pm 100 \mathrm{kcal})$; in children from 6 to 12 months, 2,300 calories $( \pm 100 \mathrm{kcal})$ per day; children under 6 months were given baby milk powder if their mothers were unable to breastfeed for various reasons. Each person, regardless of age, i.e. from 0 months onwards, was entitled to drinking water for a total of 2.5 liters of bottled water per person per day.

Candidates for the provision of catering services had to meet the qualification requirements, the place for food preparation can be checked by the hygienic inspection service. The products they planned to use for the production of food, transport, packaging and storage of food products were to comply with the Food Code and the hygiene rules defined in the Food and Beverages Act. The quality of the meals offered should be in accordance with the Food Code. The competent food service providers at the RIC Moria were required to take food samples and, if requested, provide them for analysis two to three times a month.

Portions of food were brought directly to the recipients in the Moria camp to be served at a temperature suitable for eating and in disposable containers, using disposable cutlery, cups and napkins. The criteria state the issuance of food at breakfast time: from 7:00 to 9:00, lunch time: from $12: 30$ to $14: 30$ and dinner time from 19:00 to 21:00 in the form of a self-service system with strict adherence to hygiene rules. The criteria also underline the fact that the catering service provider at the RIC Moria undertakes not to use products or processes that the Muslim religion does not allow (pork, alcohol) to prepare meals.

Fresh and seasonally available fruits and vegetables should be properly cleaned, served as often and as fresh as possible (salads, fresh and whole cucumbers, tomatoes, onions and all vegetables covered by meal plans). The distribution of fruit was to include bananas, apples, grapes, peaches, plums, oranges, cherries, melons to ensure diversity.

Meat, vegetable sauces and side dishes should be served individually, e.g. "Spaghetti with sauce" means spaghetti and sauce distrib- 
uted in separate packages. Pasta, rice and other starches should be adequately cooked and, as required by the specific recipe, served separately so that they can be mixed. The meat should have been well cooked, not raw. The supplier had to be checked whether the beef contained any pork or products from it.

The diet (menu) was to be changed at least every month to ensure nutritional diversity (with a change in products of the same category, e.g. change of legumes, alternation of pasta, tea with juice, etc.) and importance was placed on maintaining proper consumption and food expiration. [6]
The calculated energetic value of this example corresponds to 2,000 kcal daily as declared in the document. Examples of meals are shown in the following photographs in Fig. 1.

The criteria for selecting candidates for catering services in the RIC Moria correspond to the reality of catering for people living in a refugee camp very little. Due to the crisis situation, the selection of contractors took place without a public tender. The competent people state that selection processes were carried out in accordance with principles such as transparency, non-discrimination and ethics. Ethical behavior presents the economical use of resources, unjust enrich-

Tab. 1 Example of menu for persons aged 12 and up.

\begin{tabular}{|c|c|c|c|c|}
\hline Day & Breakfast & Lunch & Diner & Remarks \\
\hline Monday & $\begin{array}{l}\text { tea, croissant } 75-80 \mathrm{~g} \text {, } \\
\text { seasonal fruit } 1 \mathrm{pc}\end{array}$ & $\begin{array}{l}\text { pasta } 250 \mathrm{~g} \text { with } \\
\text { tomato sauce, } \\
\text { feta cheese } 50 \mathrm{~g}\end{array}$ & \begin{tabular}{|l|} 
omelet (3 eggs), \\
potatoes $150 \mathrm{~g}$, \\
seasonal fruit $1 \mathrm{pc}$
\end{tabular} & \multirow{7}{*}{$\begin{array}{l}\text { 1. for lunch and } \\
\text { dinner, } 2 \text { pieces } \\
\text { of Arabic bread } \\
60-70 \mathrm{~g} / \mathrm{pc} \text { are } \\
\text { added to each } \\
\text { portion } \\
\text { 2. seasonal fruit } \\
\text { should have } 100 \text { - } \\
120 \text { g per serving } \\
\text { 3. all quantities } \\
\text { refer to ready-to- } \\
\text { eat meals ready } \\
\text { for consumption } \\
\text { 4. daily diet con- } \\
\text { tains } 2,000 \\
\text { ( } \pm 100) \text { kilocalo- } \\
\text { ries per person } \\
\text { 5. each meal in- } \\
\text { cludes } 2.5 \text { liters } \\
\text { of bottled water } \\
\text { per person to } \\
\text { cover daily needs }\end{array}$} \\
\hline Tuesday & $\begin{array}{l}\text { juice, Arabic bread 60- } \\
70 \mathrm{~g} \text {, seasonal fruit } 1 \mathrm{pc}\end{array}$ & $\begin{array}{l}\text { lentils } 300 \mathrm{~g} \text {, feta } \\
\text { cheese } 50 \mathrm{~g}\end{array}$ & \begin{tabular}{|l|} 
peas with pota- \\
toes $300 \mathrm{~g}$, feta \\
cheese $50 \mathrm{~g}$, \\
seasonal fruit $1 \mathrm{pc}$
\end{tabular} & \\
\hline Wednesday & $\begin{array}{l}\text { tea, fresh artichokes } \\
100 \mathrm{~g} \text {, seasonal fruit } \\
1 \mathrm{pc}\end{array}$ & $\begin{array}{l}\text { stewed chicken } \\
250-300 \mathrm{~g} \text {, rice } \\
100 \mathrm{~g}\end{array}$ & $\begin{array}{l}\text { pasta } 250 \mathrm{~g} \text { with } \\
\text { tomato sauce, } \\
\text { feta cheese } 50 \mathrm{~g} \text {, } \\
\text { seasonal fruit } 1 \mathrm{pc}\end{array}$ & \\
\hline Thursday & $\begin{array}{l}\text { juice, Arabic bread 60- } \\
70 \mathrm{~g} \text {, seasonal fruit } 1 \mathrm{pc}\end{array}$ & \begin{tabular}{|l|} 
mashed potatoes \\
$300 \mathrm{~g}$ with \\
tomato sauce, \\
seasonal fruit $1 \mathrm{pc}$
\end{tabular} & $\begin{array}{l}\text { omelet ( } 3 \text { eggs) } \\
\text { with potatoes } \\
150 \text { g,seasonal } \\
\text { fruit } 1 \text { pc }\end{array}$ & \\
\hline Friday & $\begin{array}{l}\text { tea, fresh artichokes } \\
100 \mathrm{~g} \text {, seasonal fruit } \\
1 \mathrm{pc}\end{array}$ & $\begin{array}{l}\text { oil beans with } \\
\text { potatoes } 300 \mathrm{~g}, \\
\text { feta cheese } 50 \mathrm{~g}\end{array}$ & $\begin{array}{l}\text { roasted potatoes } \\
250 \mathrm{~g} \text {, feta cheese } \\
50 \mathrm{~g} \text {, seasonal } \\
\text { fruit } 1 \mathrm{pc}\end{array}$ & \\
\hline Saturday & $\begin{array}{l}\text { juice, Arabic bread 60- } \\
70 \mathrm{~g} \text {, seasonal fruit } 1 \mathrm{pc}\end{array}$ & $\begin{array}{l}\text { bean soup } 300 \mathrm{~g}, \\
\text { olives }\end{array}$ & \begin{tabular}{|l|} 
rice $250 \mathrm{~g}$ \\
with tomato \\
sauce, feta cheese, \\
seasonal fruit $1 \mathrm{pc}$
\end{tabular} & \\
\hline Sunday & $\begin{array}{l}\text { tea, fresh artichokes } \\
100 \mathrm{~g} \text {, seasonal fruit } \\
1 \mathrm{pc}\end{array}$ & $\begin{array}{l}\text { beef } 150 \mathrm{~g} \text {, pasta } \\
250 \mathrm{~g}\end{array}$ & $\begin{array}{l}\text { roasted potatoes } \\
250 \mathrm{~g} \text {, feta cheese } \\
50 \mathrm{~g} \text {, seasonal } \\
\text { fruit } 1 \mathrm{pc}\end{array}$ & \\
\hline
\end{tabular}


Fig. 1 Examples of meals (catering) provided for lunches and dinners in the Moria camp

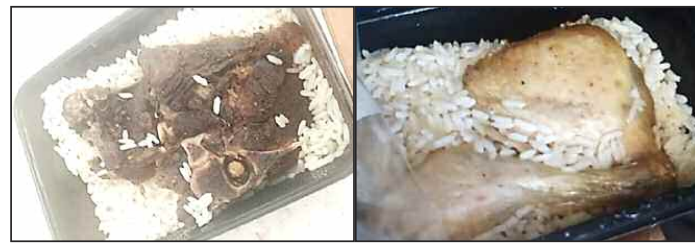

ment, non-corruption, bribery and family nepotism.(6)

Nutrition is a primary biological need and an important prerequisite for sustaining life. An adequate diet contains a balanced amount of essential nutrients. Foods differ in their nutritional value and no food provides all the essential nutrients. Improper supply of nutrients common in emergencies: reduces immunity; increases morbidity; exacerbates chronic health problems; causes anemia; sleep disorders; dermatological problems; poor wound healing; delays in mental and physical development in children; affects the body's balance.(7)

The actual level of catering provision in the RIC Moria together with the unsuitable housing conditions confirm the severity of social suffering at UASC. Nutrition and food intake not only satisfies the body's digestive system and energy reserves. Food intake, like other human biological needs, is associated with psycho-social needs and positive emotions. Long-term non-satisfaction of food needs becomes a dominant problem and controls the whole human behavior.(7)

The UASC and thousands of people living in the indecent conditions of the Moria refugee camp have long: decried their frustration, dissatisfaction with the slow asylum process; housing; food; other determinants of social suffering. The Covid-19 pandemic and subsequent strict quarantine measures joined the complicated solution to their fates. This combination proved to be explosive, resulting in protests against pandemic measures and the subsequent burning of the Moria refugee camp. [8]

\section{The End of Moria Camp}

Unfortunately, the Moria refugee camp does not exist anymore. It had been burnt down even before the results of our research were published. RIC Moria was set on fire on Tuesday night from 8th to 9th September 2020. The arsonists repeatedly set fire to the camp for 3 days. On Thursday

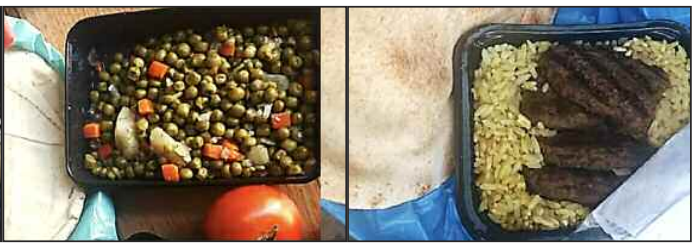

afternoon, 10th September 2020, a third fire broke out in Moria, destroying the little that was still untouched by the fire. 12,000 people became homeless in the wilderness, located between tombstones in a nearby cemetery and on country and coastal roads. As it turned out, 6 young men of Afghan descent were convicted. The quartet is 19-20 years old. The two most active were 17year-old minors who were arrested according to the arrest warrant issued by the Mytilene Prosecutor's Office in Katerini and Thessaloniki, where they were taken to safety with another 204 UASC after the complete destruction of the Moria camp. Humanitarian aid workers, activists and officials said the series of fires was deliberately started by a group of camp residents who were furious at being forced into quarantine after at least 35 people had tested positive for SARS$\mathrm{CoV}-2$ in the Moria camp. Arsonists, including two 17-year-old UASC were convicted of turning the largest refugee camp in Europe to ashes within 3 days. [9]

\section{Methods}

63 out of estimated total number 394 minor unaccompanied refugees (i.e.16\%) have been assessed for their nutritional condition as a part of a basic health care the respondents sought for at the outpatient clinic run by St. Elizabeth University of Healthcare and Social Work in Bratislava and Health Point Foundation. All of them were boys aged 12 to $17(15.7 \pm 0.9)$ from Afghanistan (59, i.e. 94\%), Syria (2), Togo (1) and Kuwait (1). 23 of them were settled in Section A, 21 in Section B, 1 in the Safe zone and 18 lived in the „Jungle“.

The assessment started by obtaining the informed consent; measurements and calculations of: weight; height; waist (halfway between the lowest rib and the top of the hipbone); hip (the largest circumference around the hip); mid-upper arm circumference; and body fat measured by advanced scales using the bio-impedance method. Eating habits were determined using a question- 
naire translated to their mother tongue by the interpreters. The whole screening took approximately 10 minutes for each respondent.

\section{Results}

The results are presented as means \pm SEM (standard error of the mean). The average length of stay in the Moria camp was $8.8 \pm 2.3$ months (from 1 to 18). The heights of the respondents were from 158 to $186 \mathrm{~cm}$, on average $171.8 \pm 5.6 \mathrm{~cm}$. The weights were from 38.5 to 90.8 , on average $60.6 \pm 9.3 \mathrm{~kg}$. Calculated body mass indexes (BMI) were from 13.6 to $28.0 \mathrm{~kg} \cdot \mathrm{m}^{-2}$, on average $20.5 \pm 2.8 \mathrm{~kg} \cdot \mathrm{m}^{-2} .15(24 \%)$ of them had BMI lower than $18.5 \mathrm{~kg} \cdot \mathrm{m}^{-2}$. Out of these 15 respondents only 3 came from the „Jungle“ (where they can have worse access to the food), also the length of the stay in the camp of these 15 respondents was $8.9 \pm 1.1$ months, i.e. similar to the whole group. Three respondents $(4,7 \%)$ had their BMI in the zone of severe thinness, i.e. $<16.0 \mathrm{~kg} \cdot \mathrm{m}^{-2}$.(15) [15] Situation where the acute malnutrition rate is $15 \%$ or more or is $10-14 \%$ with aggravating factors, i.e. energetic value below the mean energy requirements, high prevalence of respiratory or diarrheal diseases etc., is considered to be a serious nutritional emergency by UNHCR. [14]

Three $(4.8 \%)$ out of the respondents had BMI in the range of overweight, i.e. $25.1-30.0 \mathrm{~kg} \cdot \mathrm{m}^{-2}$. It is interesting that the number of corresponds, even in this small sample, to the reported prevalence of obesity in Afghanistan that was $3.2 \%$ in 2016 for male population aged $18+$ and prevalence of overweight males under 5 years that was reported $4.0 \%$ in 2018, according to the World Bank collection of development indicators.

The correlation of BMI with the length of the stay was -0.04 (i.e. they are obviously not losing their weight as they stay in the camp for a longer time). Beside the BMI other means of assessing the amount of body fat were used(7):

1. measurements of waist and hip circumference and WHR (waist-hip ratio): the waist circumference was $73.7 \pm 5.4 \mathrm{~cm}$, the hip circumference $94.8 \pm 4.8 \mathrm{~cm}$, the values of WHR were from 0.73 to $0.89(0.78 \pm 0.03)$.

2. measurements of mid-upper arm circumference taken on non-dominant upper limb: the values were from 22.5 to $33.0(26.0 \pm 2.4) \mathrm{cm}$.

3. bio-impedance analysis of body fat $(\mathrm{BF} \%)$ : the values were from 5.0 to $25.3(12.7 \pm 5.4 \%)$ percent. Normal range for males under 40 years is 8 to $20 \%$.

Correlation of these parameters with BMI was: 0.17 for WHR 0.42 for mid-upper arm circumference; 0.50 for waist circumference; 0.96 for $\mathrm{BF} \%$ from bio-impedance analysis showing almost perfect correlation of these two indicators. Poor correlation of WHR and $\mathrm{BF} \%$ has been found as in other researches.(11)

Generally, the daily requirements could be estimated as $25-35 \mathrm{kcal} / \mathrm{kg}$ of energy and $30 \mathrm{ml} / \mathrm{kg}$ of fluids in adults.(14) The basal metabolic rate (BMR) calculated using the Harris-Benedict formula (for males: $66+13.7 \times$ weight $+5 \times$ height $6.8 \times a g e)$ was from 1,318 to $2,101 \mathrm{kcal}$ per day, on average 1,649 $\pm 143 \mathrm{kcal}$ (median 1,641 kcal). Taking into account that the Harris-Benedict formula is sometimes believed to overestimate the metabolic needs, the Mifflin-St. Jeor formula (for males: $10 \times$ weight $+6.25 \times$ height $-5 \times$ age +5 ) being reported as better correlating to indirect calorimetry measurements or more accurate for overweight persons(12) was also used with results ranging from 1,355 to $1,958 \mathrm{kcal}$ per day, on average 1,607 $\pm 113 \mathrm{kcal}$ (median 1,610 kcal). To estimate the daily energetic expenditures the BMR is multiplied by an activity factor that depends on the physical activity. Daily routine of these UASC comprises attending school in the city of Mytilene where they used to be taken by buses in the morning and leisure activities like playing football, ping-pong or going swimming in the sea that were organized by different NGO's in the afternoon. We count these activities with at least light or possibly moderate ones, i.e. activity factor 1.375-1.550. An example of a daily routine comprising: 8 hours of sleep; 1 hour walking with a load; 2 hours of sitting tasks; 2.5 hours of sedentary recreation; 2.5 hours of walking around; 8 hours of sitting quietly gives weighted activity factor 1.53 for men.(13)

Moreover, the result should be multiplied by injury factor in case of ongoing injury or illness (1.30-1.55 for severe infection), healing wounds (1.2-1.6). The energetic expenditures become higher in case of: stress; cold weather (100 kcal daily for every $5{ }^{\circ} \mathrm{C}$ below $20{ }^{\circ} \mathrm{C}$ ); insufficient clothing; etc. Up to $20 \%$ must be added for every $1{ }^{\circ} \mathrm{C}$ of fever. $(13,7,12,15)$ Calculated energetic demands for respondents in our sample are shown in the tables 2 a 3 below: 
Tab. 2 Calculated energetic demands of the respondents according to the Harris-Benedict equation.

\begin{tabular}{|l|l|l|l|l|l|l|}
\hline Activities & $\begin{array}{l}\text { activity } \\
\text { factor }\end{array}$ & $\begin{array}{l}\text { minimum } \\
\text { energy } \\
\text { (kcal) }\end{array}$ & $\begin{array}{l}\text { maximum } \\
\text { energy } \\
\text { (kcal) }\end{array}$ & $\begin{array}{l}\text { average } \\
\text { energy } \\
\text { (kcal) }\end{array}$ & $\begin{array}{l}\text { median } \\
\text { energy } \\
\text { (kcal) }\end{array}$ & $\begin{array}{l}\text { need } \\
\text { 2000 kcal } \\
\text { (out of 63) }\end{array}$ \\
\hline None (BMR) & 1.000 & 1,318 & 2,101 & 1,649 & 1,641 & $1(2 \%)$ \\
\hline $\begin{array}{l}\text { Sedentary } \\
\text { (no or little } \\
\text { exercise) }\end{array}$ & 1.200 & 1,582 & 2,521 & 1,979 & 1,970 & $27(43 \%)$ \\
\hline $\begin{array}{l}\text { Light } \\
\text { (sports 1-3 } \\
\text { days/week) }\end{array}$ & 1.375 & 1,812 & 2,889 & 2,267 & 2,256 & $58(92 \%)$ \\
\hline $\begin{array}{l}\text { Moderate } \\
\text { (sports 3-5 } \\
\text { days/week) }\end{array}$ & 1.550 & 2,043 & 3,257 & 2,556 & 2,544 & $63(100 \%)$ \\
\hline
\end{tabular}

Tab. 3 Calculated energetic demands of the respondents according to the Mifflin-St. Jeor equation.

\begin{tabular}{|l|l|l|l|l|l|l|}
\hline Activities & $\begin{array}{l}\text { activity } \\
\text { factor }\end{array}$ & $\begin{array}{l}\text { minimum } \\
\text { energy } \\
\text { (kcal) }\end{array}$ & $\begin{array}{l}\text { maximum } \\
\text { energy } \\
\text { (kcal) }\end{array}$ & $\begin{array}{l}\text { average } \\
\text { energy } \\
\text { (kcal) }\end{array}$ & $\begin{array}{l}\text { median } \\
\text { energy } \\
\text { (kcal) }\end{array}$ & $\begin{array}{l}\text { need } \\
\text { >2000 kcal } \\
\text { (out of 63) }\end{array}$ \\
\hline None (BMR) & 1.000 & 1,355 & 1,958 & 1,607 & 1,609 & $0(0 \%)$ \\
\hline $\begin{array}{l}\text { Sedentary } \\
\text { (no or little } \\
\text { exercise) }\end{array}$ & 1.200 & 1,626 & 2,350 & 1,928 & 1,931 & $18(29 \%)$ \\
\hline $\begin{array}{l}\text { Light } \\
\text { (sports 1-3 } \\
\text { days/week) }\end{array}$ & 1.375 & 1,863 & 2,692 & 2,210 & 2,212 & $57(90 \%)$ \\
\hline $\begin{array}{l}\text { Moderate } \\
\text { (sports 3-5 } \\
\text { days/week) }\end{array}$ & 1.550 & 2,100 & 3,035 & 2,491 & 2,494 & $63(100 \%)$ \\
\hline
\end{tabular}

The energetic value of the supplied food during the day for such minors reliably covers their basal metabolic needs only, therefore should be higher than 2,000 kcal, roughly around at least 2,300-2,500 kcal to prevent malnutrition, in some it could be up to $3,000 \mathrm{kcal}$. It is important to notice that there is a great difference in the energetic needs where the highest value is about $60 \%$ higher than the lowest one, therefore the portions should also take in account the age, stature, etc. Prior to 1989 the daily amount of 1,500 kcal was used and then 1,900 kcal until 1993. At present, the World Health Organization and UNHCR as well recommend 2,100 kcal per capita for initial planning for standard population and light activ- ities in a developing country before more accurate calculations are carried out. An additional ration of 100-200 kcal should be provided if the health or nutritional status of the population is poor. At least $10 \%$ of the energy should be provided in the form of protein and $17 \%$ of the energy in the form of fat. $(13,15)$

The respondents were asked about their eating habits and frequency of having meals (breakfast, lunch, dinner and snacks - each was considered as one meal) and specific food using a semi-quantitative scale from: never ( 0 days a week); few days (approximately 2 days a week); most days (approximately 5 days a week) to daily (7 days a week). Besides the pro- 
vided diet they were occasionally given some snacks from NGO's and private donors.

The respondents reported having from 4 to 28 meals per week, on average $19.0 \pm 7.0$ (18.4 in the Sections and Safe zone and 16.7 in the ,Jungle“, $p=0.20$ for one-sided t-test). The approximate numbers of meals per week were 3.7 for breakfast, 5.4 for lunch, 5.2 for dinner and 3.6 for snacks. They commented in their answers that they don't have meals regularly because the food from the catering is often not eatable. Given examples of typical foodstuff for the meals are shown in the table below.

\section{Tab. 3 Examples of typical foodstuff the respondents were provided with}

\begin{tabular}{|l|l|l|l|}
\hline breakfast & lunch & dinner & Snacks \\
\hline bread & bread & bread & nuts \\
cheese & cheese & cheese & orange \\
honey & fish & honey & bread \\
müsli & rice & eggs & yogurt \\
tomato & spaghetti & müsli & raisins \\
sesame- & macaroni & tomato & chips \\
cream & chicken & macaroni & biscuits \\
milk & beans & rice & dried fruit \\
orange & potatoes & lamb & tomato \\
tea & vegetable & chicken & peach \\
yogurt & nuts & meatballss & chocolate \\
eggs & meatballs & sandwich & banana \\
banana & lamb & fish & \\
sandwich & sandwich & potatoes & \\
peach & sausage & nuts & sesame \\
jam & & cream & \\
& & orange & tea \\
& &
\end{tabular}

The correlation of BMI and the approximate number of meals per week was, surprisingly, 0.26 , i.e. weak negative dependence.

The respondents had at least one hot meal: approximately $1.6 \pm 2.6$ days a week for all; 1.2 \pm 2.4 days for the Sections and Safe zone; $2.6 \pm$ 2.7 days a week for the „Jungle“ ( $p=0.23$ for one-sided t-test). Many of the respondents commented that the cooked meals usually get cold before they are being dispensed.

The respondents had meat: approximately $2.0 \pm 0.8$ days a week; dairy products (milk, cheese, yogurt etc.) $3.1 \pm 2.5$ days a week; fruit or vegetables $4.7 \pm 2.6$ days a week; sweets 0.7 \pm 1.7 days a week. These frequencies also did not correlate with BMI: $r=0.04$ for meat; 0.02 for dairy products: 0.26 for fruit and vegetables; 0.18 for sweets.
Three of the respondents (5\%) reported drinking alcohol: one daily; two of them a few days a week. One started with it before coming to the camp, the two others in the camp. 21 (33 $\%$ ) of the respondents reported smoking cigarettes: 9 of them daily ( $43 \%$ of smokers, $14 \%$ of all). Six of them (28\%) started smoking before coming to the camp; the others (71\% of smokers, $10 \%$ of all) in the camp.

The respondents reported that they are feeling hungry $4.4 \pm 3.0$ days a week; $55(87 \%)$ at least once a week; 34 (54\%) daily. Only 8 are never starving (5 of these were from the "Jungle“). Most of the respondents complained about the very bad quality of the provided food that they found not well cooked (meat is bloody and they have to cook it again), expired (cheese) or even smelly, milk was suspected to be diluted with water, etc. Some reported stomach aches or feelings like vomiting after eating the food they were provided. The reasons that caused the profound differences between the planning of the quality of catering services and the reality in the RIC Moria were not the subject of an examination of our research.

The tap water in the camp is suitable for washing etc. but is not drinkable. The respondents were supplied with non-carbonated drinking water originally bottled in 1.5-liter bottles. Their access to bottled water is not restricted in any way; they are given new bottles when returning the empty ones. They estimate drinking 0.75 to 10 (!) liters of water per day, on average $2.3 \pm$ 1.5 (median 2.0) liters. The percentage of total body water as measured by bio-impedance method was from 53.2 to 70.0 ; on average 59.0 $\pm 3.1 \%$. The optimal range for males is 50 to $65 \%$, up to $5 \%$ more for athletic somatotypes. The correlation of estimated intake and percentage of total body water was -0.22 .

None of the respondents received any from the camp or Greek government etc. to buy extra food, only one reported that gets about 20 EUR per month, half of that he spends for food. Some reported being given food by the shopkeepers or cigarettes and alcohol by adult friends for free.

The respondents were also asked about their cooking skills: 23 (37\%) answered that they can cook; $16(25 \%)$ a bit - some simple meals; 24 $(38 \%)$ cannot cook at all.

Finally, the respondents were asked about 
their favorite meal and time they had it for the last time. They were not much demanding: pizza; kebab; chicken sandwich; hamburger; typical Afghan meals like Kabuli pulao (rice with meat and carrot); Biryani (rice, meat, spices); Shorwa (meat soup); but also fried vegetables; eggplant; beans. 15 of the respondents (24\%) reported having their favorite meal a year or more ago.

\section{Conclusions}

The BMI was found as a best simple predictor for body fat percentage measured by the bio-impedance method. About a quarter of unaccompanied minor refugees in the Moria camp have their $\mathrm{BMI}$ in the range of underweight. This number is independent of the length of stay in the camp. To prevent malnutrition, the energetic value of the provided food should be at least $15-25 \%$ higher than 2,000 kcal daily; roughly around at least $2,400 \mathrm{kcal}$ but for some up to $50 \%$ higher; around $3,000 \mathrm{kcal}$, depending on the age and stature. Nutrition screening and evaluation of real needs should be carried out on admission to the camp. Those at risk (ill and injured, with chronic wounds) or already in malnutrition should be provided with extra rations or nutrition supplements like protein bars, biscuits and ready-to-use therapeutic food. Having no money, the respondents are completely reliant on provided food. They reported starvation for approximately 4.4 days of week, $87 \%$ are feeling hungry at least once a week, but also problems with freshness and cooking procedures of the provided food that lead to even not eating the provided meal at all. These are alarming problems where further investigation and finding solutions are needed. Possibly the fact that more than a half are able to cook could help. One tenth of the respondents started smoking cigarettes after coming to the camp, therefore education about the risks of smoking is desirable. We have not found problems with access to drinking water nor worse nutrition screening outcomes of the minors living in the „Jungle“ in comparison with those living in the Sections and the Safe zone, i.e. with better and guaranteed access to catering. In such facilities we advise regular quality controls (at least of the amount and sensoric parameters: look; smell; temperature; taste) of the food provided by the catering company and evaluation surveys for the boarders, possibly also experiments with providing them with raw and semi-finished food and letting them cook for themselves under supervision of their guardians in a community kitchen.

Author Contributions: contributors in the preparation of this manuscript are as follows: Bydzovsky, J. 45\%, Jackulikova, M. 40\%, Suliman, O. $10 \%$, Faashtol, R. 5\%. Our special thanks belong to Ms. Parwin Said, the translator, without whom it would be impossible to carry out this research.

Funding: This research received no external funding.

Conflicts of Interest: The authors report no conflicts of interest.

\section{References}

1. UNITED NATIONS HIGH COMMISSIONER FOR REFUGEES (UNHCR) (2020) Figures at a Glance. [(accessed on 18 July 2020)]; Available online: https://www. unhcr.org/figures-at-a-glance.html.

2. UNITED NATIONS HIGH COMMISSIONER FOR REFUGEES (UNHCR) (2020)Europe situation. [(accessed on $8 \mathrm{Au}-$ gust 2020)]; Available online: https://www. unhcr.org/europe-emergency.html.

3. UNITED NATIONS HIGH COMMISSIONER FOR REFUGEES (UNHCR) (2020) Figures at a Glance. [(accessed on 8 August 2020)]; Available online: https:// data2.unhcr.org/en/situations/mediterranean.

4. INTERNATIONAL ORGANIZATION FOR MIGRATION (IOM) (2020) Fatal journeys volume 4: Missing migrant children. [(accessed on 6 August 2020)]; Available online: https://publications.iom.int/system/files/pdf/fatal_journeys_4.pdf.

5. WOMEN'S REFUGEE COMMISSION (WRC) (2020) More Than One Million Pains: Sexual Violence Against Men and Boys on the Central Mediterranean Route to Italy. [(accessed on 18 July 2020)]; Available online: https://www.womensrefugeecommission.org/research-resources/more-thanone-million-pains-sexual-violence-againstmen-and-boys-on-the-central-mediterranean-route-to-italy.

6. STRATOU G E(GES) (2020) Enimerosi/ Pomithies [(accessed on 29. August 2020)]; 
Available online: http://www.army.gr/el/enimerosi/promitheies.

7. WORLD HEALTH ORGANIZATION (WHO) (2000) The Management of nutrition in major emergencies. (accessed on 18 September 2020). Available online: https://apps. who.int/iris/handle/10665/42085.

8. GLOBAL DETENTION PROJECT (2020) Greece. In: COVID 19 Platform. (accessed on 22 December 2020)]; Available online: https://www.globaldetentionproject.org/coun tries/europe/greece.

9. KINGLEY P (2020) Fire Destroys Most of Europe's Largest Refugee Camp, on Greek Island of Lesbos. In: The New York Times [(accessed on 30.September 2020)]; Available online: https://www.nytimes.com/2020/ 09/09/world/europe/fire-refugee-camp-lesbos-moria.html.

10. EUROPEAN UNION (2020) 29 April 2004 - Regulation (EC) 852/2004 on the hygiene of foodstuffs. In: Legislation.[(accessed on 28.September 2020)]; Available online: https://ec.europa.eu/food/safety/biosafety/fo od_hygiene/legislation_en.

11. OSAYANDE O E, AZEKHUMEN G N, OBUZOR E O (2018) A Comparative Study of Different Body Fat Measuring Instruments. Niger. J. Physiol. Sci. 33 December 125-128.

12. PILAND C, ADAMS K (Eds.) (2009)Pocket Resource for Nutrition Assessment: 2009 Edition. 7th ed. Texas: American Dietetic Association, 2009. P 129 https://dpg-storage.s3 .amazonaws.com/dhcc/resources/Pock etResources/PRNA\%202009.pdf.

13. INSTITUTE OF MEDICINE (US) (1995) Committee on International Nutrition; Allen LH, Howson CP, editors. Estimated Mean per Capita Energy Requirements for Planning Emergency Food Aid Rations. Washington (DC): National Academies Press (US); 1995. 2, Estimating Energy Requirements of Refugee and Other Populations Requiring Food Aid. Available from: https://www.ncbi.nlm.nih.gov/books/NBK2 31163/.

14. UNITED NATIONS HIGH COMMISSIONER FOR REFUGEES (UNHCR) (2007) Handbook for Emergencies. 2007. 3rd Ed. Geneva: UNHCR.
15. CLUGSTON G A Food and Nutrition Needs in Emergencies. Geneva: UNHCR.

16. GEZAIRY H, FIELD A (1995) Guide on Rapid Nutritional Assessment in Emergencies. Alexandria: WHO, Regional Office for the Eastern Mediterranean, p 63. ISBN 929021-234-9. 
No. 2, Vol. 12, 2021

Editor-in-chief: Peter G. Fedor-Freybergh

\section{CLINICAL SOCIAL WORK AND HEALTH INTERVENTION}

\section{Indexed by:}

Web of Science/ESCI

ERIH

Alexander Street

ProQuest

ScienceOpen

Ulrich's

CrossRef Similarity Check Powered by iThenticate

Journal DOI 10.22359/cswhi

Issue DOI 10.22359/cswhi_12_2 